\author{
UNIVERSIDADE DE SÃO PAULO \\ ESCOLA DE ENFERMAGEM DE RIBEIRÃO PRETO
}

\title{
Distribuição espacial dos casos de Tuberculose no município de Ribeirão Preto, nos anos de 1998 a 2002
}

Paula Hino

\begin{abstract}
Dissertação apresentada à Escola de Enfermagem de Ribeirão Preto da Universidade de São Paulo, para obtenção do Título de Mestre em Enfermagem em Saúde Pública junto ao Departamento de Enfermagem Materno-Infantil e Saúde Pública, inserida na linha de pesquisa Processo Saúde-Doença e Epidemiologia.
\end{abstract}

Ribeirão Preto 


\author{
UNIVERSIDADE DE SÃO PAULO \\ ESCOLA DE ENFERMAGEM DE RIBEIRÃO PRETO
}

\title{
Distribuição espacial dos casos de Tuberculose no município de Ribeirão Preto, nos anos de 1998 a 2002
}

\author{
Paula Hino
}

Dissertação apresentada à Escola de Enfermagem de Ribeirão Preto da Universidade de São Paulo, para obtenção do Título de Mestre em Enfermagem em Saúde Pública junto ao Departamento de Enfermagem Materno-Infantil e Saúde Pública, inserida na linha de pesquisa Processo Saúde-Doença e Epidemiologia.

Orientadora: Claudia Benedita dos Santos

Ribeirão Preto 
FICHA CATALOGRÁFICA

Hino, Paula

Distribuição espacial dos casos de Tuberculose no município de

Ribeirão Preto, nos anos de 1998 a 2002

97 p. : il. ; $30 \mathrm{~cm}$

Dissertação de Mestrado, apresentada à Escola de Enfermagem de Ribeirão Preto/USP - Departamento de Enfermagem Materno-Infantil e Saúde Pública.

Orientadora: Santos, Claudia Benedita.

1. Tuberculose

3. Geoprocessamento
2. Análise espacial-

4. Espaço 


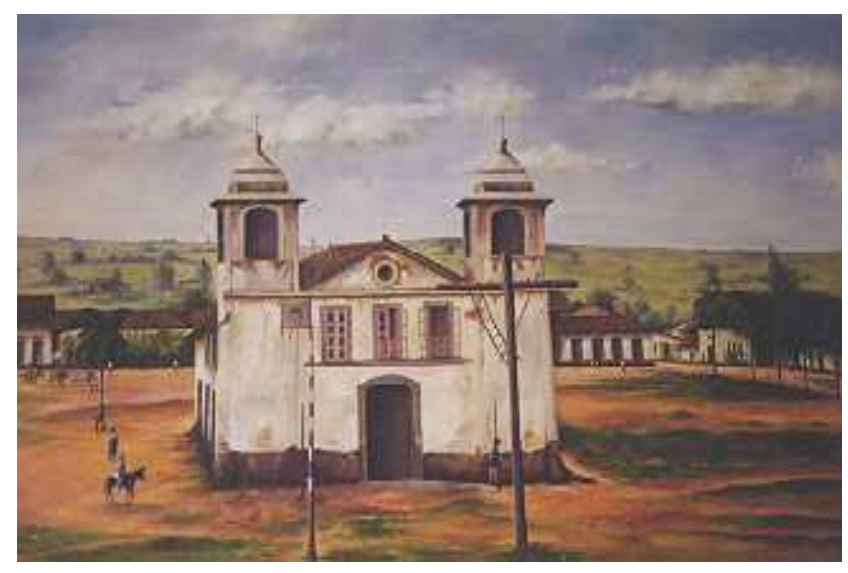

A primeira Matriz de Ribeirão Preto que existiu na atual Praça XV de Novembro.

Hoje, no local está a Fonte Luminosa 
"Embora ninguém possa voltar atrás e fazer um novo começo, qualquer um pode começar agora e fazer um novo fim"

(Chico Xavier) 
Data da defesa:

Banca Examinadora

Prof.Dr.

Julgamento

Assinatura

Prof.Dr.

Julgamento

Assinatura

Prof.Dr.

Julgamento

Assinatura 


\section{DEDICO ESTE TRABALHO}

Ao meu pai, que se faz presente em todos os momentos.

A minha mãe, que pela imensidão de seu amor, tem um pouco de Deus e pela constância de sua dedicação, tem muito de anjo. Exemplo de coragem e determinação.

Aos meus irmãos Carina e Bruno, o apoio.

Ao Marlon, a dedicação.

À Nina, a alegria. 


\section{AGRADECIMENTO ESPECIAL}

A Dra Claudia Benedita dos Santos, minha admiração pela sua competência intelectual e ensinamentos de vida. A forma descontraída de ensinar e sensibilidade em sempre ajudar as pessoas. Este trabalho foi resultado do apoio e incansável orientação, com quem gostaria de dividir os méritos . 


\section{AGRADECIMENTOS}

À Deus, a Vida e o fazer renascer a paz e o equilíbrio nos momentos difíceis, colocando no momento certo, pessoas para me ajudarem.

Aos membros da banca, Dra. Tereza Cristina Scatena Villa e Dr. Antônio Luiz Rodrigues Júnior, as sugestões que me direcionaram para a conclusão da dissertação.

Ao Tarcísio Neves da Cunha, a prontidão em todos os momentos de dúvida e disponibilidade em ajudar-nos na construção de mapas.

À Jordana Nogueira Muniz, a preciosa contribuição e relevantes considerações que foram fundamentais ao desenvolvimento desta pesquisa.

À REDE-TB e aos membros do GEO-TB: Adelita, Aline, Claudia Elli, Cinthia, Jordana, Maíra, Regiane, Ricardo, Roxana, Rúbia e Sílvia. 
Ao Dr. Antônio Ruffino Netto, que faz-se admirar enquanto profissional e pessoa.

As minhas grandes amigas: Adriana, Aline e Cinthia,. o companheirismo seja nos momentos bons ou difíceis.

As minhas " tias" Dita, Margô e Sônia, o elo de carinho que nos une.

Aos colegas de pós-gradução, o apoio.

À Secretaria Municipal da Saúde, as informações cedidas.

À Capes, o financiamento desta pesquisa.

A todos aqueles que direta ou indiretamente colaboraram para a realização deste trabalho, minha estima e consideração. 
SUMÁRIO

LISTA DE FIGURAS

LISTA DE GRÁFICOS

LISTA DE QUADROS

LISTA DE ABREVIATURAS

RESUMO

ABSTRACT

RESUMEN

A ESCOLHA E DELIMITAÇÃO DO TEMA...................................

1. INTRODUÇÃO ................................................................... 01

1.10 processo endêmico da Tuberculose.................................02

1.2 Espaço, Estatística Espacial e Geoprocessamento................06

1.3 Análise espacial de eventos..............................................22

1.3.1 Caracterização de distribuição de pontos...........................25

1.3.2 Estimador de intensidade ("Kernel estimation")..................29

1.3.3 Método do vizinho mais próximo........................................31

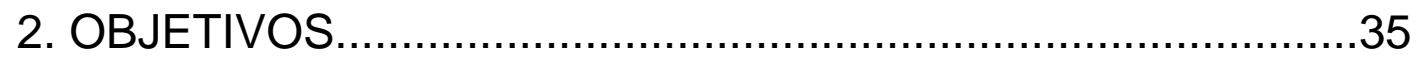

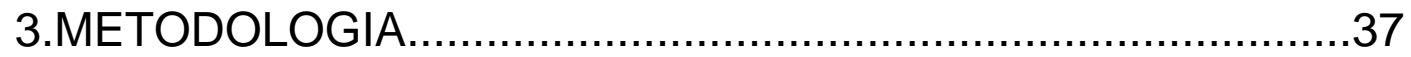

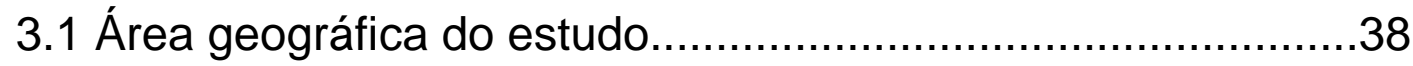

3.2 Sistema de Saúde e Programa de Controle da Tuberculose em Ribeirão Preto........................................................................40 


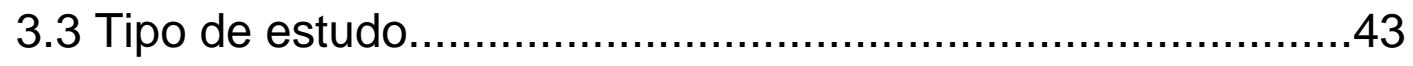

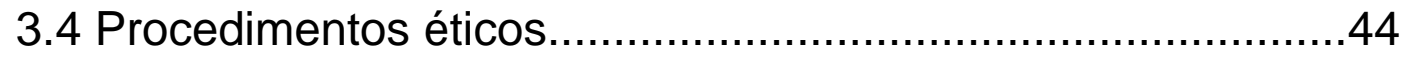

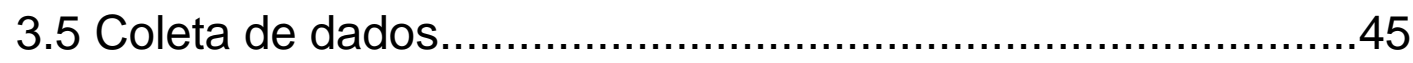

3.6 Apresentação e análise dos dados.......................................46

4.RESULTADOS....................................................................... 4

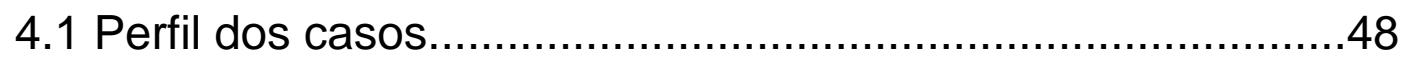

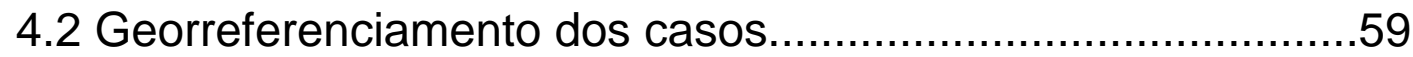

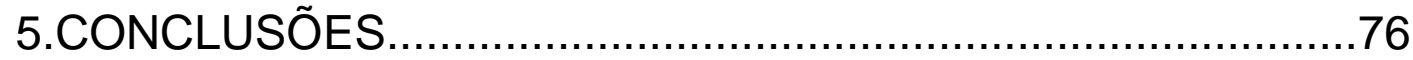

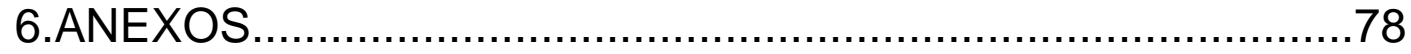

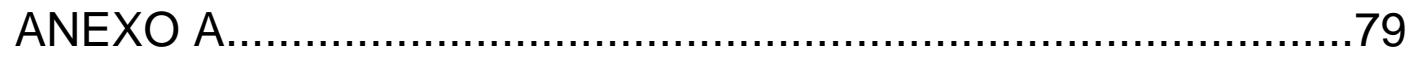

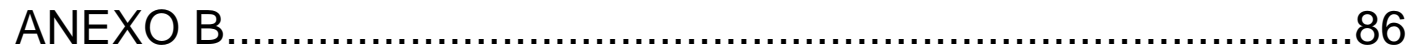

7. REFERÊNCIAS BIBLIOGRÁFICAS......................................90 


\section{LISTA DE ABREVIATURAS}

AIDS- Síndrome da Imunodeficência Adquirida

CSR- Complete Spatial Randomness

GPS- Sistema de Posicionamento Global

NGA- 59- Núcleo de Gestão Ambulatorial

OMS- Organização Mundial de Saúde

OPAS- Organização Panamericana de Saúde

PCT- Programa de Controle da Tuberculose

REDE-TB- Rede Brasileira de Pesquisa em Tuberculose

RIPSA- Rede Interagencial de Informações para Saúde

SIG- Sistema de Informação Geográfica

SMS- Secretaria Municipal de Saúde

SPSS- Statistical Program for Social Sciences

SUS- Sistema Único de Saúde 
ST- Supervised Treatment

TS- Tratamento Supervisionado

VE- Vigilância Epidemiológica 


\section{LISTA DE FIGURAS}

Figura 1- Distribuição da Tuberculose no mundo. .04

Figura 2- Estimador de intensidade de distribuição de pontos .29

Figura 3- Gráfico de $\hat{G}(\boldsymbol{h})$ (estimado) versus $\bar{G}(\boldsymbol{h})$ (CSR), com envelopes superior e inferior, para os dados de mortalidade neonatal em Porto Alegre. 1996. 34

Figura 4- Mapa do município de Ribeirão Preto com arruamento 39

Figura 5- Distribuição dos casos de Tuberculose segundo endereço de residência. Ribeirão Preto. 1998.

Figura 6- Distribuição dos casos de Tuberculose segundo endereço de residência. Ribeirão Preto. 1999.

Figura 7- Distribuição dos casos de Tuberculose segundo endereço de residência. Ribeirão Preto. 2000

Figura 8- Distribuição dos casos de Tuberculose segundo endereço de residência. Ribeirão Preto. 2001

Figura 9- Distribuição dos casos de Tuberculose segundo endereço de residência. Ribeirão Preto. 2002. 
Figura 10- Mapa da distribuição de densidade de residências de doentes de Tuberculose. Ribeirão Preto. 1998

Figura 11- Mapa da distribuição de densidade de residências de doentes de Tuberculose. Ribeirão Preto. 1999. 67

Figura 12- Mapa da distribuição de densidade de residências de doentes de Tuberculose. Ribeirão Preto. 2000. 68

Figura 13- Mapa da distribuição de densidade de residências de doentes de Tuberculose. Ribeirão Preto. 2001 68

Figura 14- Mapa da distribuição de densidade de residências de doentes de Tuberculose. Ribeirão Preto. 2002 69 


\section{LISTA DE GRÁFICOS}

Gráfico 1- Distribuição dos casos de tuberculose, segundo informação sobre faixa etária (anos). Ribeirão Preto-SP.1998. .49

Gráfico 2- Distribuição dos casos de tuberculose, segundo informação sobre resultado de sorologia para HIV. Ribeirão PretoSP.1998. 50

Gráfico 3- Distribuição dos casos de tuberculose, segundo informação sobre resultado de tratamento. Ribeirão Preto-SP.1998. 50

Gráfico 4- Distribuição dos casos de tuberculose, segundo informação sobre faixa etária (anos). Ribeirão Preto-SP.1999. 51

Gráfico 5- Distribuição dos casos de tuberculose, segundo informação sobre resultado de sorologia para HIV. Ribeirão Preto-SP.1999. .52

Gráfico 6- Distribuição dos casos de tuberculose, segundo informação sobre resultado de tratamento. Ribeirão Preto-SP.1999. .52

Gráfico 7- Distribuição dos casos de tuberculose, segundo informação sobre faixa etária (anos) Ribeirão Preto-SP. 2000 53

Gráfico 8- Distribuição dos casos de tuberculose, segundo resultado de sorologia para HIV. Ribeirão Preto-SP. 2000. 
Gráfico 9- Distribuição dos casos de tuberculose, segundo informação sobre resultado de tratamento. Ribeirão Preto-SP. 2000

Gráfico 10- Distribuição dos casos de tuberculose, segundo informação sobre faixa etária (anos). Ribeirão Preto-SP. 2001.

Gráfico 11- Distribuição dos casos de tuberculose, segundo informação sobre sorologia para HIV. Ribeirão Preto-SP. 2001

Gráfico 12- Distribuição dos casos de tuberculose, segundo informação sobre resultado de tratamento. Ribeirão Preto-SP. 2001.........56

Gráfico 13- Distribuição dos casos de tuberculose, segundo informação sobre faixa etária (anos). Ribeirão Preto-SP. 2002.

Gráfico 14- Distribuição dos casos de tuberculose, segundo informação sobre resultado de sorologia para HIV. Ribeirão Preto-SP. 2002.

Gráfico 15- Distribuição dos casos de tuberculose, segundo informação sobre resultado de tratamento. Ribeirão Preto-SP. 2002. .58

Gráfico 16- Gráfico de $\hat{G}(h)$ versus $\bar{G}(h)$, com envelopes superior e inferior, para os casos de Tuberculose em Ribeirão Preto - SP. 1998 
Gráfico 17 - Gráfico de $\hat{G}(h)$ versus $\bar{G}(h)$, com envelopes superior e inferior, para os casos de Tuberculose em Ribeirão Preto - SP. 1999 72

Gráfico 18- Gráfico de $\hat{G}(h)$ versus $\bar{G}(h)$, com envelopes superior e inferior, para os casos de Tuberculose em Ribeirão Preto - SP. 2000 73

Gráfico 19- Gráfico de $\hat{G}(h)$ versus $\bar{G}(h)$, com envelopes superior e inferior, para os casos de Tuberculose em Ribeirão Preto - SP. 2001. .73

Gráfico 20- Gráfico de $\hat{G}(h)$ versus $\bar{G}(h)$, com envelopes superior e inferior, para os casos de Tuberculose em Ribeirão Preto - SP. 2002 .74 


\section{LISTA DE QUADROS}

Quadro 1- Série histórica de casos de Tuberculose e Coeficientes de Incidência por 100.000 habitantes. Ribeirão Preto. 1990 a

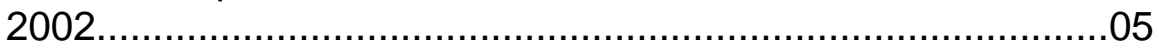

Quadro 2- Distribuição dos casos de Tuberculose no município de Ribeirão Preto, segundo número de casos geocodificados. 1998 a 2002 
RESUMO

HINO, P. Distribuição espacial dos casos de Tuberculose no município de Ribeirão Preto, nos anos de 1998 a 2002.

O uso de mapas e a preocupação com a distribuição geográfica de doenças remonta a um passado bastante distante. Um exemplo clássico foi o trabalho realizado por John Snow, que utilizou o mapeamento para localizar casos de cólera, relacionando-os com as fontes de abastecimento de água. $O$ processo saúde-doença ocorre em um espaço primariamente geográfico, sobre a qual, a ação dos homens ocorre. Apesar de seu grande potencial, as técnicas de representação espacial ainda são relativamente pouco utilizadas na área da saúde, devido, em parte, às dificuldades inerentes à manipulação deste tipo de informação. Este trabalho parte do pressuposto de que a distribuição espacial da Tuberculose não é uniforme, com diferenças entre países, estados, municípios e bairros. Dentro deste panorama, o objetivo deste trabalho foi estabelecer a distribuição espacial da doença no município de Ribeirão Preto de 1998 a 2002, buscando verificar dependência entre sua ocorrência e o espaço. Para elaboração do estudo, utilizou-se a base de dados secundários da Secretaria Municipal de Saúde do município de Ribeirão Preto- SP provenientes das fichas de notificação compulsória e digitalizados no programa computacional Epi-Tb, adaptado para esse fim. Inicialmente, procedeu-se à análise descritiva de algumas variáveis relacionadas à Tuberculose. Em seguida, efetuou-se o georreferenciamento dos casos de Tuberculose utilizando-se o software Maplnfo 6.5. A análise estatística espacial foi realizada com auxílio do software Spring. Por meio da análise do padrão espacial existente no decorrer dos anos estudados, 
concluiu-se que para cada ano estudado houve um padrão para a distribuição espacial da Tuberculose em Ribeirão Preto, identificando-se áreas homogêneas de risco para a doença embora os casos estivessem sempre concentrados em uma faixa da região noroeste do município, consistindo de bairros de classe-média e/ou média baixa da população. Os resultados contribuem para o conhecimento da distribuição espacial da Tuberculose no município de Ribeirão Preto- São Paulo, ressaltando a importância da categoria espaço como alternativa metodológica para auxiliar no planejamento, monitoramento e avaliação das ações em saúde, direcionando as intervenções para diminuir as iniqüidades.

Palavras-chave: Tuberculose, análise espacial, geoprocessamento 


\section{ABSTRACT}

HINO, P. Spatial distribution of tuberculosis cases in Ribeirão Preto City during 1998 to 2002.

The map's usage and the concerns about geographic distribution related with diseases are not a recent issue. A classical example of these is the John Snow survey -maps were used to locate cholera's cases and related them with the water supplying. The health-disease process first happens in a geographic space, in where human actions occur. Despite its real power, the spatial representation techniques are fewer used in health sectors due to troubles in managing such information. This work begins from an assumption that the spatial distribution of Tuberculosis is not uniform. It has differences between countries, states, cities and also quarter cities. So, the aim of this survey was to establish the disease spatial distribution in Ribeirão Preto city from 1998 to 2002 by looking for a dependency of its occurrence and space. Secondary data from Municipal Health Department were used to elaborate this study. These data came from compulsory notification and were digitalized in a specific computer program. First of all, a descriptive analysis of some variables related with tuberculosis was made. Then, the spatial distribution of cases was realized by using the Maplnfo 6.5 software. The spatial statistic analysis was made by utilizing the Spring software. The spatial analyses during the years demonstrate that each year has its own Tuberculosis spatial distribution in Ribeirão Preto, what reveals homogeneous areas for disease risk. Although many cases were concentrated in the northeast region in the city, which consists the quarters of medium and low economical income. The results contribute to show the Tb spatial distribution in RP-SP, they also 
reinforce the space category as a methodological alternative to manage, to monitor and to evaluate the health actions by directing interventions to decrease the iniquities.

Key-words: Tuberculosis, spatial analysis, geoprocessing. 


\section{RESUMEN}

HINO, P. Distribución espacial de los casos de Tuberculosis en el municipio de Ribeirão Preto, en los años de 1998 a 2002.

El uso de mapas y la preocupación con la distribución geográfica de enfermedades se remonta a un pasado bastante distante. Un ejemplo clásico fue el trabajo realizado por John Snow, que utilizó el mapeamiento para localizar casos de cólera, relacionandolos con las fuentes de abastecimiento de agua. El proceso salud-enfermedad ocurre en un espacio primariamente geográfico, sobre la cual la acción de los hombres sucede. A pesar de su gran potencial, las técnicas de representación espacial aún son relativamente poco utilizadas en el área de la salud, debido en parte a las dificultades inherentes a la manipulación de este tipo de información. Este trabajo parte del presupuesto de que la distribución espacial de la Tuberculosis no es uniforme, con diferencias entre paises, estados, municipios y barrios. Dentro de este panorama, el objetivo de este trabajo fue establecer la distribución espacial de la enfermedad en el municipio de Ribeirão Preto de 1998 a 2002 buscando verificar dependencia entre su ocorrencia y el espacio. Para la elaboración del estudio, se utilizó la base de datos secundarios de la Secretaria Municipal de Salud del municipio de Ribeirão Preto- SP provenientes de las fichas de notificación compulsória y digitalizados en el programa computacional Epi-Tb, adaptado para ese proposito. Inicialmente, se procedió al análisis descriptiva de algunas variables relacionadas a la Tuberculosis. A continuación se efectuó el georreferenciamiento de los casos de Tuberculosis utilizandose el software MapInfo 6.5. El análisis estadístico 
espacial fue realizada con auxilio del software Spring. Por medio del análisis del padrón espacial existente en el transcurso de los años estudiados se concluye que para cada año estudiado hubo un padrón para la distribución espacial de la Tuberculosis en Ribeirão Preto, identificándose áreas homogeneas de riesgo para la enfermedad a pesar que los casos siempre estuvieron concentrados en una parte de la región nor-oeste del municipio consistiendo de barrios de clase media y/o media baja de la población. Los resultados contribuyen para el conocimiento de la distribución espacial de la Tb en el municipio de Ribeirão Preto- São Paulo, resaltando la importancia de la categoria espacio como alternativa metodológica para auxiliar en el planeamiento, monitoramiento y evaluación de las acciones en salud, dirigiendo las intervenciones para disminuir las inequidades.

Descriptores: Tuberculosis, análisis espacial, geoprocesamiento 
INTRODUÇÃO 


\subsection{0 processo endêmico da Tuberculose}

De acordo com Ribeiro et al. (2000), as implicações sociais e epidemiológicas do descontrole da Tuberculose são de grande relevância para o nosso meio e a não adesão ao tratamento, com variações peculiares de cada região e valores inaceitáveis em muitas regiões do Brasil, constitui importante causa de insucesso terapêutico. Entretanto, a Tuberculose continua ameaçando a saúde da população com sua resistência aos tuberculostáticos e epidemia da Síndrome da Imunodeficiência Adquirida (AIDS), podendo tornar inúteis os esforços científicos desde a descoberta de Koch em 1850.

O Informe Final da reunião de diretores nacionais do PCT promovido pela Organização Panamericana de Saúde (OPAS) e Organização Mundial de Saúde (OMS), em novembro de 1997 no Equador, afirma que vários fatores têm criado condições propícias para o recrudescimento da Tuberculose. Além da epidemia de AIDS, a situação sócio-econômica tem aumentado as condições de pobreza, que resultam em dificuldades de acesso aos serviços de saúde, crescimento de populações marginais e migrações em busca de melhor qualidade de vida. A este quadro soma-se a debilidade dos serviços de saúde pública, que têm sido menos eficientes em suas ações nas últimas décadas 
(ORGANIZAÇÃO PANAMERICANA DE SAÚDE/ORGANIZAÇÃO MUNDIAL DA SAÚDE, 1997, p.1).

A OMS estima a ocorrência de oito a nove milhões de casos novos por ano no mundo. A cada segundo, um indivíduo é infectado pelo Mycobacterium tuberculosis. Cerca de um terço da população encontra-se infectada pelo bacilo da Tuberculose, e anualmente cerca de dois milhões de pessoas falecem de uma enfermidade curável. A Tuberculose leva mais indivíduos ao óbito que qualquer outra doença infecciosa e entre os doentes infectados pelo vírus da AIDS, é a maior causa de morte, mesmo quando utilizado o tratamento anti-retroviral (WORKSHOP..., 2002).

Nos 22 países com maior carga de Tuberculose, a estimativa é de 6.910 .000 casos, estando a Índia na $1^{\circ}$ posição com 1.856 .000 casos anuais e o Afeganistão na última com 70.000 casos (HIIJAR; OLIVEIRA; TEIXEIRA, 2001). O Brasil ocupa o $13^{\circ}$ lugar no ranking dos 22 países onde se estima que ocorram $80 \%$ dos casos de Tuberculose no mundo. Estima-se a incidência de 129.000 casos por ano, dos quais apenas 90.000 são notificados. O coeficiente de mortalidade em 1998 foi de 3,5/100.000; o percentual de detecção de casos igual a $67 \%$ e percentual de cura de $72 \%$. Para o abandono do tratamento, registrou-se $14 \%$, alcançando em algumas capitais o valor de $30-40 \%$, provavelmente proporcionando elevadas taxas de resistência aos medicamentos (WORKSHOP..., 2002). 


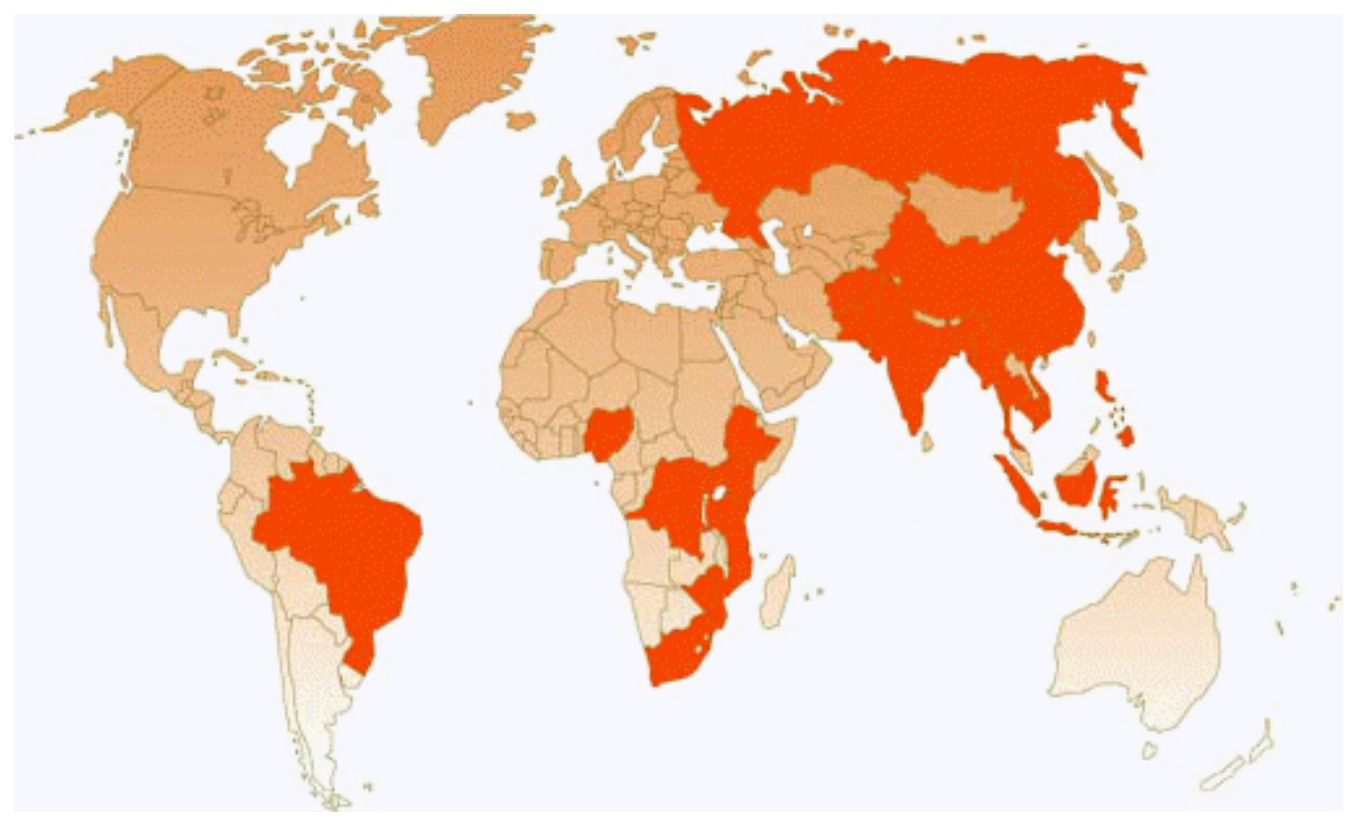

Fonte: WHO, 2003

Figura 1- Distribuição da Tuberculose no mundo

O estudo de HIIJAR, OLIVEIRA e TEIXEIRA (2001), mostra que os números do Brasil são preocupantes, seja considerando o país como um todo ou por regiões. Em 2000 foram notificados 82.249 casos novos, sendo 38.690 no sudeste, 23.196 no nordeste, 9.281 no sul, 5.901 no norte e 3.522 no centro-oeste. A distribuição das formas clínicas mostrou que $60,7 \%$ dos casos eram pulmonares com baciloscopia positiva, 24,9\% pulmonares sem confirmação bacteriológica e 14,4\% extrapulmonares.

No município de Ribeirão Preto, local de nosso estudo, foram notificados junto à VE da Secretaria Municipal de Saúde (SMS) de Ribeirão Preto para o triênio 1998 a 2000: 287, 254 e 202 casos novos de Tuberculose, respectivamente. O quadro registrado em Ribeirão Preto 
demonstra o paradoxo de uma cidade que apesar de abrigar um dos maiores centros de excelência médica do país, apresenta índices elevados de incidência de Tuberculose.

O quadro 1 apresenta o número de casos notificados de Tuberculose e o coeficiente de incidência para o período de 1990 a 2002. Com a implantação da busca ativa, em março de 1996, houve um acréscimo significativo de baciloscopias de escarro realizadas pelo município e, conseqüentemente, um aumento de casos diagnosticados.

\begin{tabular}{|c|c|c|}
\hline ANO & Casos & $\begin{array}{c}\text { Coeficiente de } \\
\text { Incidência } \\
\text { (x/100.000 } \\
\text { habitantes })\end{array}$ \\
\hline 1990 & 228 & 50,35 \\
\hline 1991 & 212 & 48,83 \\
\hline 1992 & 249 & 55,81 \\
\hline 1993 & 254 & 56,48 \\
\hline 1994 & 262 & 56,84 \\
\hline 1995 & 267 & 57,19 \\
\hline 1996 & 337 & 73,86 \\
\hline 1997 & 354 & 76,56 \\
\hline 1998 & 287 & 61,33 \\
\hline 1999 & 259 & 54,42 \\
\hline 2000 & 200 & 39,60 \\
\hline 2001 & 218 & 42,40 \\
\hline 2002 & 133 & 25,60 \\
\hline Fonte: Ficha de Investigação Epidemiológica da. S.M.S. - Ribeirão Preto \\
População: IBGE & \\
\hline
\end{tabular}

Quadro 1- Série histórica de casos de Tuberculose e Coeficientes de Incidência por 100.000 habitantes. Ribeirão Preto. 1990 a 2002 
A diminuição do número de casos a partir de 1998 pode ser atribuída aos seguintes fatores: implantação do TS a partir de 1997 como estratégia para redução da taxa de abandono e aumento da taxa de cura; informatização do banco de dados Epi-Tb que facilita a limpeza de duplicidade de casos através de auditorias periódicas. Por outro lado, não pode ser descartada uma possível desorganização dos serviços de saúde, seja pela falta de busca ativa dos sintomáticos respiratórios ou pelo atraso do diagnóstico, e também a hipótese de estar ocorrendo subnotificação dos casos.

O declínio significativo no número dos casos do ano de 2001 para 2002 pode ser justificado pela demora do envio da ficha de notificação para a VE da SMS de Ribeirão Preto. Portanto, foram considerados apenas os casos notificados até a data de coleta de dados.

\subsection{Espaço, Estatística Espacial e Geoprocessamento}

"A natureza sempre foi o celeiro do homem, ainda quando este se encontrava na sua fase pré-social. Mas, para que o animal homem se torne o homem social, é indispensável que ele também se torne o centro da natureza. Isto ele consegue pelo uso consciente dos instrumentos de trabalho. Nesse momento a natureza deixa de comandar as ações dos homens e a 
atividade social começa a ser uma simbiose entre o trabalho do homem e uma natureza cada vez mais modificada por esse mesmo trabalho. Esta fase da história não poderia realizar-se se não houvesse um mínimo de organização social e sem uma organização paralela do espaço". (SANTOS, 2002. p. 202).

Possivelmente, a primeira apreciação teórica do conceito de espaço aplicada à epidemiologia foi feita por Pavlovsky, parasitologista russo, que na década de 1930 desenvolveu a teoria dos focos naturais das doenças transmissíveis, que estabelecia o conceito de espaço como cenário no qual circulava o agente infeccioso; este cenário era classificado em natural ou intocado pela ação humana e antropúrgico, alterado pela ação humana (SILVA, 1997).

O espaço, na sua conceituação clássica em epidemiologia, na tentativa de integrar o biológico ao não biológico, é considerado estático, imutável, um espectador não participante. A aceleração da intervenção humana no espaço natural se fez de maneira tão rápida com a criação de novos padrões de organização espacial que o tratamento dado ao espaço por Pavlovsky tornou-se obsoleto, uma vez que o espaço natural quase não existe mais. Tal fato apontou a necessidade de rever o conceito de espaço enquanto categoria de análise, na perspectiva de melhor compreender o processo saúde-doença nas coletividades, através da distribuição e caracterização epidemiológica da ocorrência de endemias em áreas urbanas (BRAGA et al., 2001). 
Segundo Santos (2002), o espaço deve ser considerado como um conjunto de relações realizadas através de funções e de formas que se apresentam como testemunho de uma história escrita por processos do passado e do presente. Isto é, o espaço se define como um conjunto de formas representativas de relações sociais do passado e do presente e por uma estrutura representada por relações sociais que estão acontecendo diante dos nossos olhos e que se manifestam através de processos e funções. O espaço é, então, um verdadeiro campo de forças cuja aceleração é desigual. Daí porque a evolução espacial não se faz de forma idêntica em todos os lugares.

Esta forma de conceituar o espaço não só permite identificá-lo na sua relação com os atores sociais, rompendo com a tradição de vê-lo como algo estático e naturalizado em relação ao tempo e à ação social, como também permite compreender os diferentes arranjos e posições dos grupos sociais em luta pela conquista do território.

Para Medronho e Perez (2002), o conceito de espaço deve incorporar não apenas as características geográficas, naturais e sociais de um lugar mas também " a vida que os preenche e os anima, ou seja, a sociedade em movimento". Portanto, a teoria do espaço vai além das questões do ambiente físico; envolve também processos sociais.

A World Health Statistics Quarterly afirmou que o espaço urbano, forma elaborada de organização do espaço, é e será o cenário dos principais des 
afios no caminho para o controle das doenças infecciosas ou não (SILVA, 1997).

Há muito tempo, a coleta de dados sobre a distribuição espacial de determinadas enfermidades tem sido uma importante atividade das sociedades organizadas. Atribui-se a Hipócrates (480 A.C.) os primeiros registros sobre a relação entre a doença e o local/ambiente onde ela ocorre. No seu livro "Ares, Águas e Lugares", enfatizou a importância do modo de vida dos indivíduos e analisou a influência dos ventos, águas, solo e localização das cidades em relação ao sol, na ocorrência da doença (MEDRONHO; PEREZ, 2002; COSTA e TEIXEIRA, 1999).

A partir do século XVI, o elo entre o saber médico e a geografia foi impulsionado com os grandes descobrimentos, surgindo então a necessidade de se conhecer as doenças nas terras conquistadas visando a proteção de seus colonizadores e o desenvolvimento das atividades comerciais (COSTA; TEIXEIRA, 1999).

No Império Romano, os mapas foram bastante utilizados, diminuindo juntamente com o declínio deste. Seu uso voltou a crescer na Europa no século XVIII a partir da necessidade dos governantes da época de realizar um mapeamento sistemático de suas terras (MEDRONHO; WERNECK, 2002).

O médico britânico John Snow, analisando uma epidemia de cólera ocorrida em Londres no ano de 1854, procurou demonstrar 
associação entre mortes por cólera e suprimento de água através de diferentes bombas públicas de abastecimento. Duas companhias de água concorrentes forneciam água encanada aos lares de Londres: a Lambeth Company e a Southwark and Vauxhall Company. Uma das companhias, a Lambeth, pegava água do rio Tâmisa antes da entrada de esgoto de Londres e a outra companhia, retirava água depois deste ponto. Essa era a grande oportunidade para ver se a água contaminada pelo esgoto causava o cólera. Snow obteve uma lista das mortes por cólera na cidade e comprometeu-se a descobrir quais casas utilizavam águas de qual companhia.

Os resultados foram conclusivos: enquanto em 10 mil casas abastecidas pela Lambeth Company ocorreram 37 mortes, em 10 mil supridas pela Southwark and Vauxhall Company houve 315 mortes. Assim, ao longo de seu exaustivo trabalho de coleta e interpretação dos dados, Snow vai gradativamente construindo um dos pontos de maior importância do seu método, que é o de buscar conhecer os fatos em seus aspectos mais íntimos para então formular uma possível explicação causal para eles (SNOW, 1999).

Com isso, foi identificada a origem da epidemia mesmo sem conhecer seu agente etiológico (CÂMARA et al., 2001; MEDRONHO; PEREZ, 2002; COSTA; TEIXEIRA, 1999; SANTOS et al., 2001). Essa é uma situação onde a relação espacial entre os dados contribuiu 
significativamente para o avanço na compreensão do fenômeno, sendo considerado um dos primeiros exemplos da análise espacial.

No Brasil, pouco se sabe sobre a distribuição espacial das doenças endêmicas em áreas urbanas. Nas décadas de 60 e 70, ocorreu a expansão de endemias rurais para regiões urbanas devido aos deslocamentos populacionais. A urbanização da população e o fenômeno da periferização das metrópoles tornou ainda mais complexo o controle da transmissão de algumas endemias e passou a exigir novas estratégias de controle (XIMENES et al., 1999).

Apesar de seu grande potencial, as técnicas de representação espacial ainda são pouco utilizadas na área da saúde devido às dificuldades inerentes à manipulação deste tipo de informação, mesmo com a crescente disponibilização de tecnologias de tratamento de informações gráficas e mapas em microcomputadores (Cruz, 1996 apud Lapa, 1999).

A análise da distribuição das doenças e de seus determinantes nas populações, no espaço e no tempo é um aspecto fundamental na Epidemiologia e envolve três questões primordiais: Quem adoeceu?, Quando a doença ocorreu?, Onde a doença ocorreu?.

Segundo Câmara et al. (2001), a compreensão da distribuição espacial dos dados oriundos dos fenômenos ocorridos no espaço, constitui um grande desafio para a elucidação de questões centrais em 
diversas áreas do conhecimento, seja em saúde, ambiente, geologia e agronomia, entre tantas outras.

No que concerne à difusão espacial e temporal da doença, as informações sendo localizáveis, fornecem elementos para construir a cadeia explicativa dos problemas do território e aumentam o poder de orientar ações intersetoriais específicas criando subsídios para tomada de decisões.

De acordo com Malta et al. (2001), os mapas temáticos são instrumentos poderosos na análise espacial do risco de determinada doença apresentando os seguintes objetivos: descrever e permitir a visualização da distribuição espacial do evento; exploratório, sugerindo os determinantes locais do evento e fatores etiológicos desconhecidos que possam ser formulados em termos de hipóteses e apontar associações entre um evento e seus determinantes.

O Ministério da Saúde organizou, no âmbito da Rede Interagencial de Informações para a Saúde (RIPSA), um Comitê Temático Interdisciplinar sobre Geoprocessamento e Dados Espaciais em Saúde voltado às SMS e outros órgãos públicos do setor, facilitando acesso às informações básicas requeridas para o desenvolvimento da análise espacial (REDE INTERAGENCIAL DE INFORMAÇÕES PARA A SAÚDE, 1999).

Esses estudos vêm se tornando cada vez mais comuns, devido ao avanço dos recursos computacionais, entre eles o geoprocessamento 
que, entre outras capacidades, permite a atualização de mapas, sem necessidade de refazê-los manualmente. Geoprocessamento é o conjunto de técnicas de coleta, tratamento e exibição de informações referenciadas geograficamente, funcionando como uma ferramenta de visualização de eventos de saúde em mapas. Destacam-se: sensoriamento remoto, digitalização dos dados, automação de tarefas cartográficas, Sistema de Posicionamento Global (GPS) e Sistema de Informação Geográfica (SIG).

Os SIG foram desenvolvidos com propósitos estratégicos militares há mais de 30 anos. Após o fim da Guerra Fria tornaram-se acessíveis ao público para outros usos. Entre eles, a reorganização do meio ambiente, a exploração de recursos minerais e florestais, mercado e otimização de serviços entre outros. A aplicação dos SIG em Epidemiologia e Saúde Pública deu-se apenas recentemente. Entre as razões deste atraso, encontram-se o conhecimento limitado dos métodos, técnicas e processos dos SIG e a falta de ferramentas computadorizadas simplificadas para a análise epidemiológica (ORGANIZAÇÃO PANAMERICANA DE SAÚDE, 2002).

A aplicação do SIG na pesquisa em saúde oferece grandes possibilidades, possibilitando aos pesquisadores aplicação de novos métodos para o manejo de sua informação espacial, tornando-se uma poderosa ferramenta para conexão entre saúde e ambiente. 
Alguns exemplos das potencialidades do uso dos SIG são:

\section{Saúde Coletiva:}

* Planejamento, monitoramento e avaliação das ações de saúde e intervenções

* Localização de serviços de saúde

Definição de trajetória de ambulância

* Recuperação de dados para área delimitada próxima a serviços de saúde

\section{Epidemiologia:}

* Definir áreas de risco para ocorrência de doenças

* Estimar o potencial de difusão de doenças a partir de um ponto ou região

* Analisar a dispersão geográfica de uma epidemia

O ambiente do SIG oferece margem à integração de informações diversas, as quais poderão proporcionar visão mais abrangente da situação no espaço. No entanto, a avaliação do pesquisador é imprescindível, pois não há mecanismo automático para a interpretação dos resultados construídos (SANTOS et al., 2001). 
Embora o SIG possa ser utilizado como ambiente de consolidação e análise de grandes bases de dados sobre ambiente e saúde, é necessário um esforço para compatibilizar técnicas de endereçamento de dados, o que implica a adequação entre bases de dados e base cartográfica (BARCELLLOS; SANTOS, 1997). A qualidade da informação de endereço e a eficiência do SIG para localizar os eventos pontualmente é fundamental para possibilitar as análises dos padrões de distribuição desses eventos.

Segundo Ximenes et al. (1999), a construção de um sistema de vigilância à saúde, orientado por um modelo de análise de risco em substituição ao modelo de risco individual, tem o espaço como referência e apresenta um maior poder explicativo por expressar diferentes acessos aos bens e serviços de infra-estrutura urbana.

Inicialmente utilizado pela Epidemiologia como tentativa de integrar o biológico ao não biológico, o espaço geográfico era considerado um lugar estático, isolado, sem dimensão histórica. Na medida em que o conceito de espaço passa a ser visto sob caráter histórico e social, passam a ser entendidas as necessidades explicativas da concepção de determinação social da doença (COSTA; TEIXEIRA, 1999).

O geoprocessamento, com a incorporação de métodos estatísticos para a análise de dados espaciais, tornou-se um campo de investigação epidemiológica sobre o papel do espaço na produção e difusão de doenças (MEDRONHO; WERNECK, 2002). revela um enorme 
potencial, principalmente em países como o Brasil, que apresenta uma grande carência de informações adequadas para a tomada de decisões sobre os problemas urbanos, rurais e ambientais, pois permite uma maior compreensão da distribuição geográfica, dando margem a outros tipos de investigações futuras que poderão subsidiar os programas preventivos e contribuir para o declínio da morbi-mortalidade.

O termo "Estatística Espacial" engloba um conjunto de técnicas de Análise Geográfica que utiliza técnicas quantitativas para caracterizar o fenômeno em estudo, as quais procuram descrever a variação espacial do fenômeno, a partir de amostras disponíveis (CÂMARA et al., 2001).

O estudo quantitativo da distribuição das doenças, onde 0 objeto de estudo é referenciado geograficamente, é denominado análise espacial em saúde e tem como uma de suas aplicações a análise exploratória de dados epidemiológicos. A primeira etapa deste tipo de análise consiste em pesquisar a ocorrência de autocorrelação espacial. Quando se verifica a existência de dependência espacial, a lógica posterior da análise é identificar as variáveis explicativas dos conglomerados geográficos encontrados, que se constituem no conjunto dos possíveis fatores de risco.

Um conceito chave na compreensão e análise dos fenômenos espaciais é a dependência espacial. Waldo Tobler, denomina de primeira Lei da Geografia: "todas as coisas são parecidas, mas coisas mais próximas se parecem mais que coisas mais distantes". Ou como afirma 
Noel Cressie, "a dependência (espacial) está presente em todas as direções e fica mais fraca à medida em que aumenta a dispersão na localização dos dados" (CÂMARA; CARVALHO, 2001).

Muitos dados espaciais, especialmente os obtidos de pesquisas geo-demográficas e de saúde, não apenas possuem autocorrelação espacial global, mas também exibem padrões significantes de instabilidades espaciais, os quais relatam diferenças regionais dentro do espaço observado. Segundo Medronho e Werneck (2002), seu uso na Epidemiologia busca identificar padrões espaciais de morbidade ou mortalidade e fatores associados, descrever processos de difusão de doenças e gerar conhecimentos sobre etiologia de doenças, visando o planejamento de ações de prevenção e controle. O mapeamento dos casos permite a aplicação da pesquisa às necessidades da comunidade pois fornece subsídios para o planejamento e intervenções mais adequadas e direcionadas à realidade local.

Os métodos para análise espacial são assim divididos:

Visualização- onde o mapeamento de eventos de saúde é a ferramenta primária, variando desde a distribuição pontual de eventos até superposições complexas de mapas de incidência de doença, que descrevem a distribuição de determinadas variáveis de interesse. 
Análise exploratória de dados- utilizada para descrever padrões espaciais e relação entre mapas. Algumas técnicas exploratórias terão a forma de gráficos (histogramas, scatterplots entre outros) enquanto outras serão de natureza cartográfica.

Modelagem- utilizada quando se pretende testar formalmente uma hipótese ou estimar relações, como por exemplo, entre a incidência de uma determinada doença e variáveis ambientais.

A taxonomia mais utilizada segundo Câmara et al. (2001) para caracterizar os problemas de análise espacial considera três tipos de dados:

* Eventos ou padrões pontuais- são fenômenos expressos através de ocorrências identificadas como pontos localizados no espaço, denominados processos pontuais. Exemplos: localização de crimes, ocorrência de doenças e localização de espécies vegetais.

Superfícies contínuas- estimadas a partir de um conjunto de amostras de campo, que podem estar regular ou irregularmente distribuídas. Usualmente, este tipo de dado é resultante de levantamento de recursos naturais. 
* Áreas com contagens e taxas agregadas- tratam-se de dados associados a levantamentos populacionais, como censos e estatísticas de saúde, e que originalmente se referem a indivíduos localizados em pontos específicos do espaço. Por razões de confidencialidade estes dados são agregados em unidades de análise, usualmente delimitados por polígonos fechados (setores censitários, zonas de endereçamento postal, municípios).

São muitos os trabalhos epidemiológicos com abordagem da análise espacial, por exemplo como fez Lapa et al. (2001), estudando o conceito de risco coletivo pela definição de micro-áreas não homogêneas, no município de Olinda- PE, no período de 1991-1996. A construção de mapas retratando a situação da hanseníase no município, mostrou-se útil a instrumentalizar o planejamento em nível local, definindo prioridades das ações de saúde.

Estudo semelhante realizaram Souza et al. (2001) quando analisaram a distribuição espacial da hanseníase nos noventa e quatro bairros da cidade do Recife-PE; sendo apontadas três áreas prioritárias para o programa de controle da doença. Como o município apresentava $38,6 \%$ dos casos de hanseníase do estado de Pernambuco, foi de fundamental importância a realização de um estudo de abordagem ecológica no sentido de identificar locais de risco para a população. 
Santos et al. (2001), analisaram a distribuição espacial das residências de vítimas das principais causas de morte (acidente de transporte, homicídio e suicídio) no município de Porto Alegre no ano de 1996, visando identificar a concentração dessas ocorrências através de uma abordagem epidemiológica a partir da localização pontual dos eventos, diferenciando microáreas através do padrão espacial de ocorrência, ou seja, pelo padrão de densidade de pontos.

A maior densidade de residências de vítimas de acidentes de transporte constou de duas áreas, que embora residenciais, contavam com intenso comércio varejista, com grande fluxo de pedestre e transportes. Quanto aos homicídios, estes englobaram áreas que diferenciaram-se pelas demais do município por abrangerem setores com baixa condição sócio-econômica e abrigarem as maiores favelas da cidade. Tal fato pode estar relacionado a formas violentas de solucionar desentendimentos pessoais. Em relação aos suicídios, somente uma área foi detectada e de acordo com os autores do estudo, mereceria estudo específico pois não corresponde à área com características locais diferenciadas.

No estudo de Morais Neto et al. (2001) foi investigado o padrão espacial da mortalidade neonatal e pós-neonatal no município de Goiânia nos anos de 1992 a 1996. A análise e interpretação dos mapas contribuiu para identificar bolsões de nascidos vivos com risco de morte neonatal e pós-neonatal, subsidiar o planejamento de intervenções destinadas à 
população materno-infantil e monitorar os riscos após as intervenções, possibilitando a avaliação do impacto destas ações.

Chiesa et al. (2002) descreveram o uso de técnicas de geoprocessamento para caracterizar as desigualdades sociais que configuravam em condições de risco aos agravos respiratórios em crianças de uma área abrangida por um Centro de Saúde Escola do município de São Paulo. A partir do instrumental metodológico utilizado, o estudo pôde contribuir para o reconhecimento das condições de risco no território de responsabilidade de uma unidade de saúde, trazendo para discussão os problemas relacionados aos agravos respiratórios em crianças na infância, na perspectiva da promoção da eqüidade e melhoria das condições de saúde na população infantil.

Além disso, o uso do SIG na saúde mostra a possibilidade de associar informações de diversas bases de dados, contribuindo com o avanço das análises espaciais para os sistemas de vigilância à saúde. A produção de mapas permite visualizar situações de risco à saúde resultantes da intersecção e complementariedade dos eventos, sendo coerente com um conceito epidemiológico de vigilância do espaço (LAPA et al., 2001).

A disponibilização de banco de dados em saúde com a informação de endereço e a estruturação de SIG em diversos municípios brasileiros têm possibilitado o uso crescente da análise de padrões 
espaciais de morbi-mortalidade para diferenciar áreas dentro dos municípios (SANTOS et al., 2001).

A análise espacial de padrões epidemiológicos tem valor na análise das relações entre saúde e ambiente e no seu controle, pois o conhecimento da estrutura e dinâmica espacial possibilita a caracterização da situação em que ocorrem eventos de saúde, permitindo ações de controle, alocação de recursos e preparação de ações de emergência.

A recente disponibilidade de bases cartográficas para algumas cidades representa, sem dúvida, um avanço para o planejamento integrado de diferentes setores. Nesse sentido, o interesse das SMS no uso do SIG para esquadrinhamento da área urbana tem sido notável, embora muitas vezes, o geoprocessamento em saúde venha sendo incorporado, basicamente, como ferramenta de visualização de eventos de saúde em mapas, sem definição de uma proposta epidemiológica conceitual de vigilância do espaço.

\subsection{Análise Espacial de Eventos}

O conteúdo relatado a seguir foi escrito por Câmara e Carvalho (2001). 
Conforme referido anteriormente, o termo Estatística Espacial designa um conjunto amplo de técnicas quantitativas para caracterizar o fenômeno em estudo incluindo métodos estatísticos que procuram descrever a variação espacial do fenômeno em estudo, a partir de amostras disponíveis.

Dessa forma, os fenômenos podem ser expressos através de ocorrências pontuais ou em áreas, cujas localizações são expressas em um SIG por meio de pontos, linhas e polígonos.

A representação pontual relaciona-se a fenômenos expressos através de ocorrências identificadas como pontos localizados no espaço, tais como localização de crimes, de espécies vegetais, ocorrência de doenças. O objetivo destas análises é estudar a distribuição destes pontos, testando hipóteses sobre o padrão observado: se é aleatório, se apresenta-se em aglomerados ou se os pontos estão regularmente distribuídos, sendo o objeto de estudo a própria localização dos eventos em estudo.

No que segue, será considerado aqui o caso de fenômenos expressos através de ocorrências pontuais.

O tipo de dado nestes estudos consiste em uma série de coordenadas de pontos $\left(p_{1}, p_{2}, \ldots\right)$ dos eventos de interesse dentro da área de estudo. O termo evento refere-se a qualquer tipo de fenômeno localizável no espaço que possa estar associado a uma representação pontual. 
Os dados de distribuições pontuais têm as seguintes características:

* A área de eventos não é uma medida válida apesar de em muitos casos ocupar espaço. Mesmo na análise do padrão de distribuição de cidades estas são consideradas como um ponto no espaço do estudo.

Os pontos em geral não estão associados a valores, mas apenas à ocorrência dos eventos considerados.

* Em alguns estudos os pontos podem estar associados a atributos de identificação, como por exemplo em óbitos neonatais e pósneonatais. Quando este atributo é elemento do estudo, através da comparação da distribuição espacial destes atributos, denomina-se processo pontual marcado.

O interesse primário ao analisar padrões de distribuição de pontos ("point patterns") é denominar se os eventos observados exibem algum padrão sistemático, em oposição a uma distribuição aleatória. Busca-se detectar a existência de padrão de conglomerados espaciais (cluster), através da constatação de um número acima do esperado de casos excessivamente próximos, considerando uma distribuição 
estocástica, usualmente um processo de Poisson. Se um padrão de eventos pontuais apresentar desvios significativos do comportamento esperado para uma distribuição de Poisson, isto indica a existência de uma distribuição espacial diferente da completa aleatoriedade.

\subsubsection{Caracterização de distribuições de pontos}

Numa visão estatística, processos pontuais são definidos como um conjunto de pontos irregularmente distribuídos em um terreno, cuja localização foi gerada por um mecanismo estocástico. Para sua caracterização, este processo estocástico pode ser descrito em termos dos efeitos de primeira e segunda ordem.

Os efeitos de primeira ordem, considerados globais ou de larga escala, correspondem a variações no valor médio do processo no espaço. Neste caso, o que interessa é a intensidade do processo, isto é, o número de eventos por unidade de área. Efeitos de segunda ordem, denominados locais ou de pequena escala, representam a dependência espacial no processo, proveniente da estrutura de correlação espacial. Para medir a dependência espacial, procura-se estimar o relacionamento entre pares de eventos (por unidade de área) no espaço, o que corresponde a uma 
aproximação do cálculo da covariância entre as variáveis aleatórias que representam cada evento.

Considera-se um conjunto de pontos $\left(u_{1}, u_{2}, \ldots\right)$ numa determinada região $A$ onde ocorreram eventos. $O$ processo pontual é modelado considerando subregiões $S$ em $A$ através de sua esperança $E[N(S)]$ e a covariância $C\left[N\left(S_{i}\right), N\left(S_{j}\right)\right]$, onde $N(S)$ denota o número de eventos em S. Sendo o objetivo da análise estimar as localizações prováveis de ocorrência de determinados eventos, essas estatísticas devem ser inferidas considerando o valor limite da quantidade de eventos por área. Este valor limite corresponde à esperança de $N(S)$ para uma pequena região $d u$ em torno do ponto $u$, quando esse tende a zero. Essa esperança é denominada intensidade (propriedade de primeira ordem), sendo definida como:

$$
\lambda(u)=\lim _{|d u| \rightarrow 0}\left\{\frac{E[N(d u)]}{|d u|}\right\}
$$

Propriedades de segunda ordem podem ser definidas da mesma forma, considerando a intensidade conjunta $\lambda\left(u_{i}, u_{j}\right)$ entre duas regiões infinitesimais $/ \mathrm{d} u_{i} /$ e $/ \mathrm{d} u_{j} /$ que contém os pontos $u_{i}$ e $u_{j}$.

$$
\lambda\left(d\left(u_{i}\right), d\left(u_{j}\right)\right)=\lim _{d u_{i}, d u \rightarrow 0_{j}}\left\{\frac{C\left[N\left(d u_{i}\right), N\left(d u_{j}\right)\right]}{d u_{i}, d u_{j}}\right\}
$$


Quando o processo é estacionário, $\lambda(u)$ é uma constante, ou $\lambda(u)=\lambda$; se também é isotrópico, $\lambda\left(u_{i}, u_{j}\right)$ se reduz à $\lambda(|h|)$, sendo $|h| a$ distância entre os dois pontos. Quando o processo é não estacionário, ou seja, a intensidade média varia na região $A$, a modelagem da estrutura de dependência $\lambda\left(u_{i}, u_{j}\right)$ deve incorporar a variação de $\lambda(u)$. A maior parte das técnicas de análise de distribuição de pontos supõe, explícita ou implicitamente, um comportamento estacionário e isotrópico do processo aleatório subjacente aos eventos analisados.

A análise estatística dos padrões de distribuições de pontos requer um modelo teórico de referência, base para o desenvolvimento de métodos formais que checam a significância dos resultados exploratórios. O modelo teórico mais simples (e bastante aplicado na prática) é conhecido como aleatoriedade espacial completa ("complete spatial randomness- CSR"). Este modelo divide a região de estudo A em subáreas Si e modela a distribuição de eventos pontuais como um processo aleatório

$$
\left\{Z_{i}\left(u_{i}\right), u_{i} \in S_{i}: i=1, \ldots, n\right\}
$$

Neste caso, consideramos $Z_{i}\left(u_{i}\right)$ como o número de eventos que ocorrem na sub-área $S_{i}$. No modelo CSR, considera-se que as ocorrências em cada sub-área são não-correlacionadas e homogêneas, e estão associadas à mesma distribuição de probabilidade de Poisson. 
Numa visão intuitiva, pode-se considerar que a posição dos eventos é independente e que os eventos têm igual probabilidade de ocorrência em toda a região $A$.

Esta formulação nos permite estabelecer uma base de comparação entre uma distribuição completamente aleatória (que seria gerada por um processo de Poisson) e os dados coletados em campo. $O$ procedimento mais usual para estimar a probabilidade associada ao padrão encontrado será produzir uma simulação do processo aleatório na região de estudo. Dado um número fixo de eventos medidos em campo (denotado por $n$ ), determinamos o retângulo envolvente da região $A$ (seja $\left.\left\{(x, y): x_{1} \leq x \leq x_{2}, y_{1} \leq y \leq y_{2}\right\}\right)$. Os eventos são gerados a partir de abscissas $x$, obtidas de uma distribuição uniforme em $\left(x_{1}, x_{2}\right)$ e de ordenadas $y$, obtidas de uma distribuição uniforme em $\left(y_{1}, y_{2}\right)$. Pontos que caem fora da região são rejeitados. Este processo é repetido até que $n$ eventos tenham sido obtidos na região.

Pode ser gerado um conjunto de simulações, a fim de se obter uma base de comparação entre o comportamento de um processo aleatório e a distribuição de eventos medidos. Os conceitos de CSR são utilizados para caracterizar os efeitos de segunda ordem em distribuição de pontos, utilizando os métodos do vizinho mais próximo e da função $\mathrm{K}$. São também utilizados para avaliação em vários métodos de detecção de aglomerados (clusters). 


\subsubsection{Estimador de intensidade ("kernel estimation")}

Uma alternativa simples para analisar o comportamento de padrões de pontos é estimar a intensidade pontual do processo em toda região do estudo. Para isto, pode-se ajustar uma função bi-dimensional sobre os eventos considerados, compondo uma superfície cujo valor será proporcional à intensidade de amostras por unidade de área. Esta função realiza uma contagem de todos os pontos dentro de uma região de influência, ponderando-os pela distância de cada um à localização de interesse, como mostrado na figura 2 abaixo.

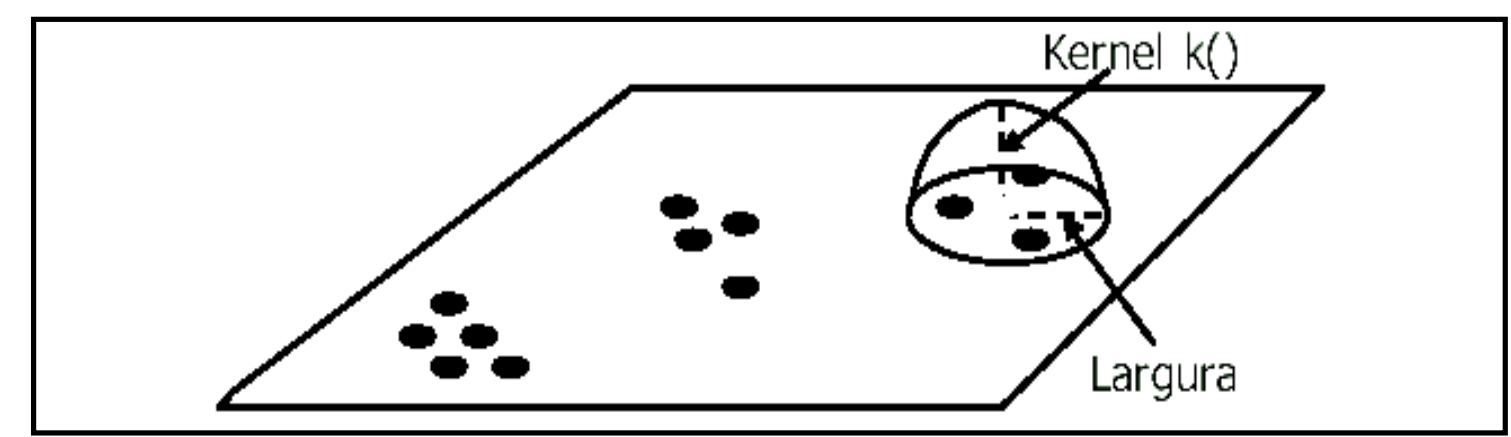

Figura 2: Estimador de intensidade de distribuição de pontos

A partir dos conceitos apresentados, suponha que $u_{1}, \ldots u_{n}$ são localizações de $n$ eventos observados em uma região $A$ e que $u$ represente uma localização genérica cujo valor queremos estimar. O estimador de intensidade é computado a partir dos $m$ eventos $\left\{\begin{array}{lll}u_{i}, \ldots & u_{i+m-1}\end{array}\right\}$ 
contidos num raio de tamanho $\tau$ em torno de $u$ e da distância $d$ entre a posição e a i-ésima amostra, a partir de funções cuja forma geral é:

$$
\hat{\lambda}_{\tau}(u)=\frac{1}{\tau^{2}} \sum_{i=1}^{n} k\left(\frac{d\left(u_{i}, u\right)}{\tau}\right), d\left(u_{i}, u\right) \leq \tau
$$

Este estimador é chamado kernel estimator e seus parâmetros básicos são: (a) um raio de influência $(\tau \geq \mathbf{0})$ que define a vizinhança do ponto a ser interpolado e controla o "alisamento" da superfície gerada; (b) uma função de estimação com propriedades de suavização do fenômeno. O raio de influência define a área centrada no ponto de estimação $u$ que indica quantos eventos $u_{i}$ contribuem para a estimativa da função intensidade $\lambda$. Um raio muito pequeno irá gerar uma superfície muito descontínua; se for grande demais, a superfície poderá ficar muito amaciada. No caso da função de interpolação k0, é comum usar funções de terceira ou quarta ordem como

$$
\boldsymbol{k}(\boldsymbol{h})=\frac{3}{\pi}\left(1-h^{2}\right)^{2}
$$

ou o kernel gaussiano

$$
k(h)=\frac{1}{2 \pi \tau} \exp \left(-\frac{h^{2}}{2 \tau^{2}}\right)
$$


Nestes estimadores, $h$ representa a distância entre a localização em que se deseja calcular a função e o evento observado. Com o uso desta função de quarta ordem (equação 5), o estimador de intensidade pode ser expresso como:

$$
\hat{\lambda}_{\tau}(\mathbf{u})=\sum_{h_{i} \leq \tau} \frac{3}{\pi \tau^{2}}\left(1-\frac{\boldsymbol{h}_{\boldsymbol{i}}{ }^{2}}{\tau^{2}}\right)^{2}
$$

O estimador de intensidade é muito útil para fornecer uma visão geral da distribuição de primeira ordem dos eventos. Trata-se de um indicador de fácil uso e interpretação.

No presente estudo, a técnica utilizada para estimação de propriedades de segunda ordem do processo pontual foi a técnica do vizinho mais próximo descrita a seguir:

\subsubsection{Método do vizinho mais próximo}

O método do vizinho mais próximo estima a função de distribuição cumulativa $\hat{G}(\boldsymbol{h})$ baseado nas distâncias $h$ entre eventos em uma região de análise. Esta função de distribuição pode ser estimada empiricamente da seguinte forma: 


$$
\hat{G}(\boldsymbol{h})=\frac{\#\left(\boldsymbol{d}\left(\boldsymbol{u}_{i}, \boldsymbol{u}_{j}\right) \leq \boldsymbol{h}\right)}{n}
$$

na qual o valor normalizado acumulado para uma distância $h$ corresponde à soma dos vizinhos mais próximos de cada evento cuja distância é menor ou igual a $h$, dividido pelo número de eventos na região.

A plotagem dos resultados desta função de distribuição cumulativa empírica $\hat{G}(\boldsymbol{h})$ pode ser usada como um método exploratório para verificar se existe evidência de interação entre os eventos. Se esta plotagem apresentar um crescimento rápido para pequenos valores de distância, esta situação aponta para interação entre os eventos caracterizando agrupamentos nestas escalas. Se esta plotagem apresentar valores pequenos no seu início, e só crescer rapidamente para valores maiores de distância, esta situação aponta para uma distribuição mais regular.

A análise de vizinhança pode ser usada como método formal para se comparar estatisticamente a distribuição dos eventos observados com o que se esperaria na hipótese de CSR. Esta metodologia consiste em se criar envelopes de simulação para distribuição CSR, a fim de se acessar a significância dos desvios. Na hipótese de CSR, a função de distribuição $G(w)$ seria dada por um processo de Poisson

$$
G(h)=1-e^{-\lambda \pi h^{2}}, h \geq 0
$$


A estimação simulada para a distribuição $G(W)$ assumindo-se CSR é calculada como

$$
\bar{G}(h)=\frac{\left.\sum_{i=1}^{k} \hat{G}_{i}^{\hat{(h}}\right)}{\boldsymbol{k}}
$$

na qual $\hat{G}_{i}(\boldsymbol{h}), \boldsymbol{i}=\mathbf{1}, \mathbf{2}, \ldots, \boldsymbol{k}$ são funções de distribuições empíricas, estimadas a partir de $k$ simulações independentes dos $n$ eventos, na hipótese de CSR ( $n$ eventos independentes e uniformemente distribuídos). Para verificar a condição de aleatoriedade, calcula-se ainda os envelopes de simulação superior e inferior, definidos como se segue:

$$
\begin{aligned}
& U(h)=\operatorname{má} x\left\{\hat{G}_{i}(h)\right\}, i=1, \ldots, k \\
& L(h)=\min \left\{\hat{G}_{i}(h)\right\}, i=1, \ldots, k
\end{aligned}
$$

A plotagem da distribuição estimada $\hat{G}(\boldsymbol{h})$ versus a distribuição simulada $\bar{G}(\boldsymbol{h})$, com a adição dos envelopes inferior e superior, permite medir a significância dos desvios relativos à aleatoriedade. Se a condição CSR for válida para os dados observados, o gráfico da curva de $\hat{G}(\boldsymbol{h})$ 
versus $\bar{G}(\boldsymbol{h})$ deve ser praticamente linear com um ângulo de $45^{\circ}$. Se o dado apresenta tendências para agrupamentos, os traçados no gráfico estarão acima da linha de $4^{\circ}$, ao passo que para padrões de regularidade os traçados ficarão abaixo da linha de $45^{\circ}$.

A figura 3 abaixo exibe um exemplo de gráfico mostrando o posicionamento da distribuição e dos envelopes com relação a linha de 45․ para dados referentes à mortalidade infantil neonatal em Porto Alegre no ano de 1996. Neste caso, percebe-se a posição dos envelopes e da distribuição acima da linha de $4^{\circ}$, o que caracteriza agrupamento para as distâncias em análise.

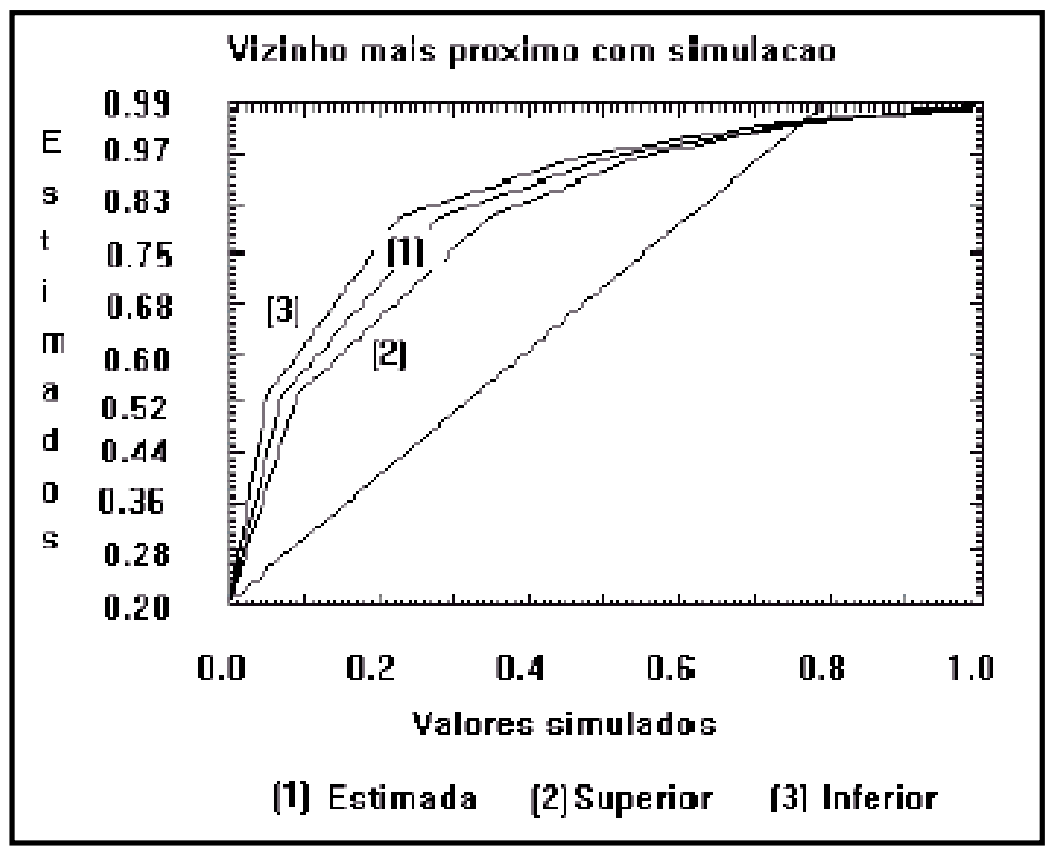

Figura 3: Gráfico de $\hat{G}(h)$ (estimado) versus $\bar{G}(h)$ (CSR), com envelopes superior e inferior, para os dados de mortalidade neonatal em Porto Alegre. 1996 
* Descrever a distribuição espacial da incidência da Tuberculose na área urbana do município de Ribeirão Preto para o período de 1998 a 2002 utilizando dados secundários

* Analisar a dependência espacial de casos de Tuberculose na área urbana do município de Ribeirão Preto para o período de 1998 a 2002 
METODOLOGIA 


\section{1 Área geográfica do estudo}

Ribeirão Preto localiza-se a 47048'24" W de longitude e 21010'42" S de latitude, na região nordeste do estado de São Paulo, a cerca de $313 \mathrm{~km}$ da capital. Os limites da cidade são dados pelos seguintes municípios: ao sul, Guatapará; ao norte, Jardinópolis; ao leste, Serrana; ao oeste, Dumont. O resumo do processo de formação de Ribeirão Preto encontra-se no Anexo A.

Apresenta clima tropical com verão chuvoso e inverno seco, com médias de temperatura: $19^{\circ} \mathrm{C}$ no inverno e $25^{\circ} \mathrm{C}$ no verão. Topografia de planalto com uma altitude de 518 metros. A área total do município é de $651 \mathrm{~km}^{2}$.

É sede de uma das principais praças financeiras do país, apresentando um forte setor de prestação de serviços e comércio, sendo que nele se concentram $65 \%$ da população economicamente ativa do município. Com 504.923 habitantes segundo o Censo Demográfico de 2000, o município de Ribeirão Preto encontra-se entre os maiores do estado de São Paulo e do Brasil. Ribeirão Preto apresentou um intenso crescimento populacional durante as décadas de 70 e 80. A taxa média de crescimento populacional durante o período 1970-1980 do município se manteve maior que a taxa de crescimento estadual (4,06 para Ribeirão Preto e 3,45 para o Estado), fazendo com que sua participação se elevasse no total da população do estado. Este crescimento pode ser 
explicado pelo fato de Ribeirão Preto ter se mantido como um pólo de atração populacional, tendo sido uma das poucas regiões do estado a ter apresentado um fluxo migratório positivo.

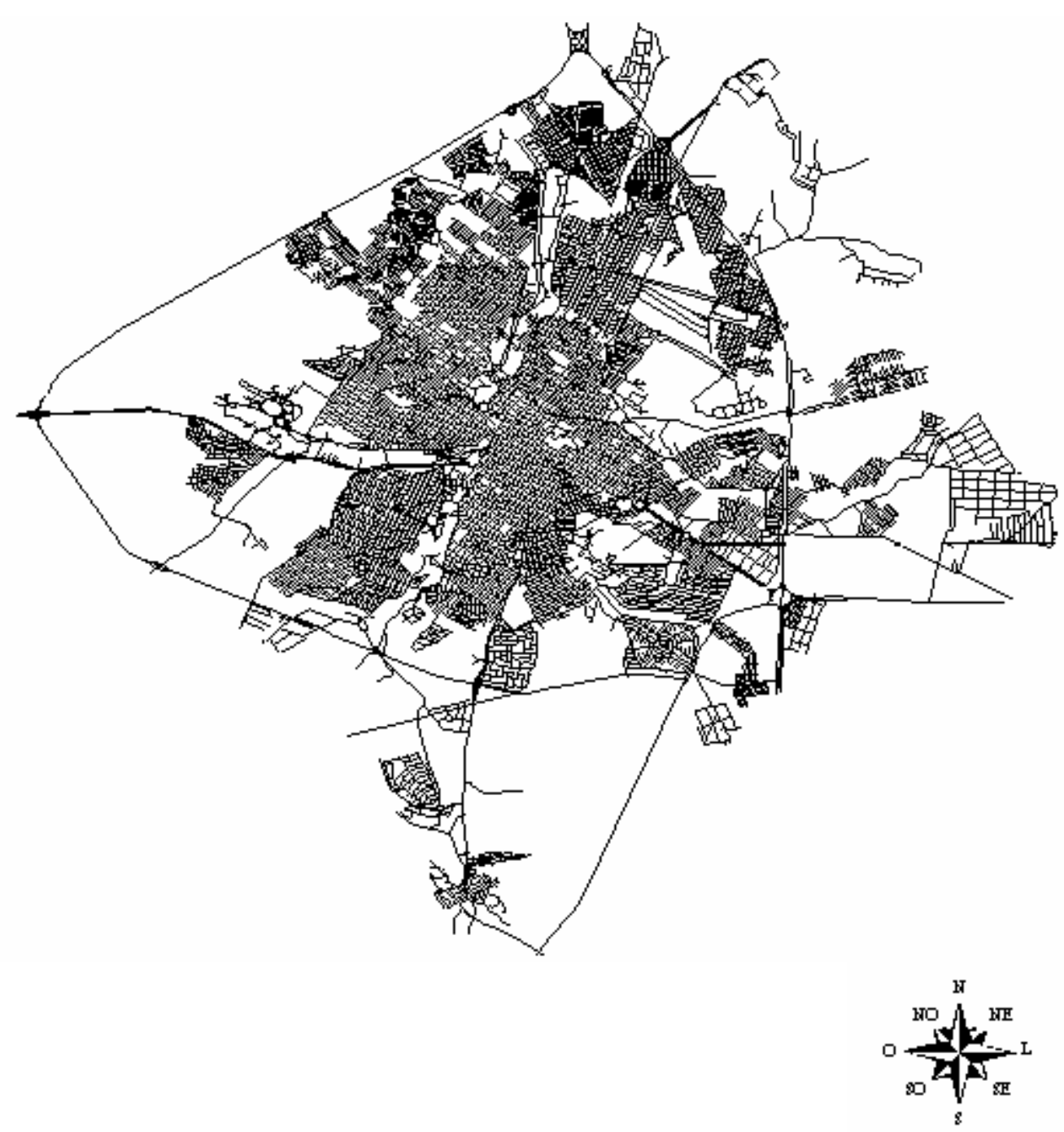

Figura 4: Mapa do município de Ribeirão Preto com arruamento 
3.2 Sistema de Saúde e o Programa de Controle da Tuberculose em Ribeirão Preto

Segundo Muniz (1999), o município de Ribeirão Preto conta com ampla rede de serviços de saúde privada, filantrópica e pública, abrangendo a atenção primária, secundária e terciária à saúde. A rede hospitalar é constituída por 11 hospitais, sendo 9 gerais (1 hospital escola de caráter público, 3 filantrópicos e 5 privados) e 2 psiquiátricos (1 público e 1 filantrópico). Destes, 6 estão ligados ao Sistema Único de Saúde (SUS). Possui uma rede básica ambulatorial composta por 33 unidades de saúde, sendo 28 unidades básicas e 5 unidades distritais de saúde. Além do atendimento básico e especializado, oferece serviços ambulatoriais para hospitais conveniados e contratados.

Através da SMS são desenvolvidas ações de abrangência coletiva relacionadas à assistência comunitária, promoção e educação em saúde nos serviços de VE, Controle de Vetores, Divisão Veterinária e Programas de Saúde.

No processo de municipalização, Ribeirão Preto encontra-se em Gestão Plena do Sistema. Possui Conselho Municipal de Saúde, que se reúne periodicamente, com representação paritária, no qual participam o Secretário Municipal da Saúde, representantes dos prestadores de serviço e usuários. As unidades de saúde da SMS são informatizadas, 
através do sistema "Hygia". A implantação do sistema de informação trouxe benefícios como: emissão de cadastro único do paciente (Registro Geral da Saúde), prontuário informatizado e agendamento de consultas pelo computador.

O processo de municipalização da saúde no município de Ribeirão Preto iniciou-se no final de 1987 havendo, a partir deste período significativa ampliação da rede básica, com conseqüente redistribuição de competências entre as instâncias do governo.

As ações de VE que eram de competência estadual, começaram a ser gradativamente incorporadas pelo município no ano de 1989, com a implantação do serviço de VE da SMS, hoje Divisão de Vigilância Epidemiológica. O município passou a executar as ações de vigilância, exercendo participação ativa no sistema.

No ano de 1995 o município de Ribeirão Preto foi identificado como prioritário ao combate da Tuberculose. Dentre os critérios estabelecidos para a priorização dos municípios naquele período, Ribeirão Preto apresentava: população acima de 50 mil habitantes; coeficiente médio de incidência nos últimos cinco anos, de 56/100000 habitantes; taxa média de abandono de $16 \%$ e de cura de $50 \%$, nos últimos cinco anos; taxa de co-infecção TB/HIV, em média de 29\%, nos últimos dois anos.

Sob iniciativa da Divisão de Vigilância Epidemiológica da SMS foi realizado em dezembro de 1995 o I Fórum Regional de Tuberculose e 
co-infecção TB/HIV, com objetivo de sensibilizar os profissionais da área da saúde quanto à situação alarmante da Tuberculose no país e no município.

Em março de 1996, criou-se pela SMS de Ribeirão Preto, o cargo de coordenação do PCT, para atender às propostas estabelecidas pela Divisão de Vigilância Epidemiológica, passando então o município a gerenciar o PCT.

No ano de 1996, foi implantada a estratégia de busca ativa de sintomáticos respiratórios. Ofereceu-se treinamento a profissionais de enfermagem (um enfermeiro e um auxiliar de enfermagem de cada unidade de saúde) para identificar o sintomático respiratório na demanda do serviço de saúde e proceder à coleta de escarro. Com a implantação da busca ativa de sintomáticos respiratórios pelas unidades de saúde, houve um acréscimo significativo de baciloscopias de escarro realizadas pelo município e um aumento de casos diagnosticados.

A implantação do TS, associada à reorganização das ações do Programa, ocasionou importantes alterações nos indicadores epidemiológicos da Tuberculose. Contudo, esforços ainda devem ser despendidos com propósito de ampliar as taxas de cura e alcançar o proposto pelo Plano Nacional de Controle da Tuberculose (1999), que apresenta as seguintes metas: implementar a cobertura do PCT para 100\% dos municípios em três anos (2001); diagnosticar pelo menos 92\% dos casos esperados e tratar com sucesso pelo menos $85 \%$ dos casos 
diagnosticados e em nove anos (2007) reduzir a incidência, no mínimo, a $50 \%$ e a mortalidade em dois terços.

\subsection{Tipo de estudo}

Este estudo caracteriza-se seccional. Segundo Almeida Filho e Rouquayrol (2002), estudos seccionais ou de corte transversal são investigações que produzem instantâneos da situação de saúde de uma população ou comunidade, com base na avaliação individual do estado de saúde de cada um dos membros do grupo, daí produzindo indicadores globais de saúde para o grupo investigado, sendo de grande utilidade para realização de diagnósticos comunitários da situação local de saúde. A sua designação precisa é estudo individuado-observacional-seccional.

O termo "estudo seccional" no contexto metodológico da epidemiologia, pretende dar uma idéia de seccionamento transversal, um corte no fluxo histórico da doença, evidenciando as suas características e correlações naquele momento. Trata-se de um estudo epidemiológico no qual fator e efeito são observados em um mesmo momento histórico.

O subtipo de desenho seccional aqui empregado foi o estudo de grupos em tratamento, que com o emprego de registros institucionais, localiza a procedência de cada paciente para desta forma identificar a 
base populacional para os respectivos denominadores. Apesar da lógica aparentemente simples e de custo potencialmente baixo, pois utiliza dados secundários, um problema fundamental dessas investigações é que as estimativas por elas produzidas são afetadas pela quantidade, qualidade e distribuição dos serviços de saúde, bem como pela quantidade do sistema de registro de admissões adotado pelas unidades de tratamento. Mesmo quando corretamente conduzido, esse desenho é eficaz apenas para as patologias de maior grau de gravidade, aquelas que levam necessariamente ao tratamento. Mesmo assim, fatores étnicos e sociais podem ser mais importantes para definir a hospitalização ou o tratamento do que a própria gravidade do transtorno.

\subsection{Procedimentos éticos}

Para realização do referido estudo, o projeto foi previamente submetido à apreciação e aprovação pelo Comitê de Ética em Pesquisa da Escola de Enfermagem da Universidade de São Paulo.

Como este estudo utilizou exclusivamente informações do banco de dados Epi-Tb e este não envolveu a identificação dos doentes, 
foi solicitado dispensa do termo de consentimento livre e esclarecido devido à garantia do sigilo. (Anexo B)

\subsection{Coleta de dados}

As informações referentes ao período de janeiro de 1998 a dezembro de 2002 foram coletadas na VE da SMS do município de Ribeirão Preto- SP; utilizou-se o banco de dados Epi-Tb, que é um programa padronizado pelo estado de São Paulo, possibilitando um seguimento mensal do doente. Esse banco de dados é alimentado e atualizado mensalmente com informações enviadas pelos Distritos de Saúde sobre o seguimento do doente. A população do presente estudo compreende os doentes de Tuberculose, inscritos no PCT do município de Ribeirão Preto, no período de 1998 a 2002. 


\subsection{Apresentação e análise dos dados}

Após a coleta e preenchimento do instrumento, os dados obtidos foram dispostos em um banco de dados com auxílio do software Excel. A técnica de dupla verificação foi empregada para verificar possíveis erros de transcrição.

Os dados foram apresentados em duas fases distintas. A primeira contempla resultados descritivos, onde foram apresentados gráficos, valores médios e medianos, bem como medidas de dispersão, quando possível das variáveis em estudo. O programa estatístico utilizado foi o SPSS (Statistical Program for Social Sciences) versão 10.0. Para a obtenção dos mapas temáticos, os dados foram geocodificados com auxílio do programa MapInfo versão 6.5. Inicialmente, utilizou-se a forma automática de geocodificação, recorrendo-se à forma interativa quando necessário. Nesta fase foram montados padrões de pontos dos eventos. $\mathrm{Na}$ segunda fase, inferencial, foram apresentados os resultados da análise estatística espacial decorrente da utilização das técnicas apropriadas para eventos pontuais. O padrão de densidade dos casos de Tuberculose foram apresentados por alisamento Kernel e analisados pelo método do vizinho mais próximo com simulação através do software Spring. 
RESULTADOS 


\subsection{Perfil dos casos}

Para o período estudado foram notificados 1094 casos de Tuberculose, sendo $26,23 \%$ para o ano de $1998 ; 23,22 \%$ para 1999 ; 18,46\% para 2000; 19,93\% para 2001 e 12,16\% para 2002.

Em relação ao gênero, no ano de 1998, 69,69\% dos casos de Tubérculose foram do sexo masculino. A idade média dos doentes foi de 35 anos, com desvio-padrão de 16,3 anos. A mediana das idades foi de 34 anos, com amplitude semi-quartílica de 18 anos (quartis 1 e 3 iguais a 26 e 44 anos, respectivamente). O valor mínimo de idade foi de 0 ano e o máximo de 96 anos. A faixa etária mais atingida foi a de 30-39 anos (33,10\%), como apresentado no Gráfico 1.

A presença da Tuberculose em menores de 5 anos foi de $4,9 \%$. A análise dos casos notificados de crianças menores de 15 anos revelou predomínio em menores de 5 anos, exceto para o ano de 2001. Segundo Kritiski et al (1999), as pessoas recém-infectadas com o Mycobacterium tuberculosis até a idade de 4 anos, tem um risco de adoecer muito elevado (400/100.000 habitantes). Isto, associado a outros fatores como desnutrição, deterioração do serviço público de saúde, falha na distribuição de tuberculostáticos, falta de pessoal treinado para 0 diagnóstico, notificação e acompanhamento do doente de Tuberculose, principalmente pediátrico. 


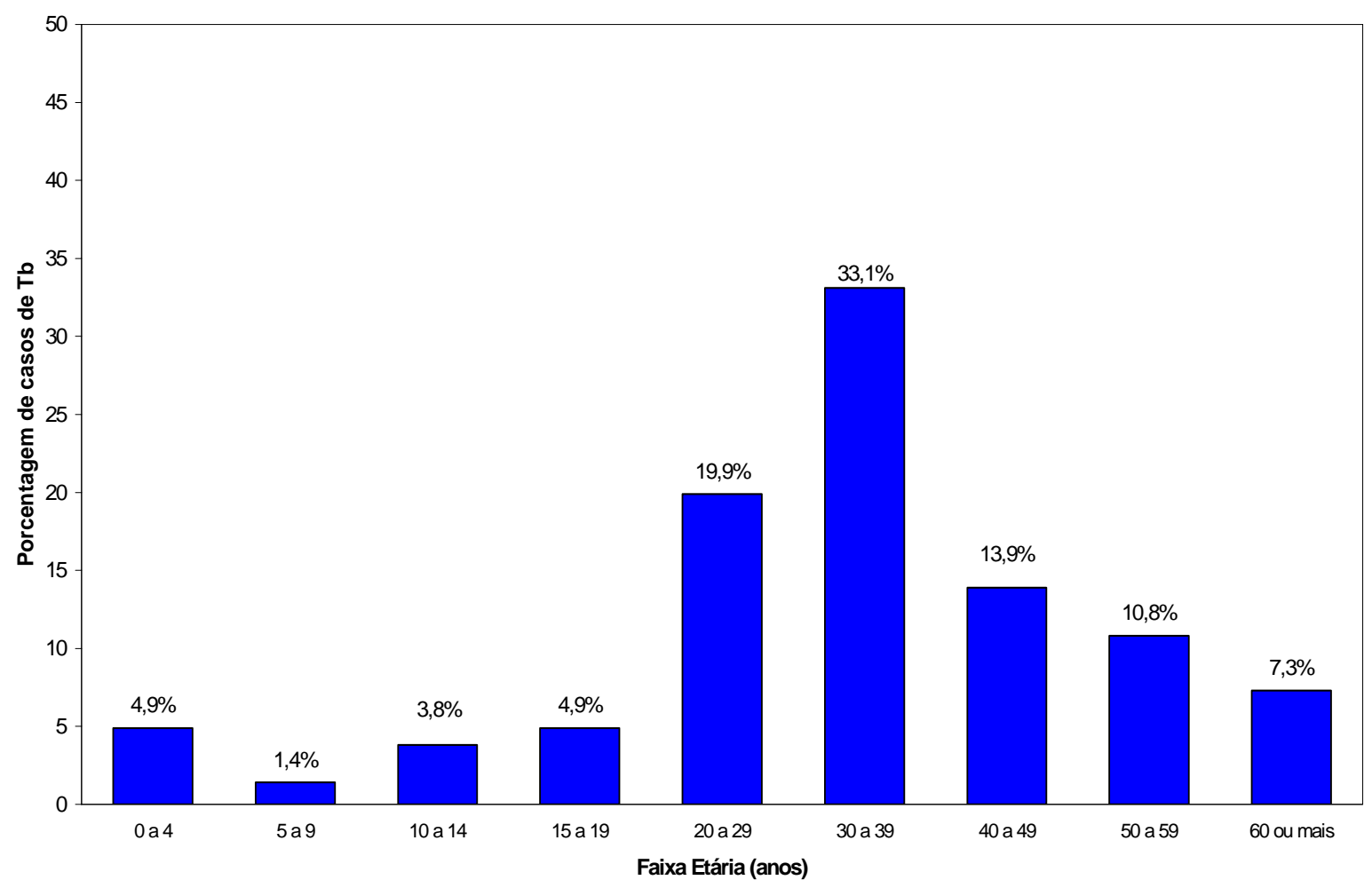

Fonte: Epi-Tb - Vigilância Epidemiológica - Secretaria Municipal de Saúde - Ribeirão Preto-SP

Gráfico 1 - Distribuição dos casos de tuberculose, segundo informação sobre faixa etária (anos). Ribeirão Preto-SP.1998

Quanto ao resultado de sorologia para HIV, 34\% dos doentes eram portadores do HIV. Apesar do teste anti-HIV ser recomendado para todos os casos diagnosticados de Tuberculose, devido à alta prevalência da co-infecção Tb/HIV não foram realizados em $25 \%$ dos doentes. Dos 287 casos notificados no referido ano, $66 \%$ dos doentes evoluíram para cura. O percentual de abandono foi de $10 \%$. Os resultados estão apresentados nos gráficos 2 e 3 a seguir. 


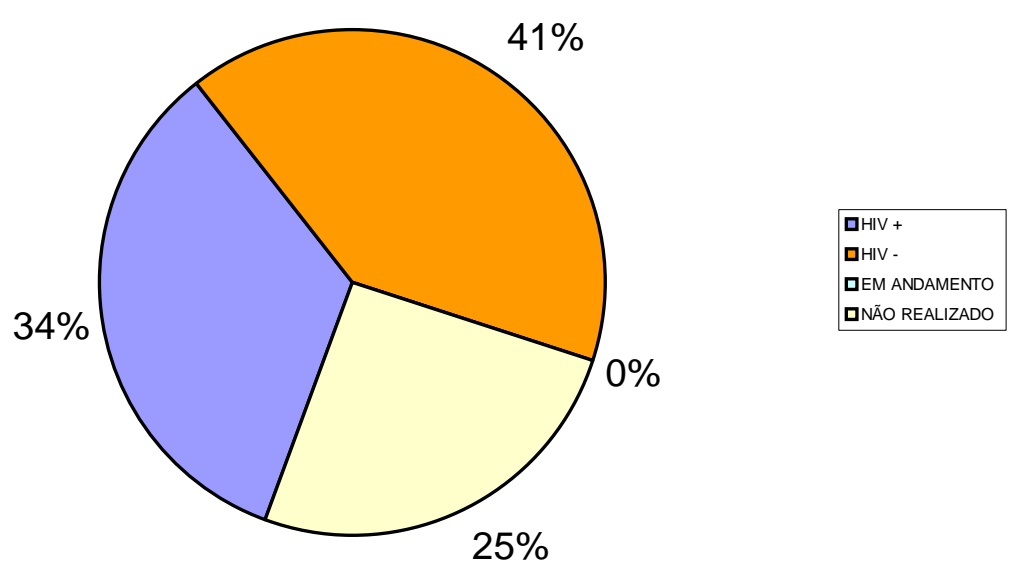

Fonte: Epi-Tb - Vigilância Epidemiológica - Secretaria Municipal de Saúde - Ribeirão Preto-SP

Gráfico 2 - Distribuição dos casos de tuberculose, segundo informação sobre resultado de sorologia para HIV. Ribeirão Preto-SP.1998

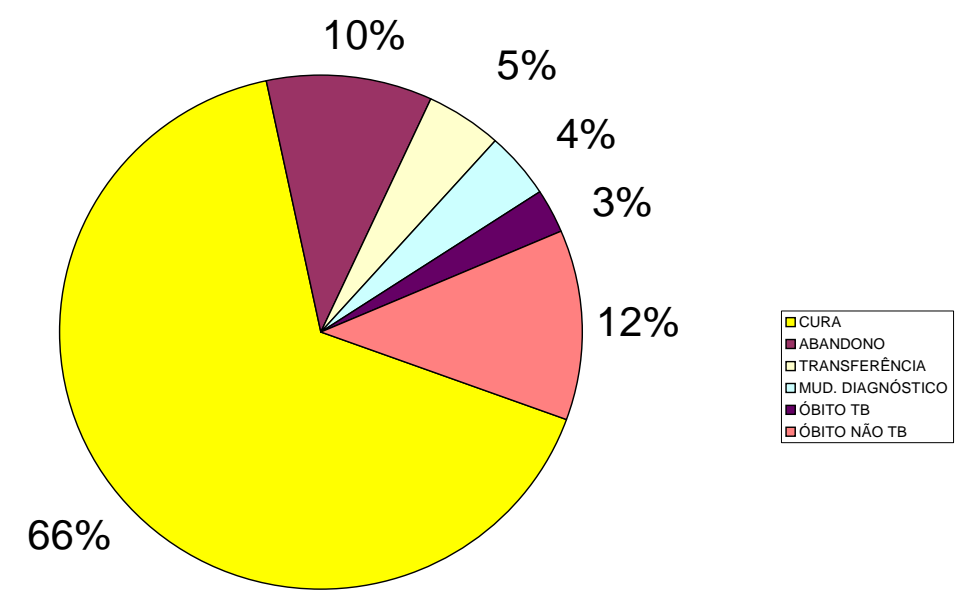

Fonte: Epi-Tb - Vigilância Epidemiológica - Secretaria Municipal de Saúde - Ribeirão Preto-SP

Gráfico 3 - Distribuição dos casos de tuberculose, segundo informação sobre resultado de tratamento. Ribeirão Preto-SP.1998 
O gráfico 4 mostra, para o ano de 1999, a existência de um maior número de casos para a faixa etária de 30-39 anos, representando $33,10 \%$ dos casos (houve uma perda para a variável idade). A idade média dos doentes foi de 38 anos, com desvio-padrão de 14,52 anos. A mediana das idades foi de 36 anos, com amplitude semi-quartílica de 14 anos (quartis 1 e 3 iguais a 30 e 44 anos, respectivamente). O valor mínimo de idade foi de 0 ano e o máximo de 86 anos.

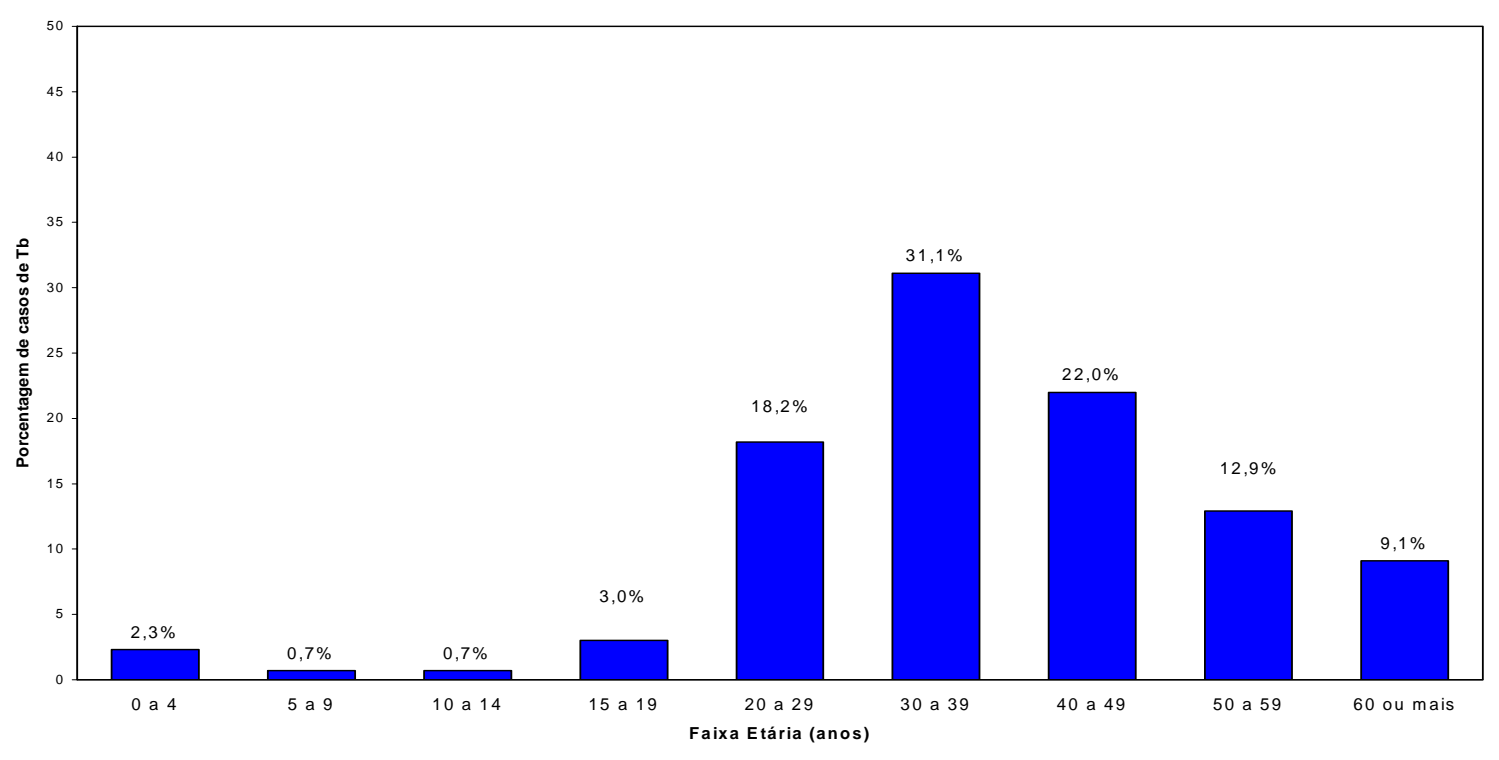

Fonte: Epi-Tb - Vigilância Epidemiológica - Secretaria Municipal de Saúde - Ribeirão Preto-SP

Gráfico 4 - Distribuição dos casos de tuberculose, segundo informação sobre faixa etária (anos). Ribeirão Preto-SP.1999

Quanto ao gênero, houve predomínio do sexo masculino (70,87\%). O resultado de sorologia para HIV apontou que $31 \%$ dos doentes apresentavam co- infecção Tb/HIV (Gráfico 5) . 


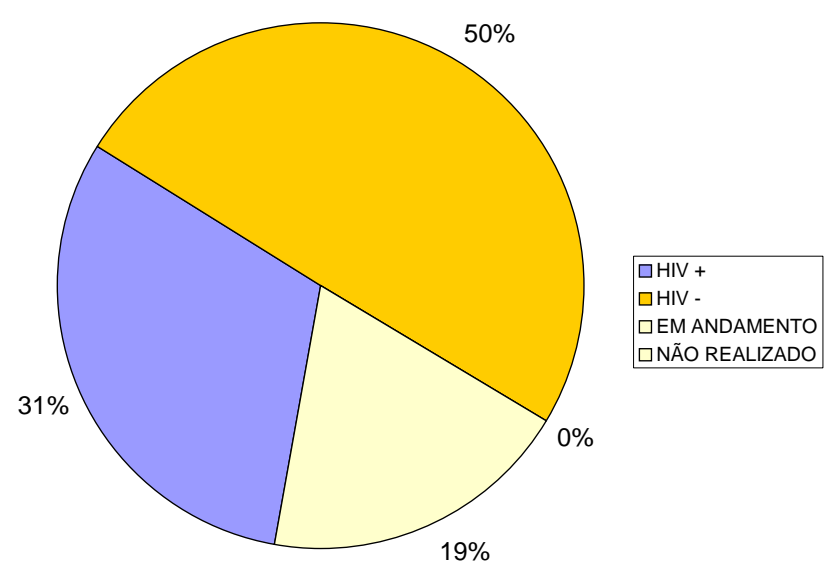

Fonte: Epi-Tb - Vigilância Epidemiológica - Secretaria Municipal de Saúde - Ribeirão Preto-SP

Gráfico 5 - Distribuição dos casos de tuberculose, segundo informação sobre resultado de sorologia para HIV. Ribeirão Preto-SP.1999

O gráfico 6 a seguir apresenta a distribuição dos casos de Tuberculose, segundo informação sobre resultado de tratamento, no qual observa-se uma taxa de cura de $66 \%$.

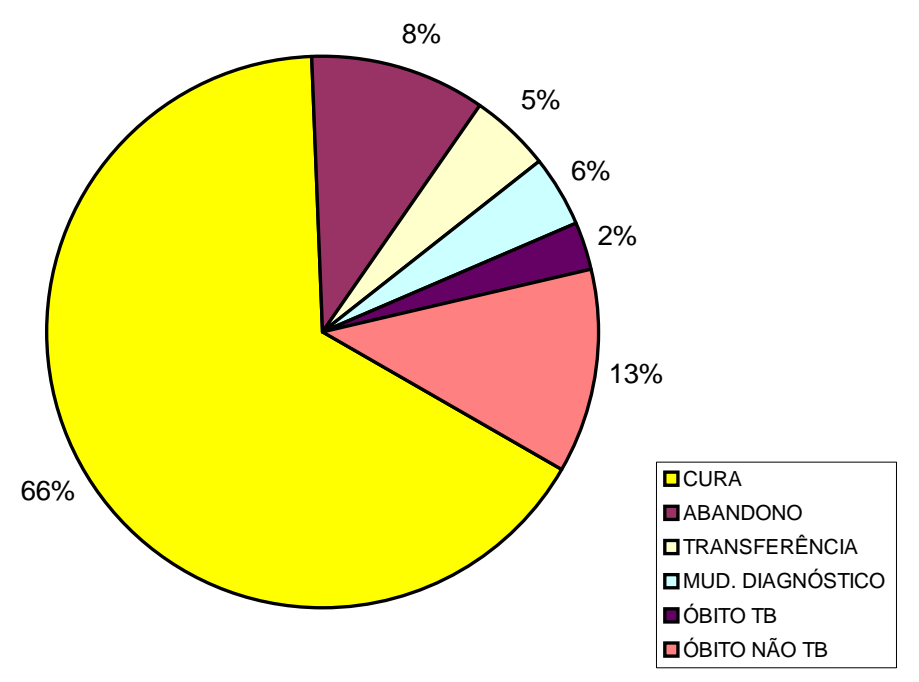

Fonte: Epi-Tb - Vigilância Epidemiológica - Secretaria Municipal de Saúde - Ribeirão Preto-SP

Gráfico 6 - Distribuição dos casos de tuberculose, segundo informação sobre resultado de tratamento. Ribeirão Preto-SP.1999 
Para o ano de 2000, 64,85\% dos doentes eram do sexo masculino. Houve uma perda para a variável idade, a faixa etária predominante foi a de 30-39 anos (32,70\%). A idade média dos doentes foi de 39 anos, com desvio-padrão de 14,96 anos. A mediana das idades foi de 37 anos, com amplitude semi-quartílica de 17 anos (quartis 1 e 3 iguais a 29,5 e 46,5 anos, respectivamente). O valor mínimo de idade foi de 0 ano e o máximo de 85 anos.

A co-infecção Tb/HIV manteve-se como no ano anterior, a uma taxa de 31\%. Observou-se que o percentual de cura foi de $74 \%$ e o de abandono 8\%. Os resultados são mostrados nos gráficos 7, 8 e 9.

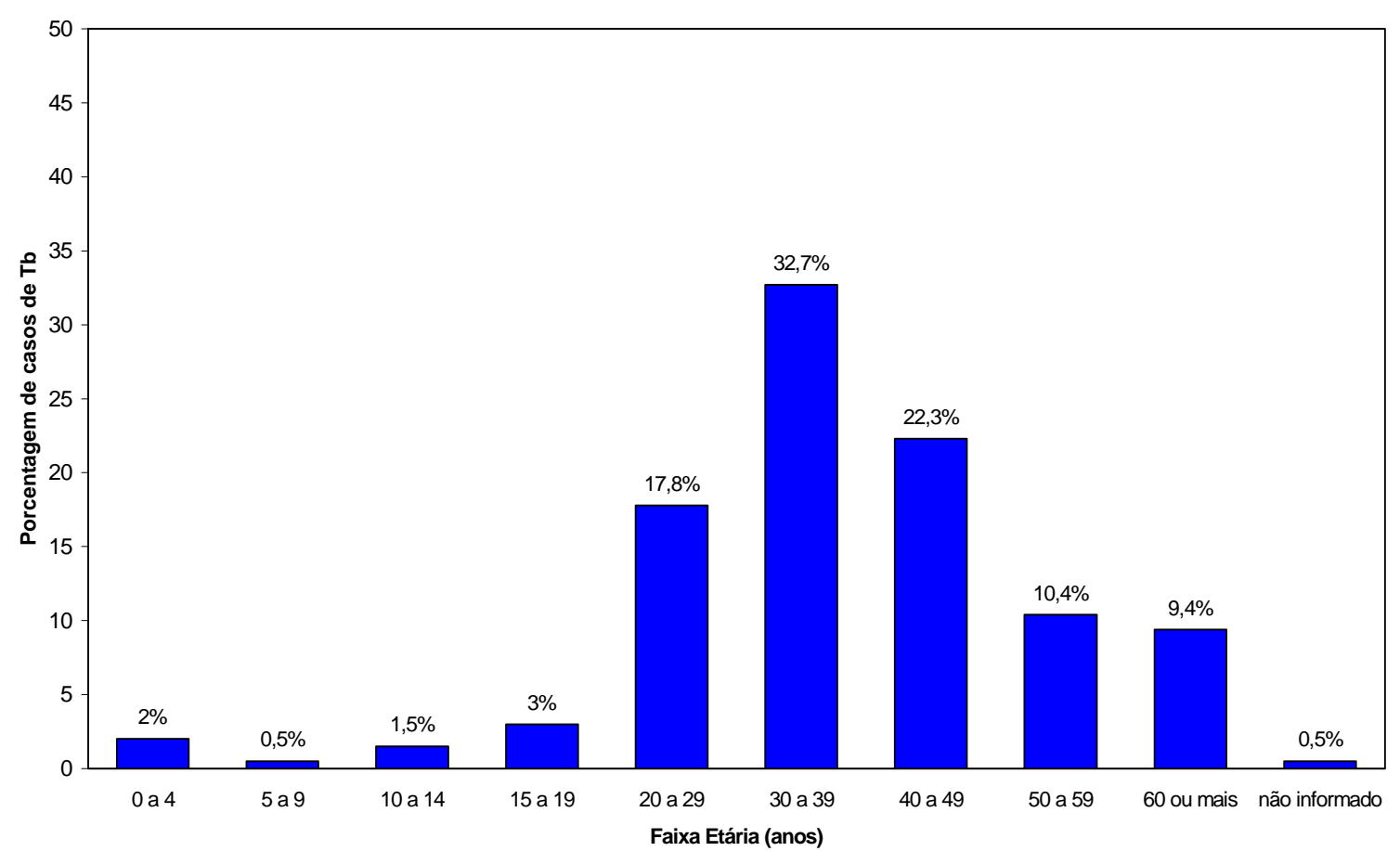

Fonte: Epi-Tb - Vigilância Epidemiológica - Secretaria Municipal de Saúde - Ribeirão Preto-SP

Gráfico 7 - Distribuição dos casos de tuberculose, segundo informação sobre faixa etária (anos) Ribeirão Preto-SP. 2000 


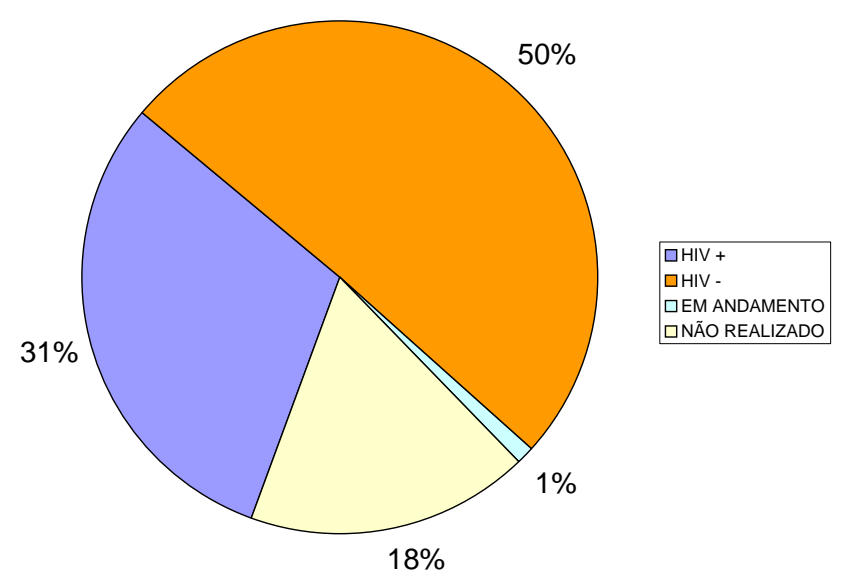

Fonte: Epi-Tb - Vigilância Epidemiológica - Secretaria Municipal de Saúde - Ribeirão Preto-SP

Gráfico 8 - Distribuição dos casos de tuberculose, segundo informação sobre resultado de sorologia para HIV. Ribeirão Preto-SP. 2000

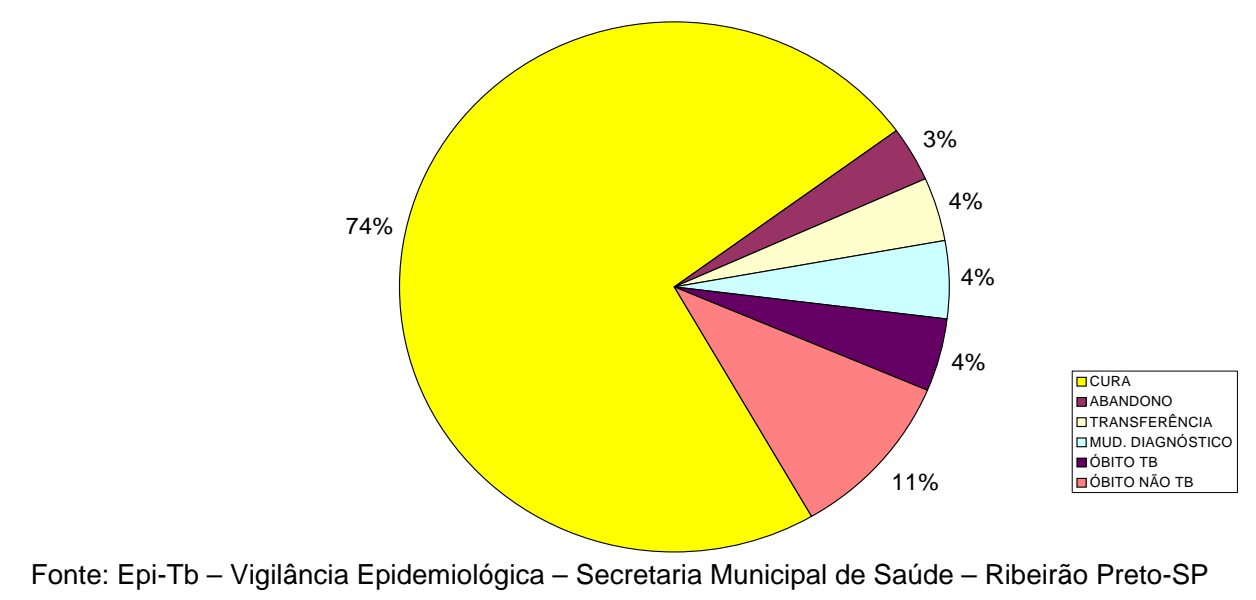

Gráfico 9 - Distribuição dos casos de tuberculose, segundo informação sobre resultado de tratamento. Ribeirão Preto-SP. 2000

Em 2001, 70\% dos casos foram do sexo masculino. Para a variável idade houve uma perda em 2001. A idade média dos doentes foi de 41 anos, com desvio-padrão de 13,6 anos. A mediana das idades foi de 41 anos, com amplitude semi-quartílica de 17 anos (quartis 1 e 3 iguais a 32 e 49 anos, respectivamente). O valor mínimo de idade foi de 0 ano e 
o máximo de 86 anos. Dentre os casos informados, a faixa etária predominante foi de $30-39$ anos $(29,60 \%)$. Os resultados apontam que a maior proporção dos casos de Tuberculose foram entre os adultos, o que representa o setor mais produtivo da população (Gráfico 10).

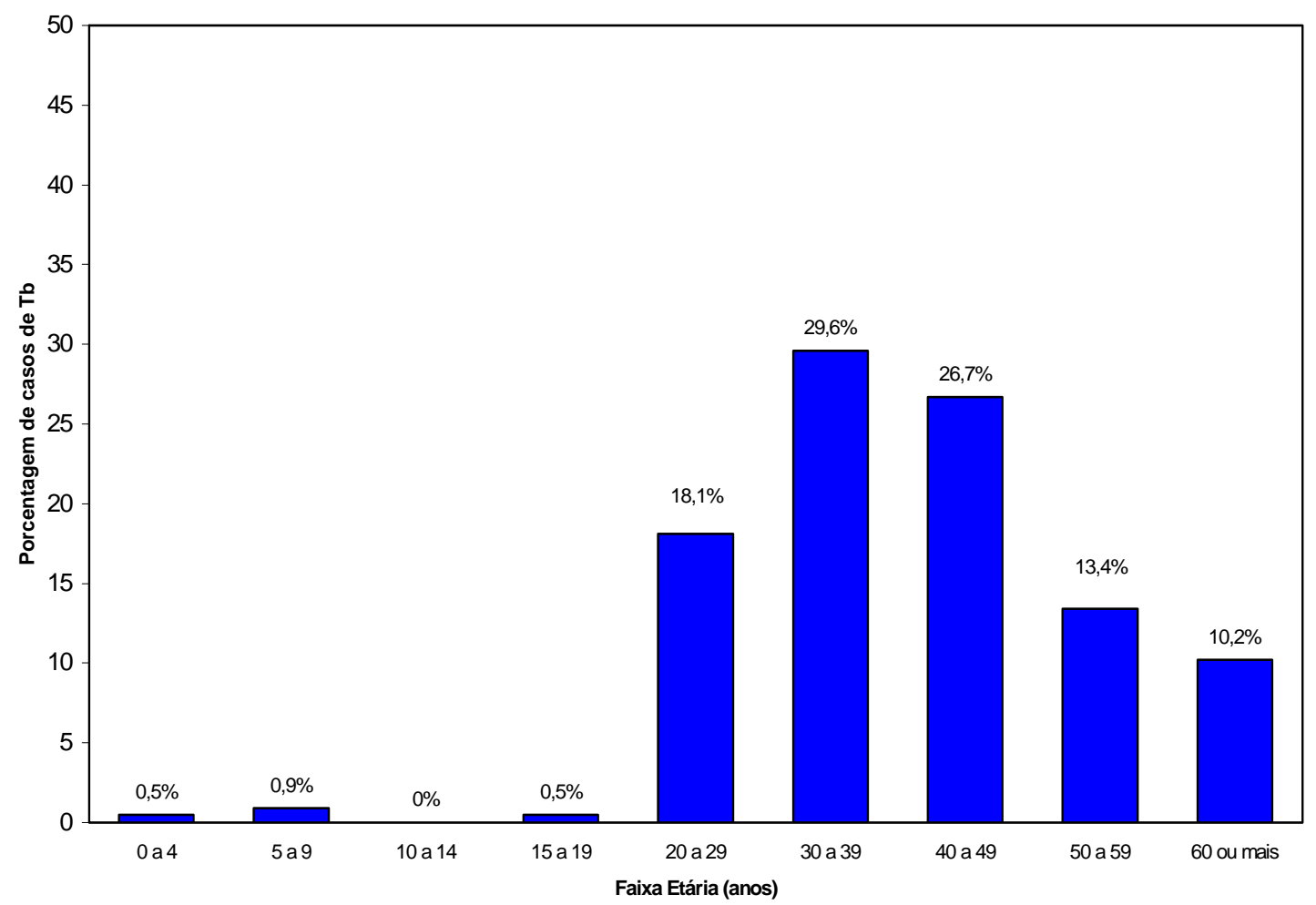

Fonte: Epi-Tb - Vigilância Epidemiológica - Secretaria Municipal de Saúde - Ribeirão Preto-SP

Gráfico 10 - Distribuição dos casos de tuberculose, segundo informação sobre faixa etária (anos). Ribeirão Preto-SP. 2001

Observou-se que $25 \%$ dos doentes apresentaram sorologia positiva para o HIV. Quanto ao resultado de tratamento, em 2001 observou-se que $73 \%$ dos doentes foram curados. O percentual de abandono foi de 7\% (Gráficos 11 e 12). 


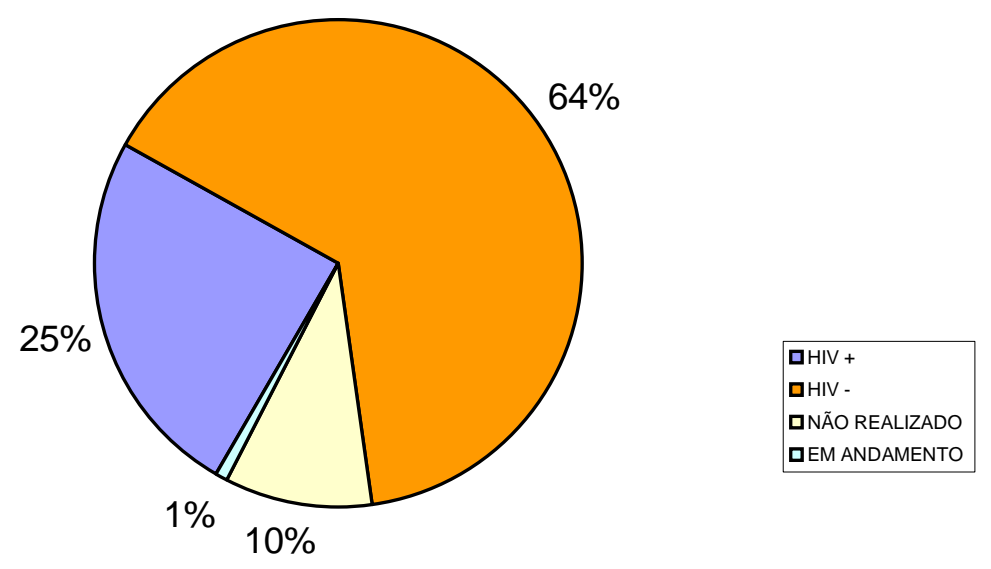

Fonte: Epi-Tb - Vigilância Epidemiológica - Secretaria Municipal de Saúde - Ribeirão Preto-SP

Gráfico 11 - Distribuição dos casos de tuberculose, segundo informação sobre sorologia para HIV. Ribeirão Preto-SP. 2001

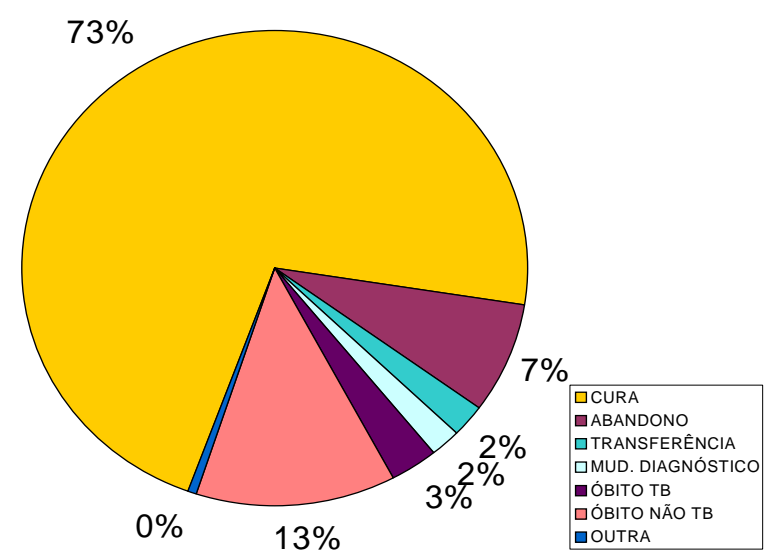

Fonte: Epi-Tb - Vigilância Epidemiológica - Secretaria Municipal de Saúde - Ribeirão Preto-SP

Gráfico 12 - Distribuição dos casos de tuberculose, segundo informação sobre resultado de tratamento. Ribeirão Preto-SP. 2001

No ano de $2002,77 \%$ dos casos eram do sexo masculino. Para a variável idade houve uma perda. A idade média dos doentes foi de 38 anos, com desvio-padrão de 15,5 anos. A mediana das idades foi de 37 
anos, com amplitude semi-quartílica de 17 anos (quartis 1 e 3 iguais a 29 e 46 anos, respectivamente). O valor mínimo de idade foi de 1 ano e o máximo de 83 anos. A faixa etária de 30-39 anos foi de 31,10\%.

Em relação ao resultado de sorologia para HIV, houve uma perda de informação. A co-infecção Tb/HIV representou $32 \%$ dos casos. A cura foi de $50 \%$ e $5 \%$ o percentual de abandono. A taxa de cura reduzida para o referido ano deveu-se ao fato da coleta de dados ter ocorrido em fevereiro de 2003, e devido o tratamento medicamentoso ser de no mínimo 6 meses, 27\% dos doentes ainda encontravam-se em tratamento. Os achados estão representados nos gráficos 13, 14 e 15 a seguir.

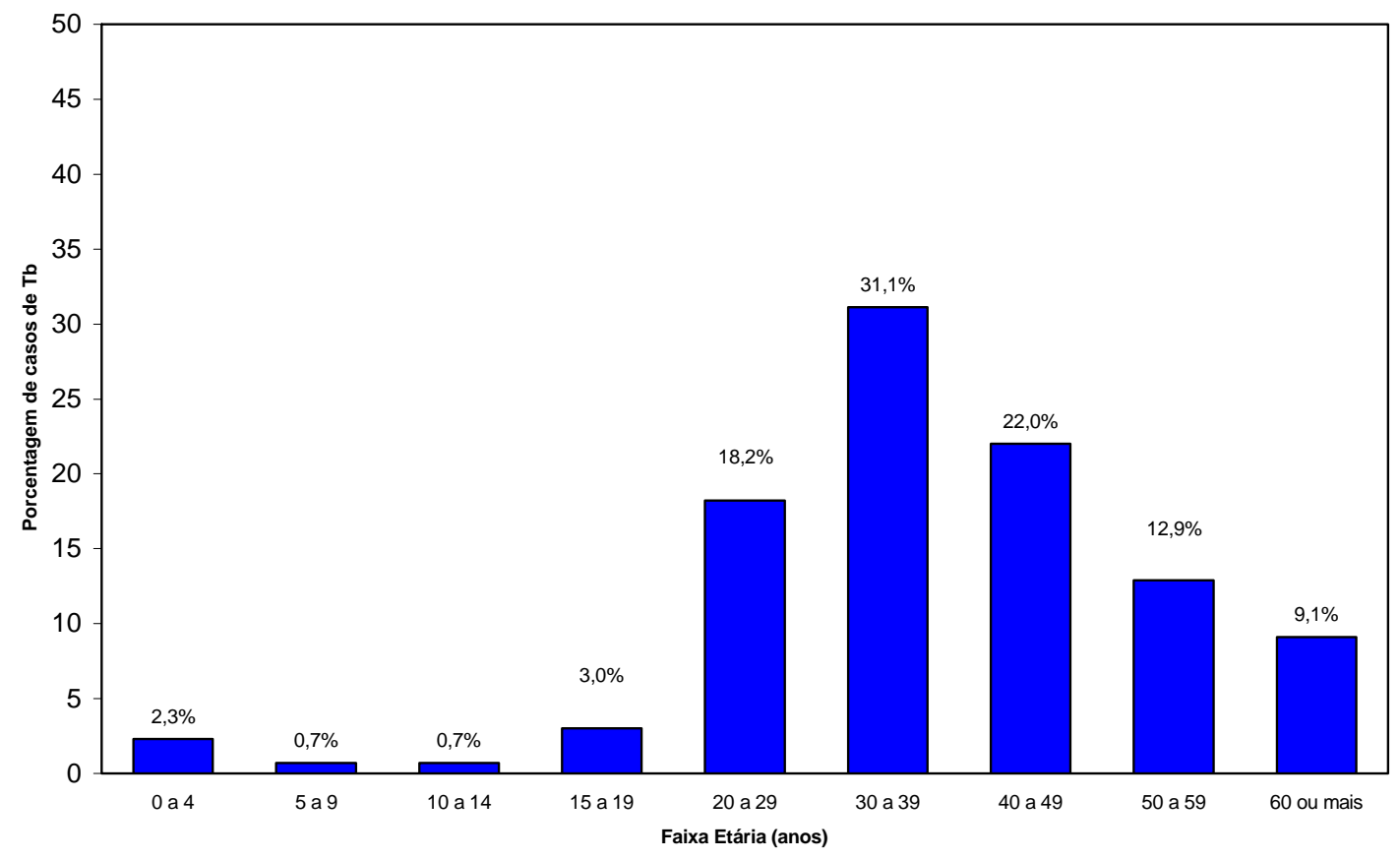

Fonte: Epi-Tb - Vigilância Epidemiológica - Secretaria Municipal de Saúde - Ribeirão Preto-SP

Gráfico 13 - Distribuição dos casos de tuberculose, segundo informação sobre faixa etária (anos). Ribeirão Preto-SP. 2002 


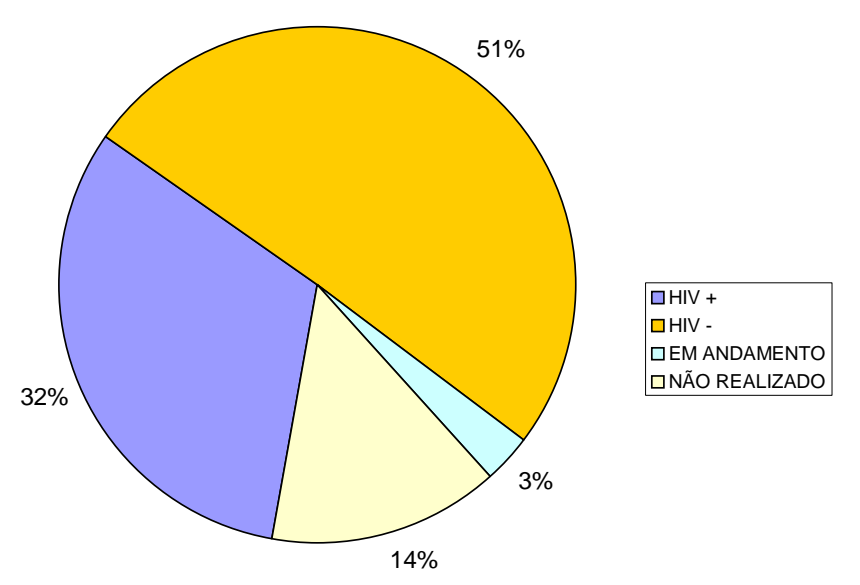

Fonte: Epi-Tb - Vigilância Epidemiológica - Secretaria Municipal de Saúde - Ribeirão Preto-SP

Gráfico 14 - Distribuição dos casos de tuberculose, segundo informação resultado de sorologia para HIV. Ribeirão Preto-SP. 2002

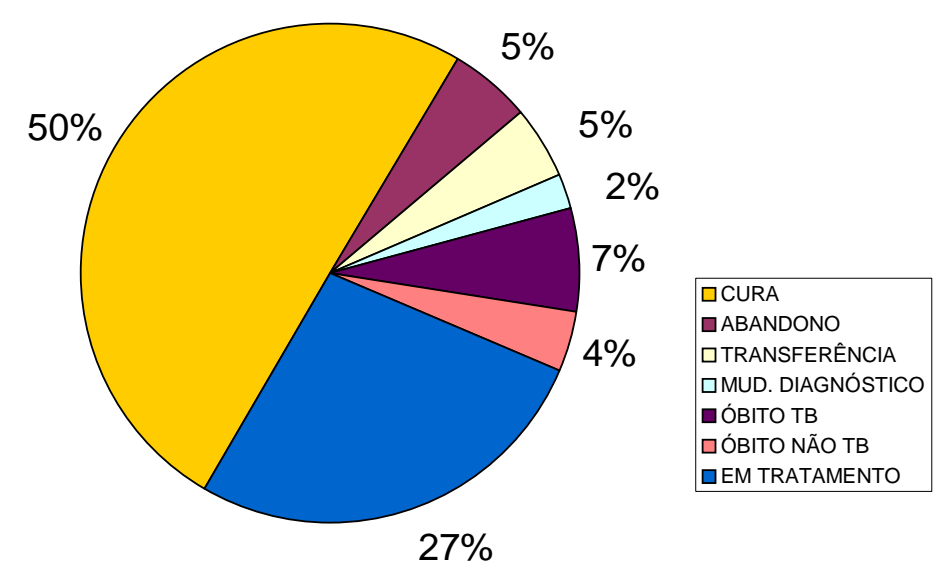

Fonte: Epi-Tb - Vigilância Epidemiológica - Secretaria Municipal de Saúde - Ribeirão Preto-SP

Gráfico 15 - Distribuição dos casos de tuberculose, segundo informação resultado de tratamento. Ribeirão Preto-SP. 2002 
Dentre as características individuais do doente, confirma-se, conforme encontrado na literatura, um maior predomínio da doença em pessoas do sexo masculino, faixa etária de 20-39 anos e relacionados a baixo nível sócio-econômico.

\subsection{Georreferenciamento dos casos}

O número de casos de Tuberculose notificados segundo o EpiTb no período de 1998 a 2002 foram georreferenciados de acordo com o endereço de residência e estão apresentados no quadro 2 a seguir.

Evidencia-se que para todos os anos do estudo, foi obtido um percentual de georreferenciamento superior a $85 \%$ dos casos.

\begin{tabular}{|c|c|c|c|}
\hline & Casos & Notificados \\
\hline Ano & Total & Georreferenciados & $(\%)$ \\
\hline 1998 & 287 & 262 & 91,29 \\
\hline 1999 & 259 & 232 & 89,57 \\
\hline 2000 & 200 & 182 & 91,00 \\
\hline 2001 & 218 & 186 & 85,32 \\
\hline 2002 & 133 & 115 & 86,46 \\
\hline Total & 1094 & 977 & 89,30 \\
\hline
\end{tabular}

Quadro 2 - Distribuição dos casos de Tuberculose no município de Ribeirão Preto, segundo número de casos geocodificados. 1998 a 2002

A qualidade da informação da variável endereço e a eficiência do SIG para localizar os eventos pontualmente são imprescindíveis para 
possibilitar as análises dos padrões de distribuição dessas ocorrências. Os endereços referentes às notificações foram dispostos de forma a obter um link com o mapa digital. Esse procedimento foi trabalhoso e despendeu grande quantidade de tempo devido a alguns endereços informados estarem incompletos e também porque as características de arruamento não permitiram realizar esta etapa de forma automatizada. Foram realizadas pesquisas em lista telefônica, guia de ruas e mapa analógico para viabilizar esta transformação. Nesse estudo, foi possível georreferenciar $89,30 \%$ dos locais de residência dos casos de Tuberculose.

Os fatores que impediram o georreferenciamento de $10,70 \%$ dos casos foram: endereço informado inexistente no município ou não preenchimento do campo endereço.

Isto aponta para a necessidade de uma melhor qualidade das informações que possam ser utilizadas em benefício da comunidade a fim de que se tomem as medidas adequadas para a redução dos danos aos indivíduos acometidos e seus comunicantes e, conseqüentemente, para impedir a disseminação da doença na comunidade.

Os mapas temáticos com os casos de Tuberculose para o período estudado são mostrados a seguir. 


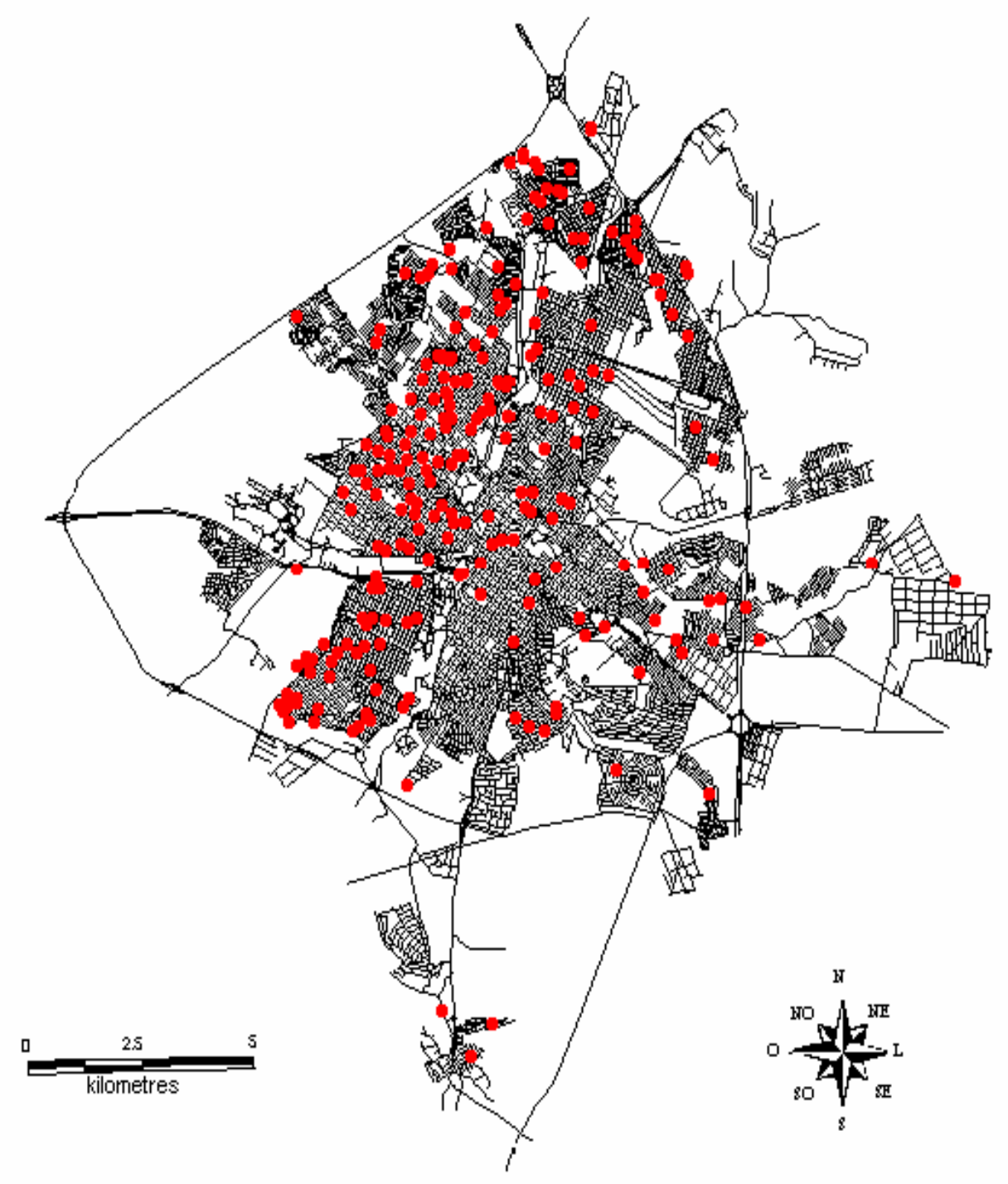

Figura 5: Distribuição dos casos de Tuberculose segundo endereço de residência. Ribeirão Preto - SP. 1998 


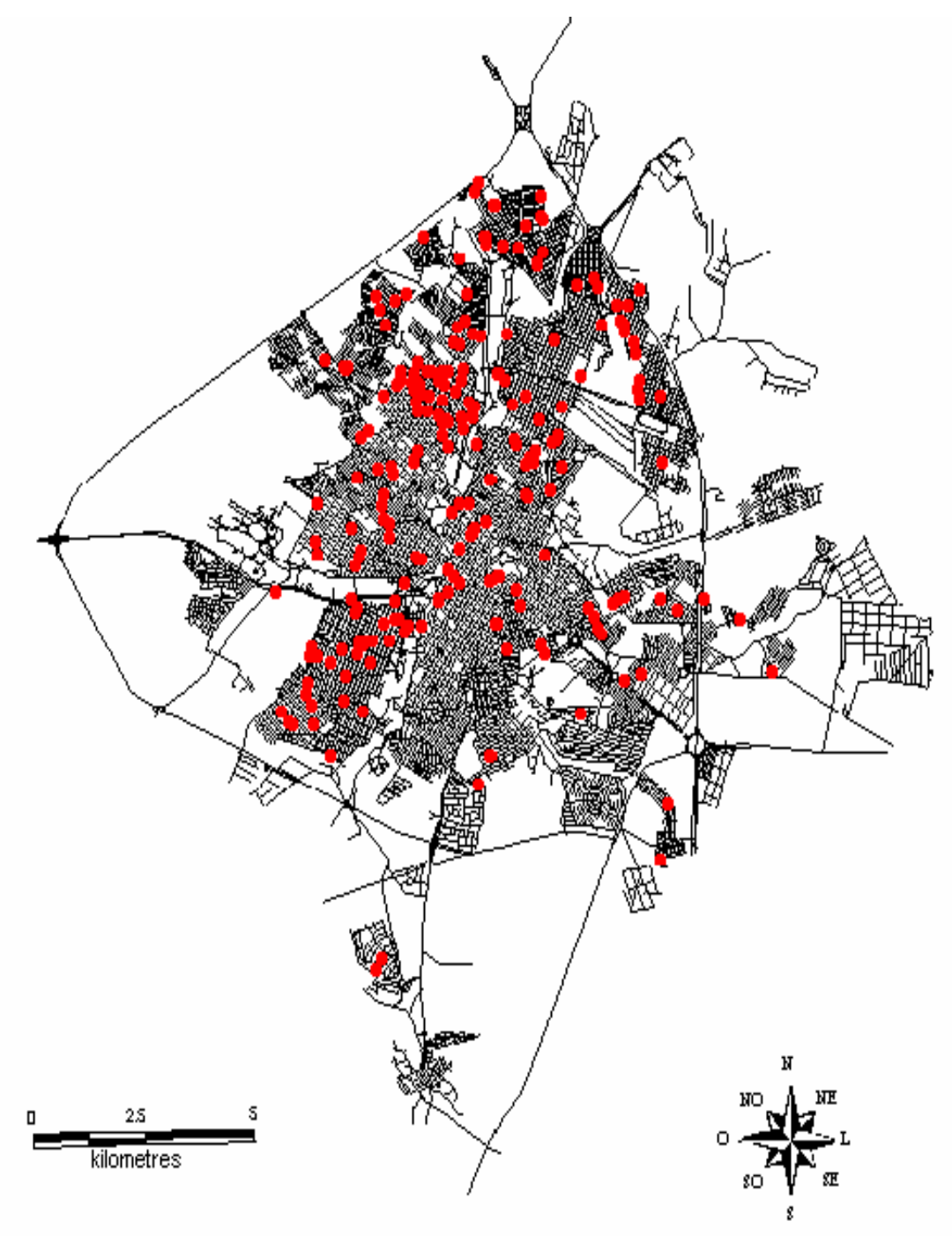

Figura 6: Distribuição dos casos de Tuberculose segundo endereço de residência. Ribeirão Preto - SP. 1999 


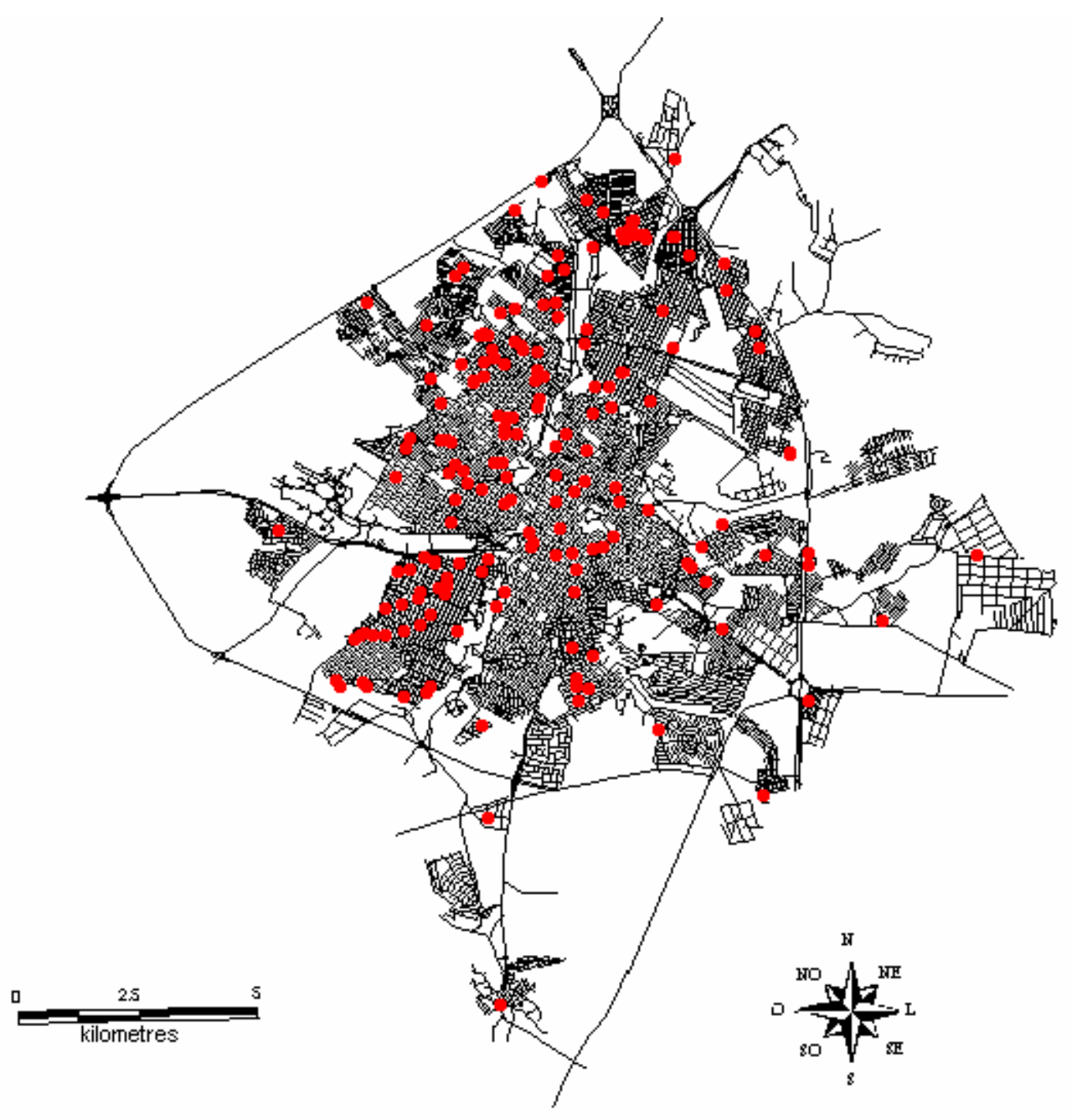

Figura 7: Distribuição dos casos de Tuberculose segundo endereço de residência. Ribeirão Preto - SP. 2000 


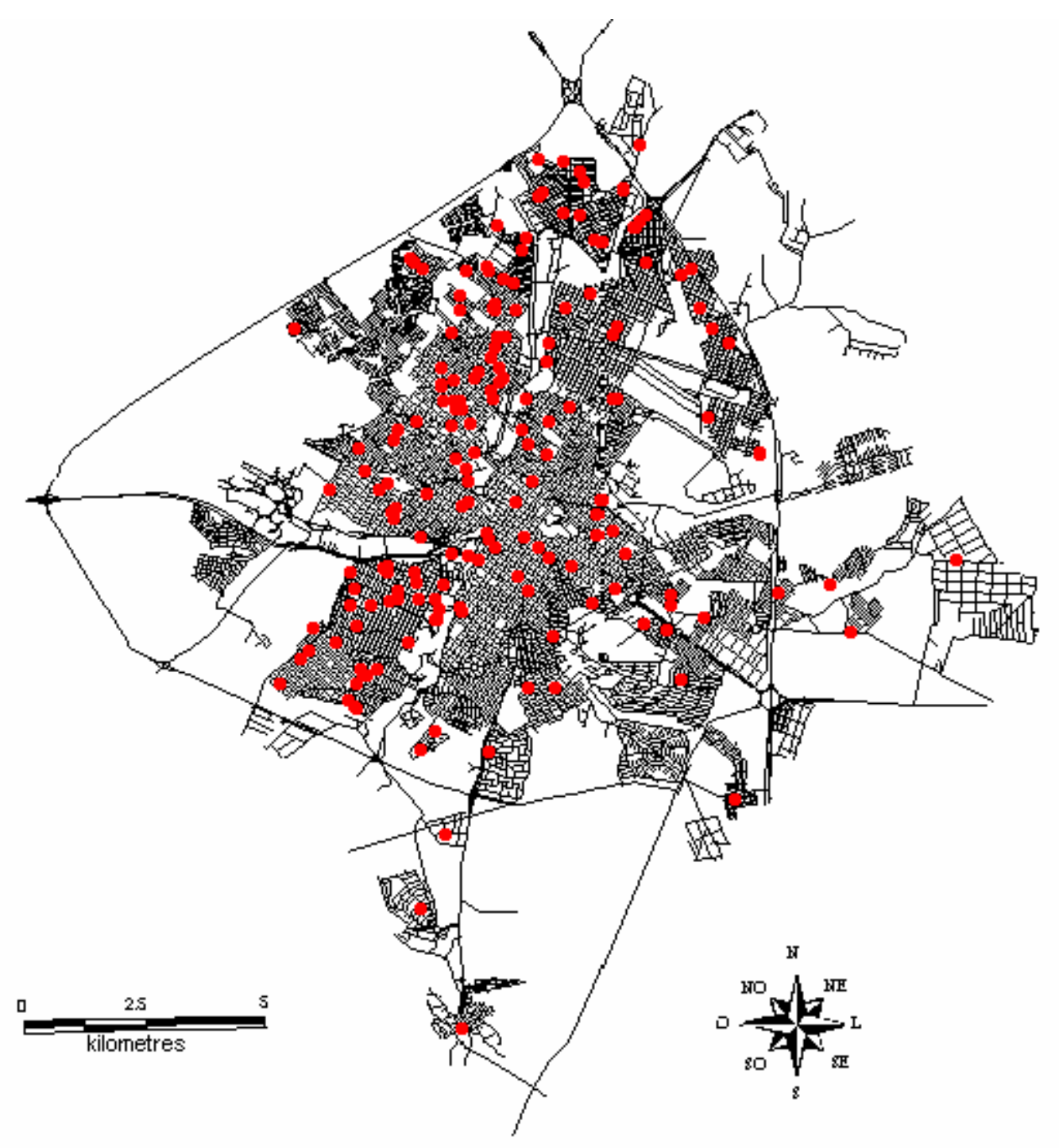

Figura 8: Distribuição dos casos de Tuberculose segundo endereço de residência. Ribeirão Preto - SP. 2001 


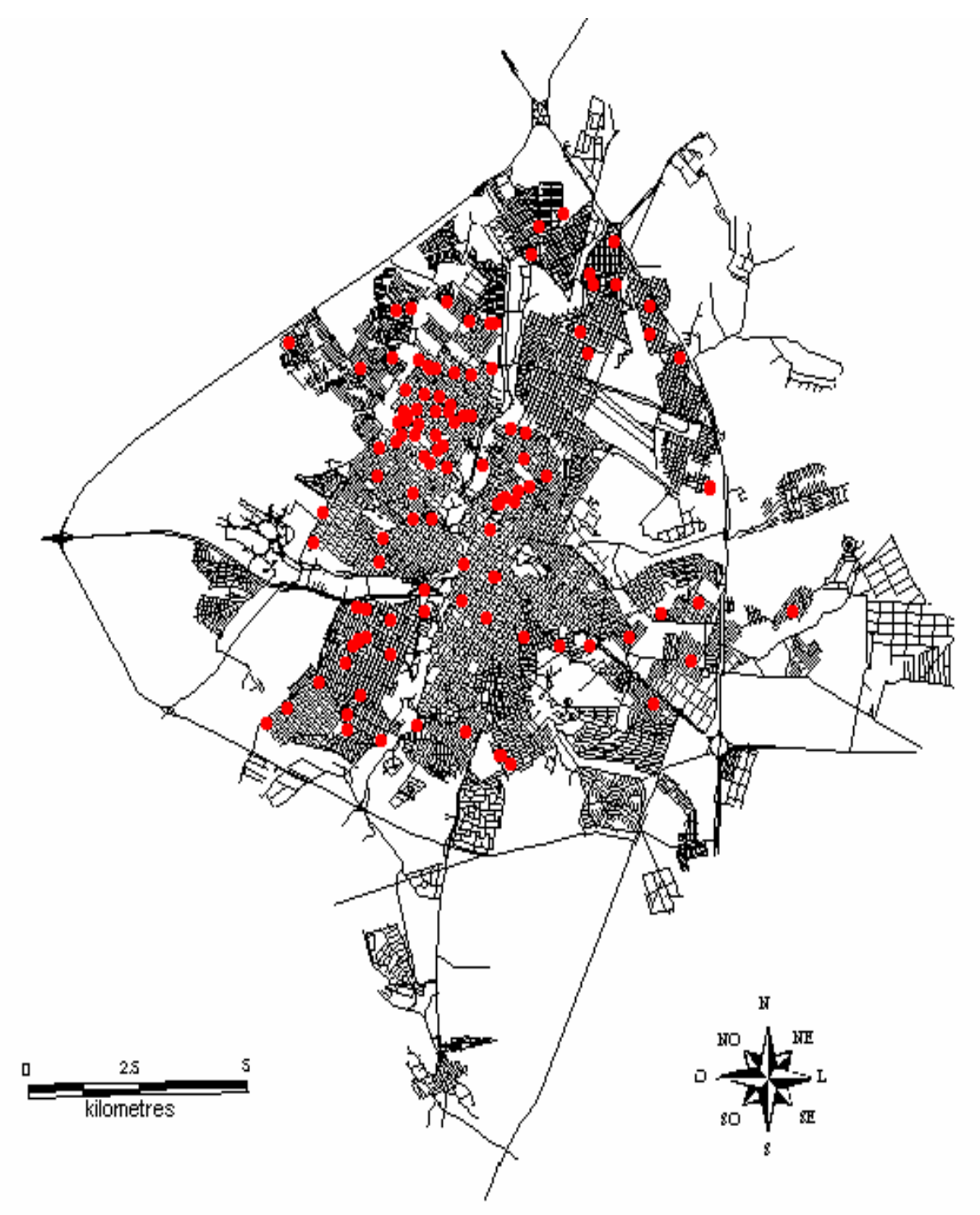

Figura 9: Distribuição dos casos de Tuberculose segundo endereço de residência. Ribeirão Preto - SP. 2002 
Através dos mapas temáticos, nota-se a heterogeneidade da distribuição espacial dos casos de Tuberculose para o período estudado. Uma fração considerável dos casos concentra-se na região noroeste do município, enquanto que o restante encontra-se irregularmente distribuído nos demais bairros.

Foi proposta uma abordagem epidemiológica a partir da localização pontual dos eventos, diferenciando micro-áreas através do padrão espacial de local de residência dos casos de Tuberculose, ou seja, pelo padrão de densidade de pontos. Tal método permitiu a identificação de áreas de maior concentração dos casos de Tuberculose sem necessitar da prévia agregação destes em unidades administrativas, como os bairros.

Para fins de verificação da existência de agregação espacial dos casos de tuberculose, procedeu-se à realização da técnica "Kernel" para estimativa de intensidade local, cujas representações para o período estudado são mostradas a seguir: 


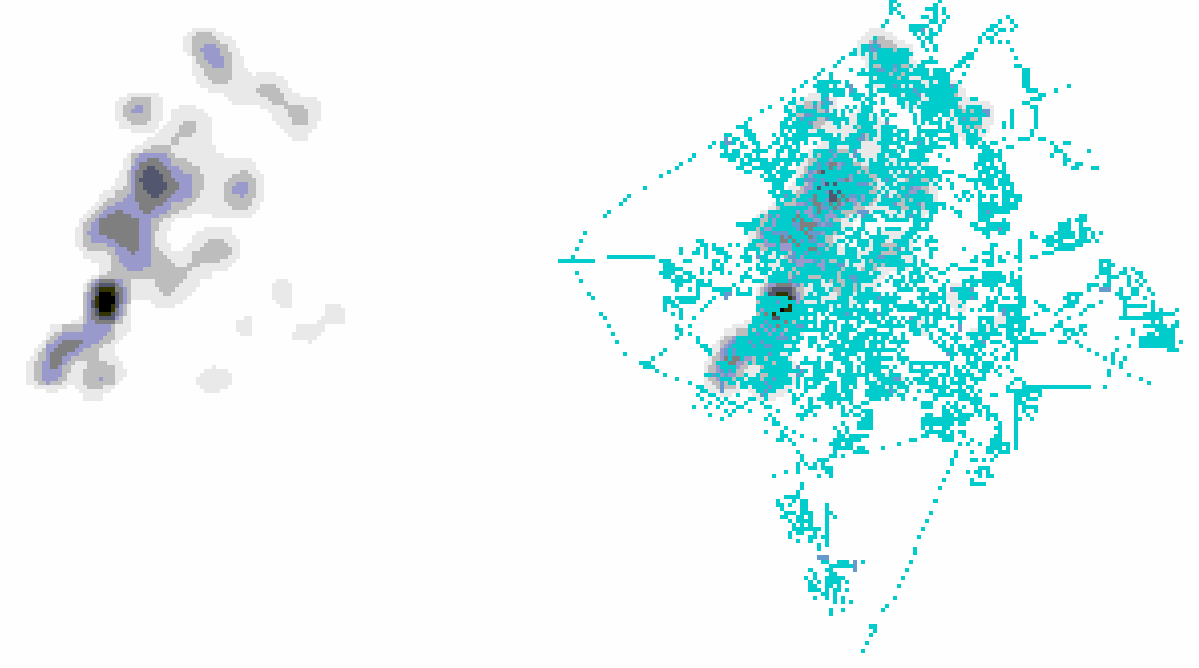

Figura 10: Mapa da distribuição da densidade de residências de doentes de Tuberculose. Ribeirão Preto - SP. 1998

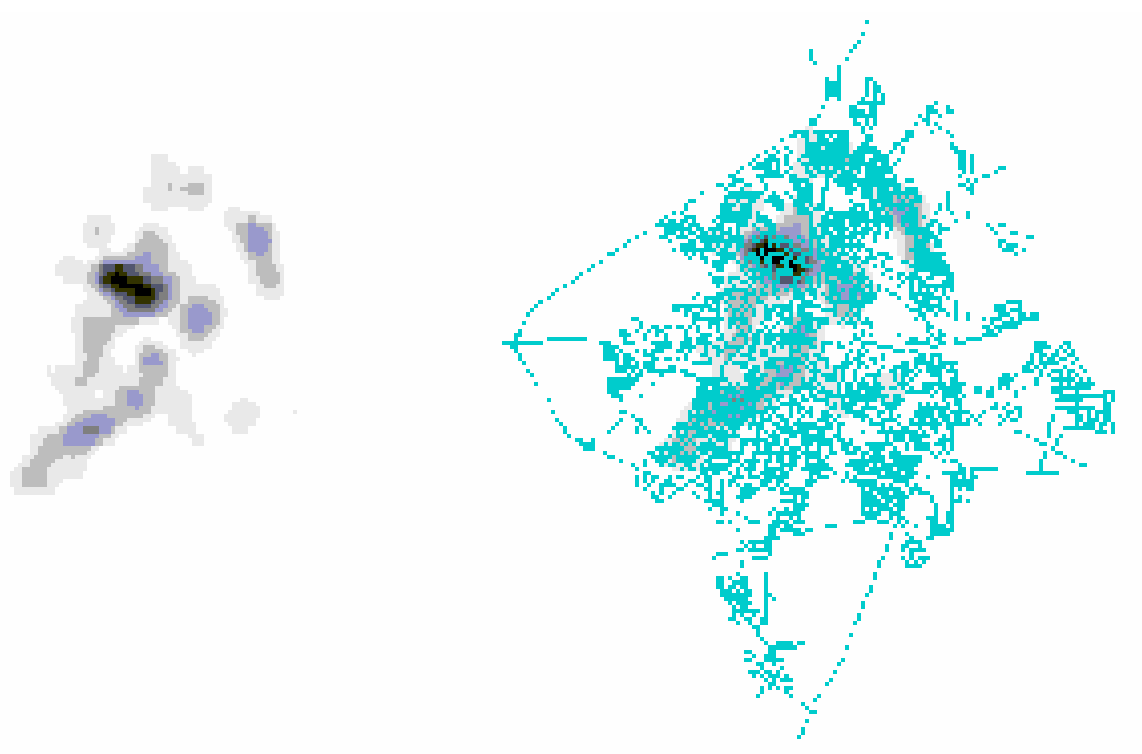

Figura 11: Mapa da distribuição da densidade de residências de doentes de Tuberculose. Ribeirão Preto - SP. 1999 


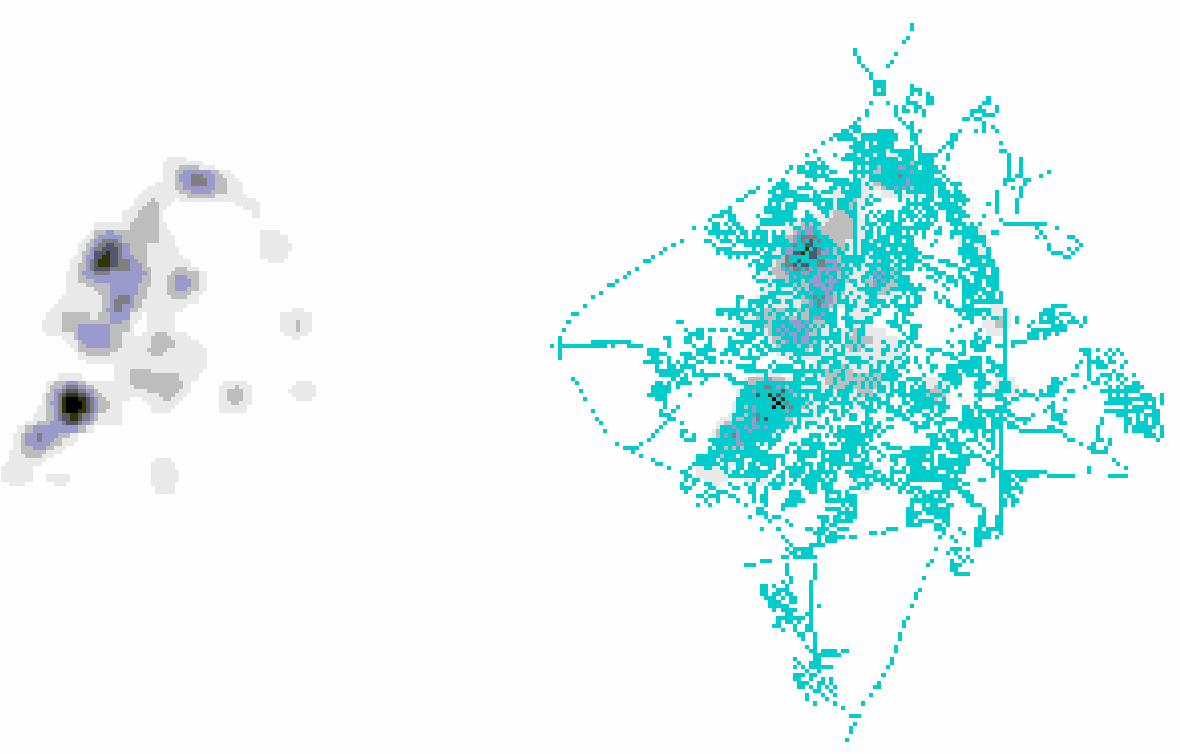

Figura 12: Mapa da distribuição da densidade de residências de doentes de Tuberculose. Ribeirão Preto - SP. 2000
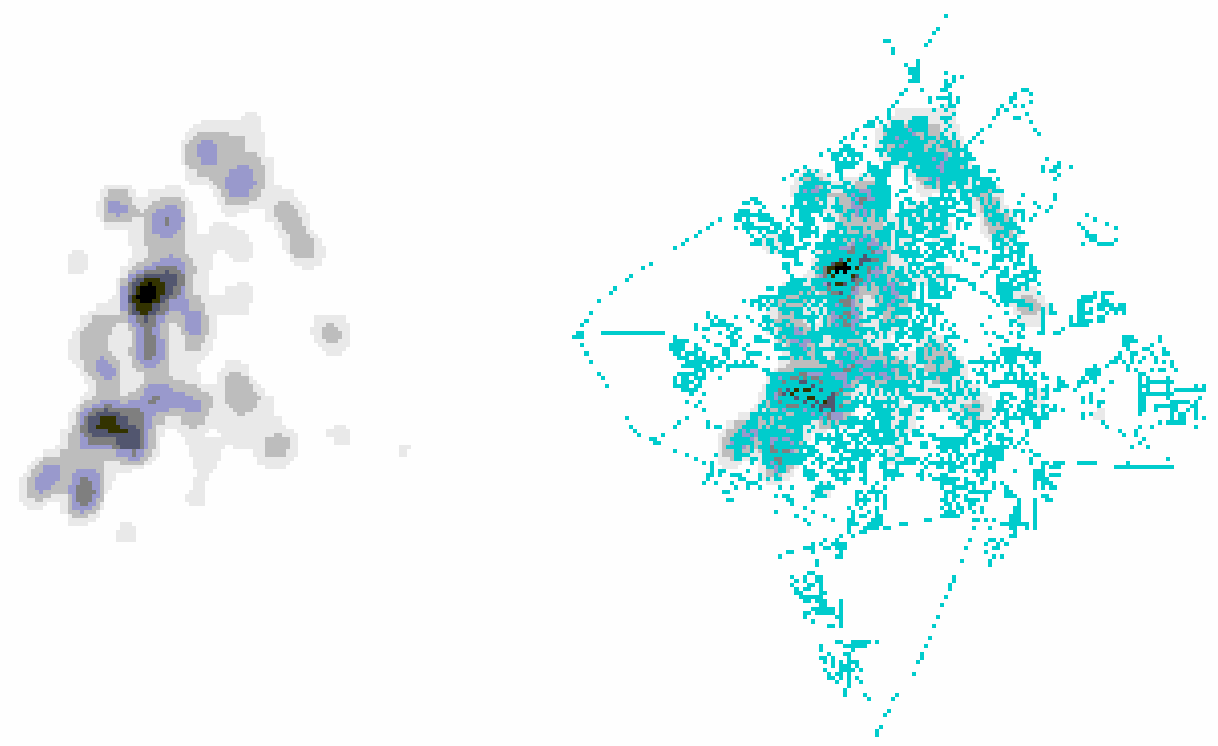

Figura 13: Mapa da distribuição da densidade de residências de doentes de Tuberculose. Ribeirão Preto - SP. 2001 


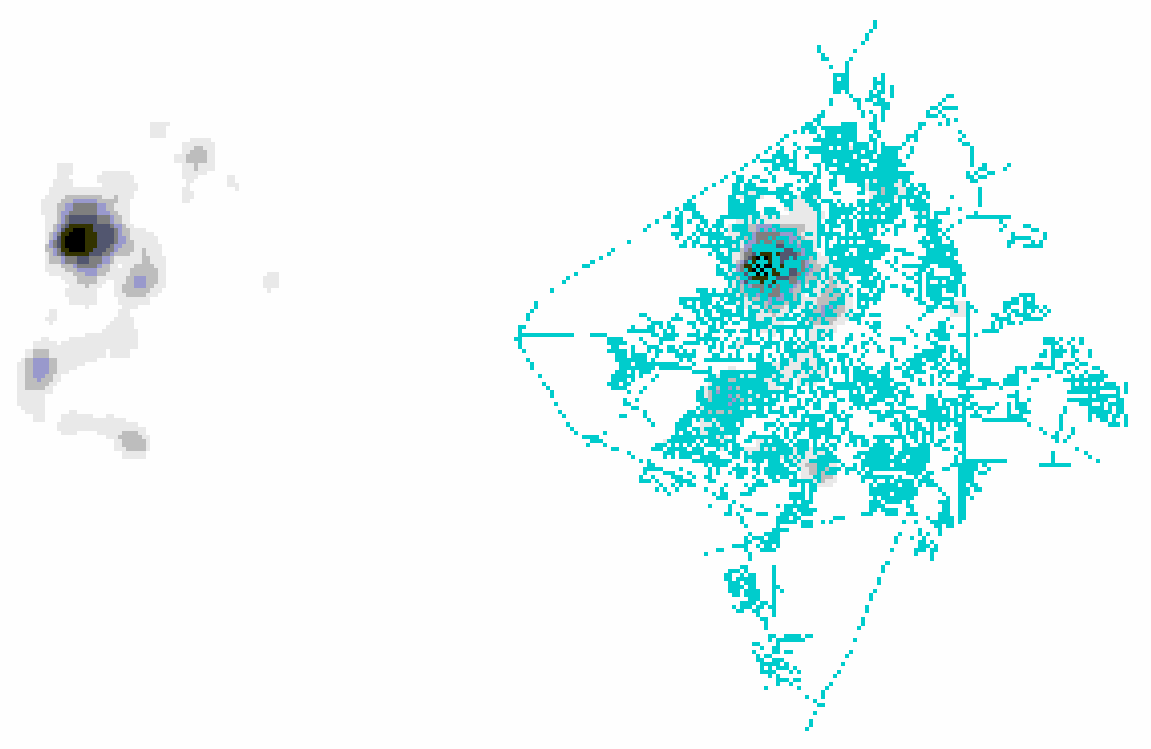

Figura 14: Mapa da distribuição da densidade de residências de doentes de Tuberculose. Ribeirão Preto - SP. 2002

Através da visualização dos mapas, notou-se a heterogeneidade da distribuição da população de risco onde o padrão espacial da densidade de residências de casos de Tuberculose para o ano de 1998 mostrou maior concentração de casos numa área da região oeste do município que engloba os bairros de Jardim Piratininga, Vila Virgínia, Vila Guanabara, Vila Guanabara, Vila Tibério e Jardim Antártica, e decrescendo em direção a outros bairros.

A área com maior coeficiente de incidência de Tuberculose no município para o referido ano concentrou-se em bairros periféricos como Vila Virgínia, Parque Ribeirão Preto e Branca Salles, onde estão localizados alguns locais de maior risco para transmissão da doença: 
Favela das Mangueiras e Cadeia Pública Vila Branca, onde prevaleciam a insalubridade, miséria e superlotação.

Pode-se observar para 1999 um padrão fortemente localizado na área norte do município que compreende os bairros Vila Augusta, Vila Recreio, Vila Albertina, Ipiranga, Alto do Ipiranga e parte do Sumarezinho. Como anteriormente, foi possível identificar áreas de alto (área branca) e baixo (área negra) risco em determinadas regiões.

Nos anos de 2000 e 2001, o foco observado em 1999 mantémse, podendo-se destacar também o ressurgimento de uma concentração dos casos conforme observado em 1998. Para o ano de 2002, a situação assemelha-se a encontrada em 1999.

Para todos os anos do estudo, constatou-se uma distribuição desigual de casos de Tuberculose no espaço urbano de Ribeirão Preto, verificando-se uma concentração na região noroeste do município. A Tuberculose é considerada uma doença estritamente ligada à desigualdade social. De acordo com Enarson et al. (1995), “a Tuberculose é uma estranha doença: é infecciosa mas é crônica; é causada por um bacilo mas também pela pobreza; reflete o que está ocorrendo no presente e o que ocorreu décadas atrás; é exógena mas ainda endógena. Seria prudente dizer que a Tuberculose é tão complexa que encerra inúmeros condicionantes e não um só".

Este estudo adotou o pressuposto de que a distribuição espacial da Tuberculose não é uniforme, havendo tendência à 
concentração de casos em determinados locais. O método de Kernel permitiu detectar onde os eventos estavam concentrados, evidenciando desigualdades de eventos na superfície do município e evidenciar a presença de aglomeração espacial dos casos. Portanto, o instrumento utilizado para estratificar o município em áreas de risco, através do conhecimento da distribuição espacial da Tuberculose possibilita a definição de prioridades para o planejamento de ações mais adequadas voltadas para áreas de maior risco.

Como dito anteriormente, o estimador de intensidade é muito útil para fornecer uma visão geral da distribuição de primeira ordem dos eventos. Para estimação de propriedades de segunda ordem do processo pontual, a técnica utilizada foi a do vizinho mas próximo, com os resultados apresentados nos gráficos 16 a 20 . 
Vizinho mais próximo com sim

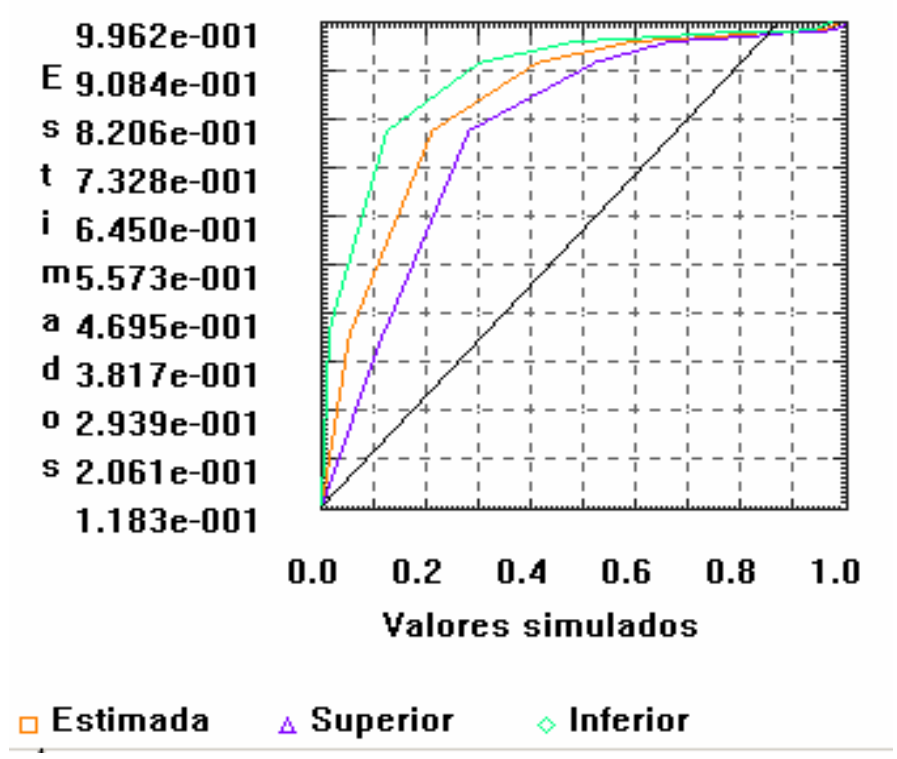

Gráfico 16: Gráfico de $\hat{G}(h)$ versus $\bar{G}(h)$, com envelopes superior e inferior, para os casos de Tuberculose em Ribeirão Preto - SP. 1998

Vizinho mais próximo com sim

$\begin{array}{rr} & 1.000 \mathrm{e}+000 \\ \text { E } 9.114 \mathrm{e}-001 \\ \text { s } 8.229 \mathrm{e}-001 \\ \text { t } 7.343 \mathrm{e}-001 \\ \text { i } 6.457 \mathrm{e}-001 \\ \text { m } 5.571 \mathrm{e}-001 \\ \text { a } 4.686 \mathrm{e}-001 \\ \text { d } 3.800 \mathrm{e}-001 \\ \text { o } 2.914 \mathrm{e}-001 \\ \text { s } 2.029 \mathrm{e}-001 \\ 1.143 \mathrm{e}-001\end{array}$

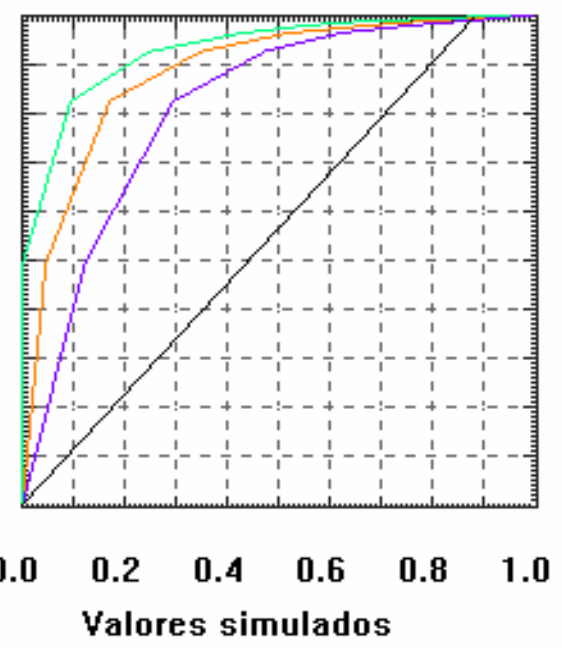

Estimada $\triangle$ Superior $\diamond$ Inferior

Gráfico 17: Gráfico de $\hat{G}(h)$ versus $\bar{G}(h)$, com envelopes superior e inferior, para os casos de Tuberculose em Ribeirão Preto - SP. 1999 


\section{Vizinho mais próximo com sim}

$9.688 \mathrm{e}-001$
E $8.756 \mathrm{e}-001$
s $7.825 \mathrm{e}-001$
t $6.894 \mathrm{e}-001$
i $5.963 \mathrm{e}-001$
m5.031e-001
a $4.100 \mathrm{e}-001$
d $3.169 \mathrm{e}-001$
o $2.238 \mathrm{e}-001$
s $1.306 \mathrm{e}-001$
$3.750 \mathrm{e}-002$

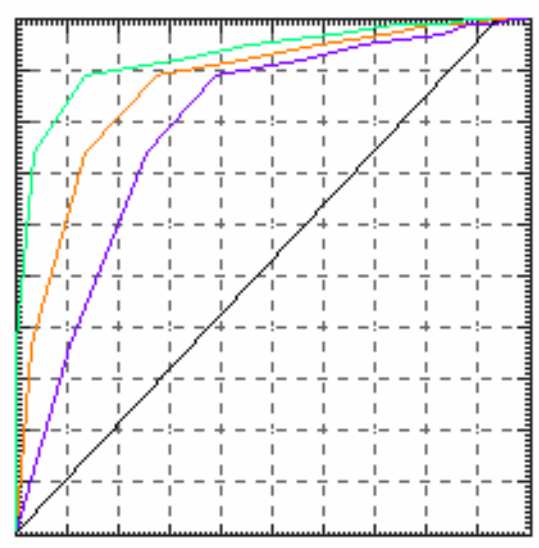

$0.000 \div 1.97563 .95065 .92567 .90069 .875 \mathrm{e}-001$

Valores simulados

$\neg$ Estimada $\quad \Delta$ Superior $\diamond$ Inferior

Gráfico 18: Gráfico de $\hat{G}(h)$ versus $\bar{G}(h)$, com envelopes superior e inferior, para os casos de Tuberculose em Ribeirão Preto - SP. 2000

Vizinho mais próximo com sim

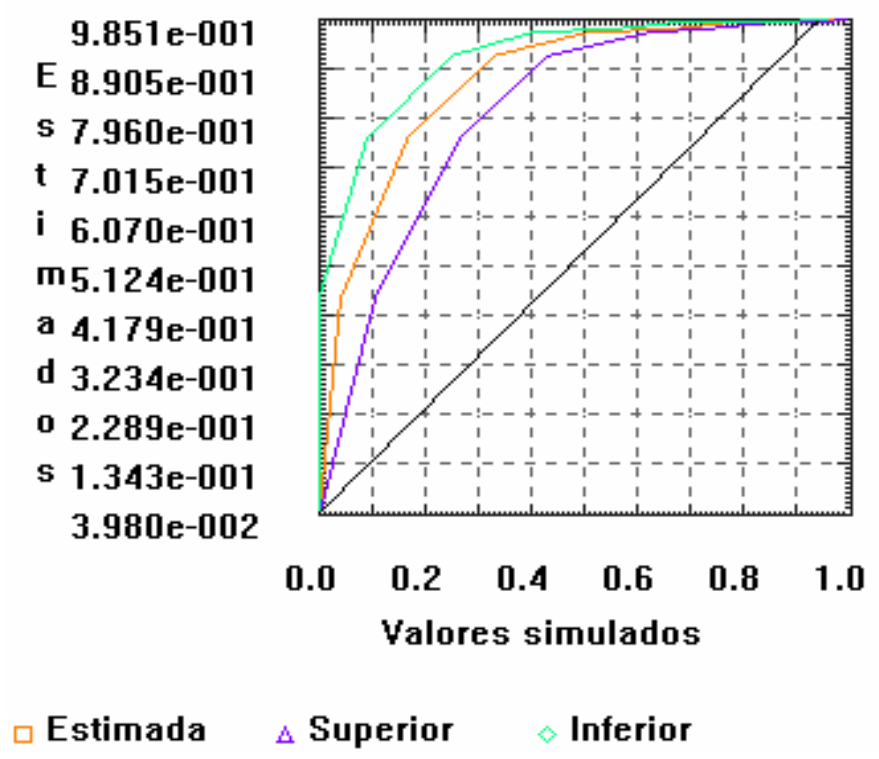

Gráfico 19: Gráfico de $\hat{G}(h)$ versus $\bar{G}(h)$, com envelopes superior e inferior, para os casos de Tuberculose em Ribeirão Preto - SP. 2001 
Vizinho mais próximo com sim

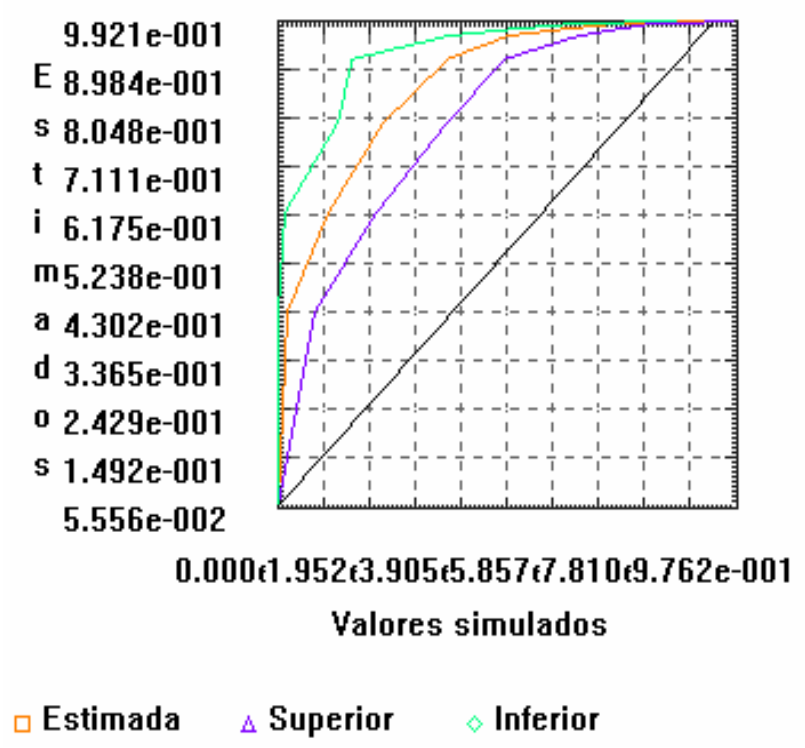

Gráfico 20: Gráfico de $\hat{G}(h)$ versus $\bar{G}(h)$, com envelopes superior e inferior, para os casos de Tuberculose em Ribeirão Preto - SP. 2002

Os gráficos 16 a 20 mostram o posicionamento das distribuições e dos envelopes com relação à linha de $45^{\circ}$, para os dados referentes aos casos de Tuberculose de residentes em Ribeirão Preto nos anos de 1998 a 2002. Em todos os casos percebe-se a posição dos envelopes e das distribuições acima da linha de $45^{\circ}$, o que caracteriza agrupamento para as distâncias em análise, ou seja, o padrão observado não é aleatório.

Sem pretensão de esgotar o assunto, este estudo buscou contribuir de alguma forma com o sistema local de saúde apontando as áreas de maior incidência dos casos de Tuberculose para o município de 
Ribeirão Preto sugerindo prioridades para algumas atividades, tais como: controle de comunicantes, busca ativa de sintomáticos respiratórios, investigação de casos resistentes aos tuberculostáticos e até mesmo avaliar a necessidade de se realizar o TS, dentro de uma lógica territorial. 
o uso do SIG, pela sua capacidade integradora, permitiu associar informações do banco de dados Epi-tb com o espaço, constituindo-se em instrumento poderoso através de mapas onde podem ser visualizados o local de residência dos casos de Tuberculose, contribuindo no avanço das análises espaciais

os resultados do estudo apontam que para cada ano estudado há um padrão para a distribuição espacial da Tuberculose em Ribeirão Preto, identificando-se áreas homogêneas de risco para a doença. A distribuição não uniforme dos casos de Tuberculose no município sugere uma associação com áreas tradicionalmente mais carentes da região.

a estratificação do município em áreas de risco, permite enxergá-lo não mais como um todo, mas sim como uma coleção de subconjuntos heterogêneos, o que é de fundamental importância para a definição de prioridades das ações de saúde, permitindo assim uma racionalização de recursos. 
ANEXO A 


\section{Processo de formação de Ribeirão Preto}

O processo de formação de Ribeirão Preto iniciou-se no ano de 1845 quando o Sr José Mateus dos Reis doou parte da Fazenda das Palmeiras para construção de uma capela, cujo marco foi a Cruz da Capela de São Sebastião das Palmeiras (bairro das Palmeiras). A capela não chegou a ser construída, mas iniciou-se aí a constituição de um patrimônio.

Em 19 de junho de 1856, com a incorporação de novas doações e a redemarcação da área destinada à capela (em local diferente do proposto), as autoridades diocesanas formalizaram a criação do povoado de São Sebastião de Ribeirão Preto, entre os córregos do Retiro e Ribeirão Preto.

A primeira Matriz de São Sebastião de Ribeirão Preto demorou 5 anos para ser construída (onde atualmente existe a fonte da Praça XV de Novembro) e foi entregue à população em 1868. Em 1905, ela foi demolida e uma nova matriz, a Catedral, na Praça das Bandeiras foi concluída em 1918. A Vila de São Sebastião de Ribeirão Preto foi desmembrada do município de São Simão em 1873. Em 1879, a Câmara alterou o nome da vila para Vila entre Rios, prevalecendo este nome até 1882. Em 1883 foi restabelecido o nome de Vila de São Sebastião de 
Ribeirão Preto. A vila foi elevada a cidade em 1889, contando na época com aproximadamente 10.500 habitantes (900 eram escravos).

Os bandeirantes (final do século XVIII) abriram caminho para a chegada dos primeiros habitantes à região. Vinham em sua maioria de Minas Gerais e eram de origem portuguesa. O café estava começando a aparecer.

Segundo o historiador Rubem Cione (1989),

" o advento do café, com a formação de fazendas e a vinda em massa de imigrantes peninsulares, o surto imigratório benéfico, transformou completamente o ambiente agrário local e regional, bem como fez surgir estruturas humanas e econômicas novas destinadas a servir o café e lhe propiciar meios de seu desenvolvimento, sua ampla cultura ante a perspectiva certa da riqueza que ensejaria".

O café foi o grande acontecimento da primeira metade do século XIX, passando a ser a base da economia nacional, como também a base da economia Ribeirãopretana, quando ficou conhecida como Eldorado do Café. 
O primeiro vetor de crescimento da cidade aconteceu em 1883, quando foi inaugurada a estação de ferro da Mogiana em conseqüência da necessidade de um meio de transporte para a produção do café. Localizava-se no lugar onde hoje está a rodoviária central. A estação provisória localizava-se atrás do Casarão Villa Lobos da avenida Caramuru, já tombado. Fora do núcleo central, a cidade começou a crescer em direção à estação provisória devido à circulação de pessoas e serviços.

O primeiro bairro de Ribeirão Preto foi a região que liga 0 centro até a Avenida Caramuru e chamava-se República, em homenagem à Proclamação da República .

Quando foi inaugurada a estação definitiva da Mogiana, ocorreu um segundo vetor de crescimento da cidade, mas agora com características mais comerciais; foram abertos restaurantes, hotéis, lojas, bancos e outros estabelecimentos em volta da estação. Logo depois, começaram a vir muitos imigrantes para as lavouras de café. Uma das contribuições mais importantes para o crescimento da cidade veio dos imigrantes de várias nacionalidades que chegaram a Ribeirão Preto e ajudaram a construir a história, principalmente com a cultura do café, que por longo período sustentou a economia regional e foi o principal produto de exportação do país.

Devido à crise econômica mundial de 1929, a cultura cafeeira começou seu declínio, sendo, paulatinamente, substituída por outras 
atividades produtivas que exigiam um menor contingente de mão-de-obra no campo. Essas culturas, ao longo das décadas seguintes foram sendo alteradas pela cana-de-açúcar, que na década de 70 , com a política federal do Pró-Álcool, tornou a mudar quase que radicalmente o cenário rural de Ribeirão Preto e região.

Paralelamente a isto existia a estação dos imigrantes, que se chamava Barracão e localizava-se onde é hoje o bairro do Ipiranga; ali os imigrantes esperavam para serem contratados pelos fazendeiros ou seus representantes. O processo de desenvolvimento econômico repercutiu na dinâmica demográfica e na própria urbanização do município. Na década de 50 , notadamente com os investimentos na área da saúde e da educação e com o crescimento e modernização do comércio local, acentuou-se ainda mais o fortalecimento do setor terciário de nossa economia. Apareceu o bairro Jardim Paulista e também começaram a se expandir os bairros em volta da Avenida Independência, principalmente o Sumaré. Em 1960, há novamente um crescimento para a região norte da cidade por causa dos vários conjuntos habitacionais: Simioni, Quintino I e II entre outros. No começo da década de 80, começa a se desenvolver a cidade no sentido de Bonfim Paulista favorecido pela inauguração do primeiro shopping center. O centro da cidade também mudou devido ao "boom" de prédios altos e residenciais de luxo nesta região. No final de 1999 mais dois shoppings center se instalaram na cidade reforçando sua posição de pólo terciário regional. 
Em relação à região na qual se insere o município de Ribeirão Preto, esta constitui-se em um dos principais centros universitários e de pesquisa do estado e do país, com destaque para as áreas médicas em Ribeirão Preto, engenharia em São Carlos, agronomia e veterinária em Jaboticabal, zootecnia e engenharia de alimentos em Pirassununga, entre outros. Assim, a região consolida-se como um dos principais pólos de geração de tecnologia e mão-de-obra qualificada do país.

Os excelentes indicadores econômicos e sociais do município ancoram-se em uma estrutura econômica forte e diversificada tanto no município como na região. Em primeiro lugar deve-se destacar o desempenho da agricultura. A qualidade dos solos (uma grande mancha de terra roxa) e o clima, faz com que esta seja uma das principais regiões agrícolas do estado e do país, caracterizando-se por uma grande produção e por elevados níveis de rendimento das culturas, com destaque para a cana-de-açúcar, laranja, soja, amendoim entre outros.

Em relação à indústria, deve-se destacar em primeiro lugar, a força da agroindústria, que está muito relacionada ao desempenho do setor primário. A região é a maior produtora mundial de açúcar e álcool. As usinas representam uma das principais atividades econômicas da região. São 21 usinas que empregam em torno de 8.000 funcionários. Isso acaba estimulando o desenvolvimento de outros setores, como por exemplo, o de máquinas agrícolas e equipamentos para usinas. Fazem-se também presentes na região várias indústrias de suco de laranja, 
beneficiadoras de café, soja, amendoim. Além da agroindústria, percebese na região a presença de outros setores industriais relevantes: o de produtos médicos, odontológicos e farmacêuticos no município. 
ANEXO B 

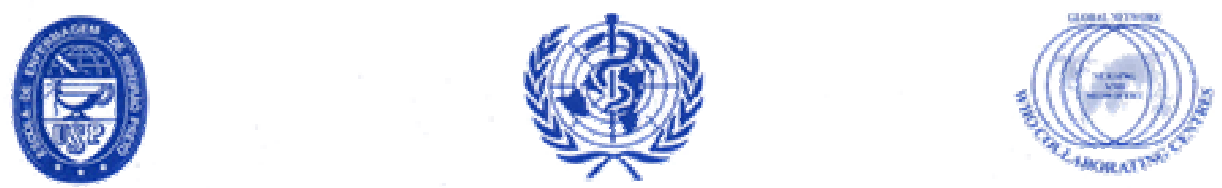

ESCOLA DE ENFERMAGEM DE RIBEIRĀO PRETO - UNIVERSIDADE DE SĀO PAULO CENTRO COLABORADOR DA ORGANZACAOO MUNDIAL DA SAUDE PARA O DESENVOLVIMENTO DA PESQUISA EM ENFERMAGEM

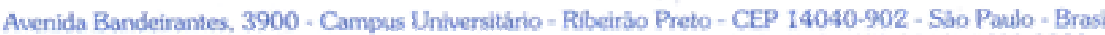
FAX 55 - 016 - $6333271 / 55$ - 016 - 630-2561/ TELFFONES: 55 - 016 - 6330379// 6023382

\section{COMITÊ DE ÉTICA EM PESQUISA DA EERP/USP}

Of.CEP-EERPIUSP - 123/2002

Ribeirăo Preto, 28 de outubro de 2002.

Prezada Senhora,

Comunicamos que o projeto de pesquisa, abaixo especificado, foi analisado e considerado APROVADO pelo Comitê de Ética em Pesquisa da Escola de Enfermagem de Ribeirăo Preto da Universidade de Săo Paulo, em sua $45^{\mathrm{a}}$ Reuniẩo Ordinária, realizada em 28 de novembro de 2002.

Protocolo: $\quad n^{\circ} 0303 / 2002$

Projeto: Difusăo Temporal e Espacial da Tuberculose no Municipio de Ribeirão Preto, no Periodo de 1998 A 2001

Pesquisadores: PAULA HINO

CLAUDIA BENEDITA DOS SANTOS

Em atendimento à Resolução 196/96, deveră ser encaminhado ao CEP o relatório final da pesquisa e a publicaçăo de seus resultados, para acompanhamento, bem como comunicada qualquer intercorrencia ou a sua interrupçăo.

Atenciosamente,

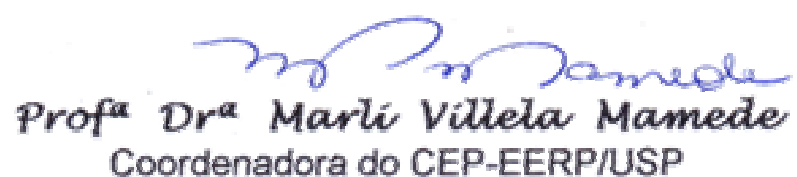

Coordenadora do CEP-EERPIUSP

lima. Sra.

Prof ${ }^{2} r^{2}$ Claudia Benedita dos Santos

Departamento de Enfermagem Matemo-Infantil e Saúde Pública da Escola de Enfermagem de Ribeirão Preto da Universidade de ao Paulo 
ALMEIDA FILHO, N.; ROUQUAYROL, M.Z. Introdução à Epidemiologia. 3.ed. Rio de Janeiro: MEDSI, 2002. 287p.

ANDRADE, C.L.T.; SZWARCWALD, C.L. Análise espacial da mortalidade neonatal precoce no município do Rio de Janeiro, 1995-1996. Cadernos de Saúde Pública, Rio de Janeiro, v. 17, n. 5, p. 1199-10, set./out. , 2001.

BARCELLOS, C.; SANTOS, S.M. Colocando dados no mapa: a escolha da unidade espacial de agregação e integração de bases de dados em saúde e ambiente através do geoprocessamento. Informe Epidemiológico do SUS, Brasília, v. 1, n. 1, jan./mar., 1997.

BRAGA, C.; XIMENES, R.A.A.; ALBUQUERQUE, M.F.P.M.; SOUZA, W.V.; MIRANDA, J.; BRAYNER, F.; ALVES, L.; SILVA, L.; DOURADO, I. Avaliação de indicador sócio-ambiental utilizado no rastreamento de áreas de transmissão de filariose linfática em espaços urbanos. Cadernos de Saúde Pública, Rio de Janeiro v. 17, n. 5, p.1211-18, set./out. , 2001.

BRASIL. Ministério da Saúde. Fundação Nacional de Saúde. Centro Nacional de Epidemiologia. Coordenação Nacional de Pneumologia Sanitária. Controle da Tuberculose : diretrizes do plano de ação emergencial para municípios prioritários. Brasília,1997.

BRASIL. Ministério da Saúde. Fundação Nacional de Saúde. Centro Nacional de Epidemiologia. Coordenação Nacional de Pneumologia Sanitária. Plano Nacional de Controle da Tuberculose. Brasília, 1999.

CÂMARA, G.; CARVALHO, M.S. Análise espacial de eventos, INPE, 2001. Disponível em : < http:// www.dpi.inpe.br/gilberto/livro. Acesso em: 05 jan. 2003.

CÂMARA, G.; CORREA, V.; PAIVA, J.A.; MONTEIRO, A.M.V.; CARVALHO, M.S.; FREITAS, C.C.; RAMOS, F.R.; NEVES, M.C. Estatística Espacial, INPE, 2001. Disponível em: < http:// www.dpi.inpe.br/gilberto/livro. Acesso em: 05 jan. 2003. 
CÂMARA, G.; MONTEIRO, A.M.V. Geocomputation techniques for spatial analysis: are they relevant to health data?. Cadernos de Saúde Pública, Rio de Janeiro, v. 17, n. 5, p. 1059-81, 2001.

CÂMARA, G.; MONTEIRO, A.M. FUCKS, S.D.; CARVALHO, M.S. Análise espacial e geoprocessamento, INPE, 2001, disponível em: < http://www.dpi.inpe.br/gilberto/livro. Acesso em: 05 jan. 2003.

CARVALHO, M.S.; PINA, M.F.; SANTOS, S.M. Conceitos Básicos de Sistemas de Informação Geográfica e Cartografia Aplicados à Saúde. Brasília: Organização Pan-Americana da Saúde/Ministério da Saúde, 2000.

CHIESA, A.M.; WESTPHAL, M.F.; KASHIWAGI, N.M. Geoprocessamento e a promoção da saúde: desigualdades sociais e ambientais em São Paulo. Revista de Saúde Pública, São Paulo, v. 36, n. 5, p. 559-67, 2002.

CIONE, R. História de Ribeirão Preto. 2 ed. Ribeirão Preto: IMAG, 1989.

CONDE, M.B.; SOUZA, G.M.; KRITSKI, A.L. Tuberculose sem medo. São Paulo: Atheneu, 2002.

COSTA, M.C.N.; TEIXEIRA, M.G.L.C. A concepção do "espaço" na investigação metodológica. Cadernos de Saúde Pública, Rio de Janeiro, v. 15, n. 2, p. 271-279, 1999.

ENARSON, D.A.; GROSSET, J.; MWINGA, A.; HERSHFIELD, E.S.; O'BRIEN, R.; COLE, S.; REICHMAN, L. The challenge of Tuberculosis: statements on global control and prevention. The Lancet, v. 346, p. 80919, 1995.

FARREL, J. A assustadora história das pestes e epidemias. São Paulo: Ediouro, 1998.

FIORAVANTI, C. O alvo é a saúde humana. Pesquisa Fapesp, São Paulo, n. 81, nov., p. 36-43, 2002. 
HIIJAR, A.M.; OLIVEIRA, M.J.P.R.; TEIXEIRA, G.M. A Tuberculose no Brasil e no mundo. Boletim de Pneumologia Sanitária, Rio de Janeiro, v. 9,n. 2, p. 9-14, 2001.

ISEMAN, M.D. Tuberculose. In: Goldman, L.; Benett, J.C. Cecil tratado de medicina interna. 21 ed, Rio de Janeiro: Guanabara Koogan, 2001. p.1922-31.

IZIQUE, C. O mapa da exclusão. Pesquisa Fapesp, São Paulo, n. 83, jan., p. 14-20, 2003.

KRITSKI, A.L.; CONDE, M.B.; SOUZA, G.R.M. A epidemiologia da tuberculose. Do ambulatório à enfermaria. Rio de Janeiro: Atheneu, 1999.

LAPA, T.M. Análise espacial da distribuição da hanseníase no município de Olinda: uma contribuição ao sistema local de Vigilância Epidemiológica. 69p. Dissertação (Mestrado em Saúde Pública)Faculdade de Saúde Pública, Universidade de São Paulo, São Paulo, 1999.

LAPA, T.; XIMENES, R.; SILVA, N.N.; SOUZA, W.; ALBUQUERQUE, M.F.M.; CAMPOZANA, G. Vigilância da hanseníase em Olinda, Brasil, utilizando técnicas de análise espacial. Cadernos de Saúde Pública, Rio de Janeiro, v. 17, n. 5, p. 1153-62, 2001.

MALLETA, C.H.M. Epidemiologia e Saúde Pública. São Paulo: Atheneu, 1988.

MALTA, D.C.; ALMEIDA, M.C.M.; DIAS, M.A.S.;MERHY, E.E. A mortalidade infantil em Belo Horizonte, Minas Gerais, Brasil, por área de abrangência dos Centros de Saúde (1994-1996). Cadernos de Saúde Pública, Rio de Janeiro, v. 17, n. 5, p. 1189-98, 2001.

MEDRONHO, R.A. Estudos ecológicos. Epidemiologia. São Paulo: Atheneu, 2002. cap 13, p.191-98. 
MEDRONHO, R.A.; PEREZ, M. A distribuição das doenças no espaço e no tempo. Epidemiologia. São Paulo: Atheneu, 2002, cap 4, p.57-71.

MEDRONHO, R.A.; WERNECK. G.L. Técnicas de análise espacial em saúde. Epidemiologia. São Paulo: Atheneu, 2002, cap 29, p.427-46.

MORRONE, N.; SOLHA, M.S.S.; CRUVINEL, M.C.; JÚNIOR, N.M.; FREIRE, J.A.S.; BARBOSA, Z.L.M. Tuberculose: tratamento supervisionado "vs" tratamento auto-administrado. Jornal de Pneumologia Sanitária,v. 25, n. 4, p. 198-206, 1999.

MUNIZ, J.N. O tratamento supervisionado no controle da Tuberculose em Ribeirão Preto: uma intervenção de que tipo?. 152 p. Dissertação (Mestrado em Enfermagem em Saúde Pública)- Escola de Enfermagem de Ribeirão Preto, Universidade de São Paulo, Ribeirão Preto, 1999.

MORAIS NETO, O.L.M.; BARROS, M.B.A.; MARTELLI, C.M.T.; SILVA, S.A.; CAVENAGHI, S.M.; SIQUEIRA JÚNIOR, J.B.S. Diferenças no padrão de ocorrência da mortalidade neonatal e pós-neonatal no município de Goiânia, Brasil, 19992-1996: análise espacial para identificação das áreas de risco. Cadernos de Saúde Pública, Rio de Janeiro, v. 17, n. 5, p. 1241-50, 2001.

ORGANIZAÇÃO PANAMERICANA DE SAÚDE/ORGANIZAÇÃO MUNDIAL DA SAÚDE. Reunion regional de directores nacionales de la tuberculosis. Informe final. Equador, 1997.

ORGANIZAÇÃO PANAMERICANA DE SAÚDE. Sistema de Informação Geográfica em Saúde. Brasília, 2002.

PEREIRA, M.G. Métodos empregados em Epidemiologia. Epidemiologia teoria e prática. 6.ed. Rio de Janeiro: Guanabara- Koogan, 2002. cap. 12, p. 269-88.

REDE INTERAGENCIAL DE INFORMAÇÕES PARA A SAÚDE. Sistemas de informação geográfica e a gestão da saúde no município. Rede Interagencial de Informações para a Saúde, 1999. 24p. 
RIBEIRO, S.A.; AMADO, V.M.; CAMELIER, A.A.; FERNANDES, M.M.A.; SHENKMAN, S. Estudo caso-controle de indicadores de abandono em doentes de Tuberculose. Jornal de Pneumologia Sanitária, v. 26, n. 6, nov./dez., p.291-96, 2000.

RUFFINO NETTO, A. Impacto da reforma do setor saúde sobre os serviços de Tuberculose no Brasil. Boletim de Pneumologia Sanitária. Rio de Janeiro, v. 7, n. 1, 1999.

RUFFINO NETTO, A.; SOUZA, A.M.A.F. Reforma do Setor Saúde e Controle da Tuberculose no Brasil. Informe Epidemiológico do SUS, Brasília, v. 8, n. 4, out./dez., 1999.

RUFFINO NETTO, A. Programa de Controle da Tuberculose no Brasil: situação atual e novas perspectivas. Informe Epidemiológico do SUS , Brasilia, v. 10, n. 3, 2001.

RUFFINO NETTO, A. Tuberculose: a calamidade negligenciada. Revista da Sociedade Brasileira de Medicina Tropical, v. 35, n. 1, p. 51-8, 2002.

SANTOS, M. Por uma geografia nova. São Paulo: EDUSP, 2002. 285p.

SANTOS, S.M.; BARCELLOS, C.; CARVALHO, M.S.; FLORES, R. Detecção de aglomerados espaciais de óbitos por causas violentas em Porto Alegre, Rio Grande do Sul, Brasil, 1996. Cadernos de Saúde Pública, Rio de Janeiro, v. 17, n. 5, p. 1141-51, 2001.

SASSAKI, C.M. Tempo de tratamento da Tuberculose de pacientes inscritos em um serviço de saúde no município de Ribeirão Preto- SP (1998-1999). 96p.Dissertação (Mestrado em Enfermagem em Saúde Pública)- Escola de Enfermagem de Ribeirão Preto, Universidade de São Paulo, Ribeirão Preto, 2003.

SILVA, L.J. O conceito de espaço na epidemiologia das doenças infecciosas. Cadernos de Saúde Pública, Rio de Janeiro, v. 13, n. 4, p. 585-93, 1997. 
SNOW, J. Sobre a maneira de transmissão do cólera. São Paulo/ Rio de Janeiro: Hucitec/Abrasco. 1999. 249p.

SOUZA, W.V. O uso de informações sócio-econômicas na construção de indicadores de situação coletiva de risco para a ocorrência de Tuberculose em Olinda- PE. 74p. Dissertação (Mestrado em Saúde Pública)- Instituto Aggeu Magalhães, Fundação Oswaldo Cruz, Recife, 1998.

SOUZA, W.V.; BARCELLOS, C.C.; BRITO, A.M.; CARVALHO, M.S.; CRUZ, O.G.; ALBUQUERQUE, M.F.M.; ALVES, K.R.; LAPA, T.M. Aplicação do modelo bayesiano empírico na análise espacial da ocorrência da hanseníase. Revista de Saúde Pública, São Paulo, v. 35, n. 5, p. 474-80, 2001.

SPSS Incorporation, 1999. SPSS for Windows. Statistical Program for Social Sciences. Release 10.0. Chicago: SPSS, Corporation.

VENDRAMINI, S.H.F. O tratamento supervisionado no controle da tuberculose em Ribeirão Preto sob a percepção do doente. 120p. Dissertação (Mestrado em Enfermagem em Saúde Pública)- Escola de Enfermagem de Ribeirão Preto, Universidade de São Paulo, Ribeirão Preto, 2001.

VERONESI, R.; FOCACCIA, R.; DIETZE, R. Doenças Infecciosas e Parasitárias. 8. ed. Rio de Janeiro: Guanabara- Koogan, 1991.

WAKSMAN, S.A. A vitória sobre a Tuberculose. São Paulo: Cultrix , 1964.

WATANABE, A; RUFFINO NETO, A; Aspectos epidemiológicos da coinfecção Tuberculose/HIV- Ribeirão Preto- SP. Revista de Medicina, Ribeirão Preto, v.28, p.856-65, 1995.

WHO. WORLD HEALTH ORGANIZATION. Stop Tuberculosis. Disponível em: www.stoptb.org. Acesso em: 10 dez. 2003. 
WORKSHOP DA REDE BRASILEIRA DE PESQUISA EM TUBERCULOSE, 1., Rio de Janeiro. Anais... Rio de Janeiro: REDE- TB, 2002.

XIMENES, R.A.A.; MARTELLI, C.M.T.; SOUZA, W.V.; LAPA, T.M.; ALBUQUERQUE, M.F.M.; ANDRADE, A.L.S.S.; NETO, O.L.M.; SILVA, S.A.; LIMA, M.L.C.; PORTUGAL, J.L. Vigilância de doenças endêmicas em áreas urbanas: a interface entre mapas de setores censitários e indicadores de morbidade. Cadernos de Saúde Pública, Rio de Janeiro, v. 15 , n. 1, p. 53-61, 1999. 


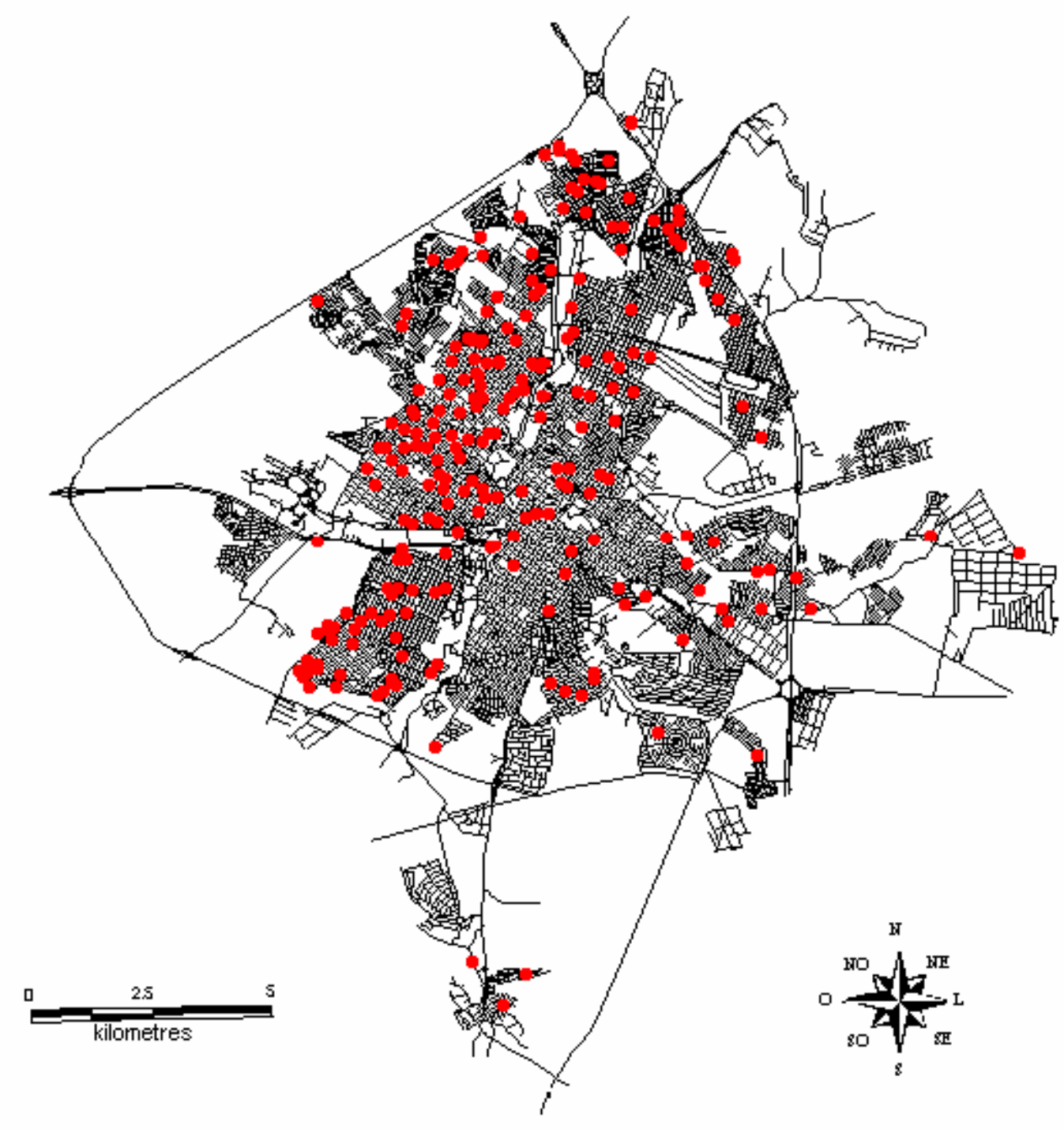

Figura 5: Distribuição dos casos de Tuberculose segundo endereço de residência. Ribeirão Preto - SP. 1998 


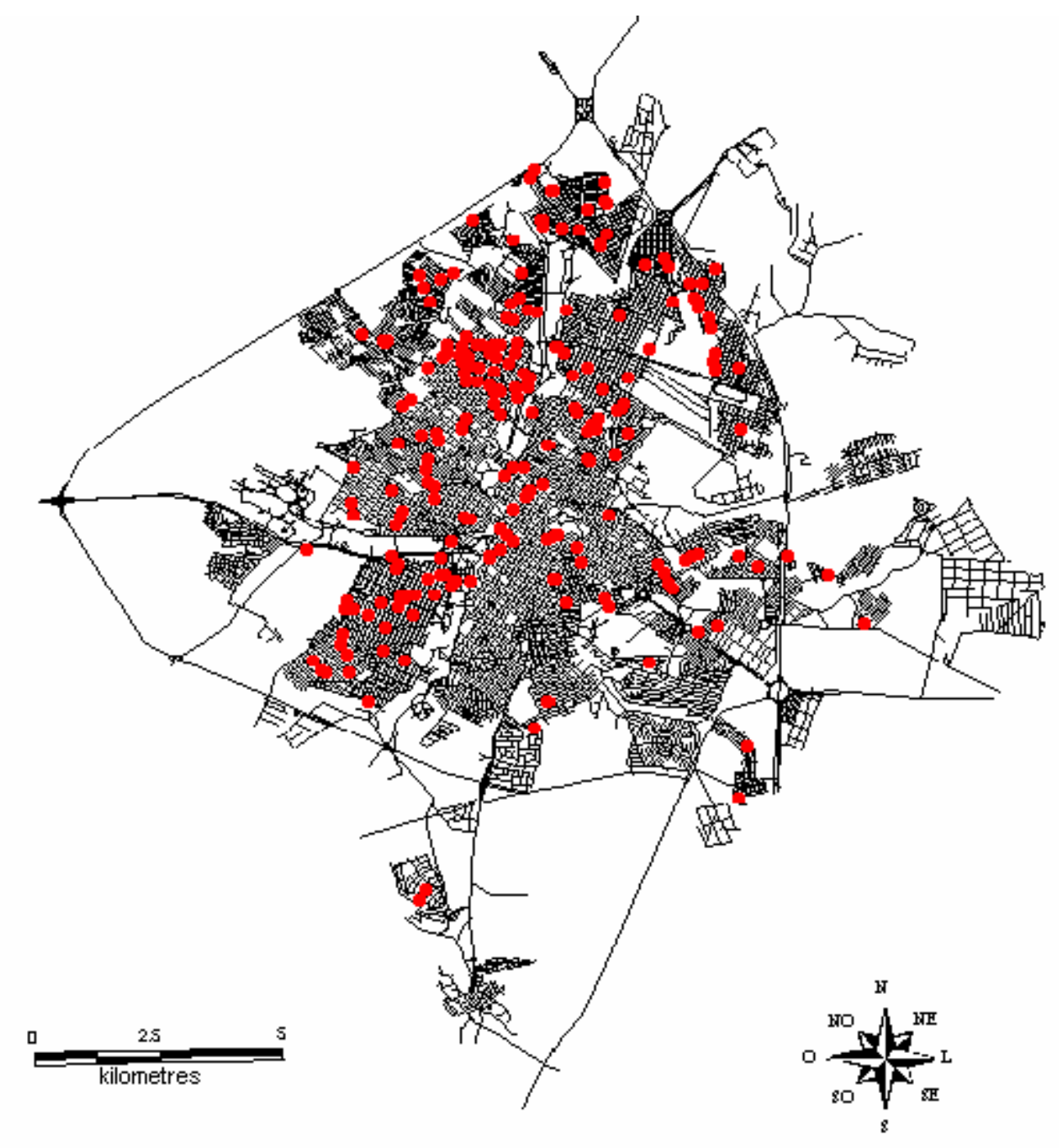

Figura 6: Distribuição dos casos de Tuberculose segundo endereço de residência. Ribeirão Preto - SP. 1999 


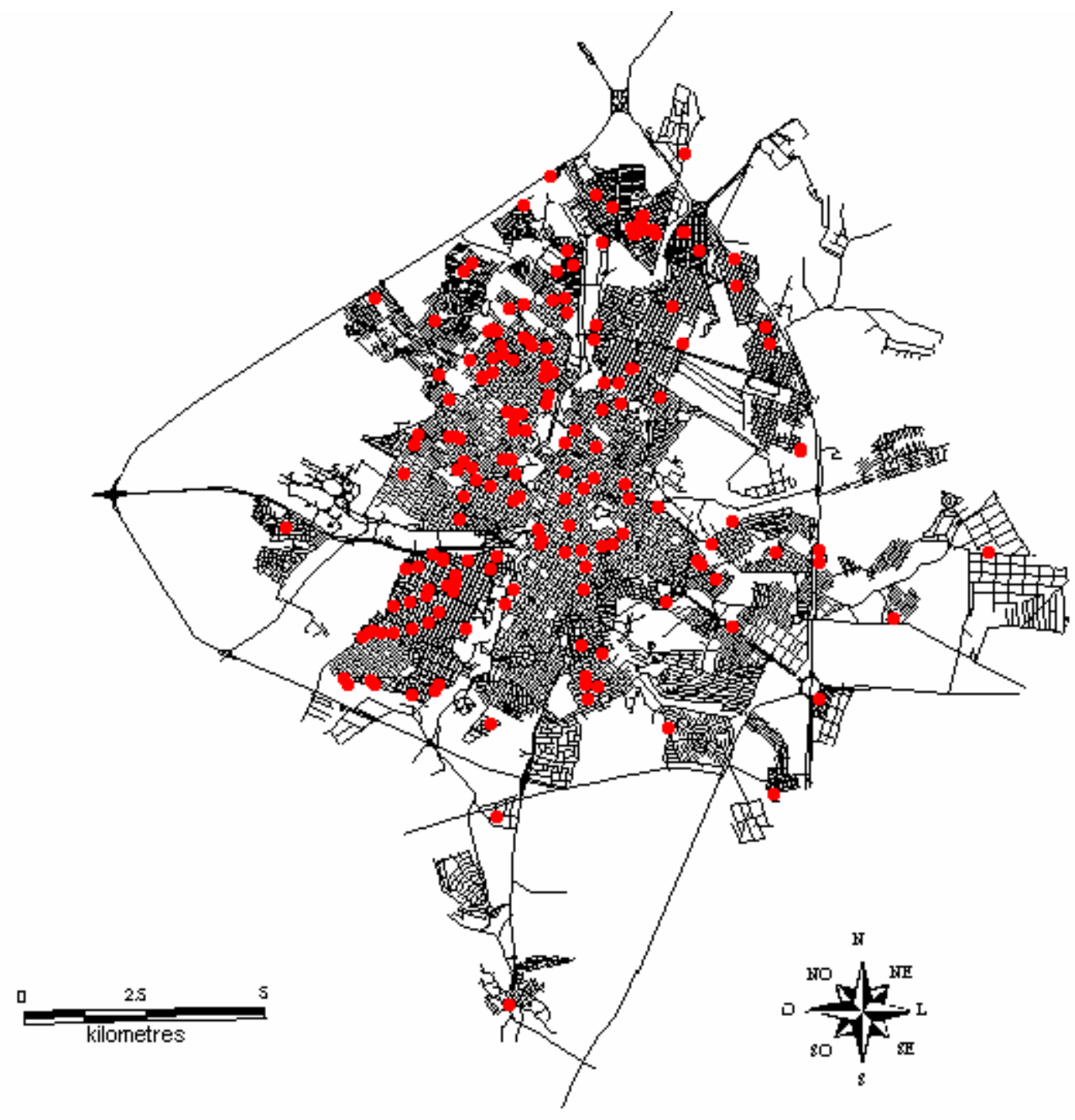

Figura 7: Distribuição dos casos de Tuberculose segundo endereço de residência. Ribeirão Preto - SP. 2000 


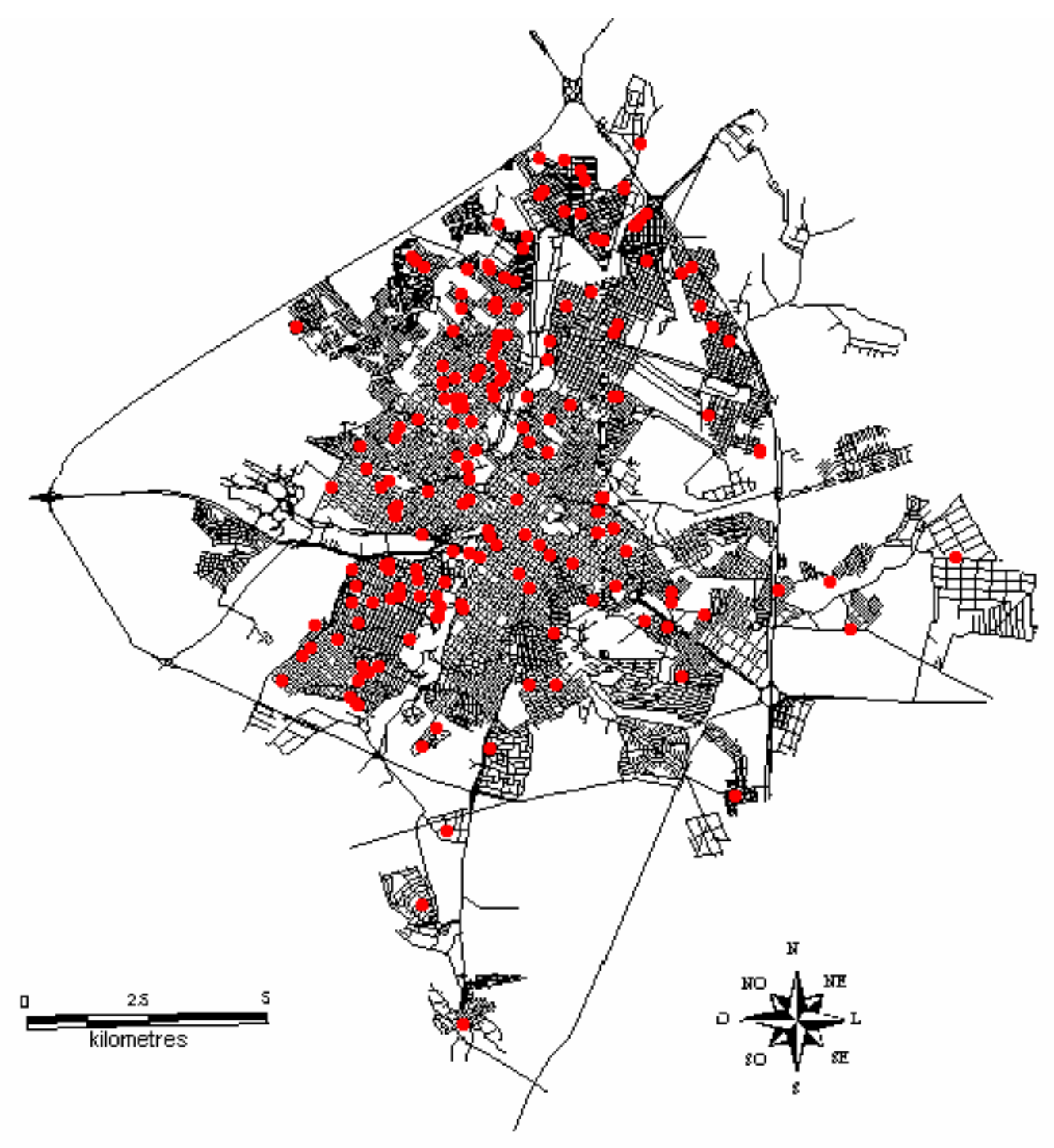

Figura 8: Distribuição dos casos de Tuberculose segundo endereço de residência. Ribeirão Preto - SP. 2001 


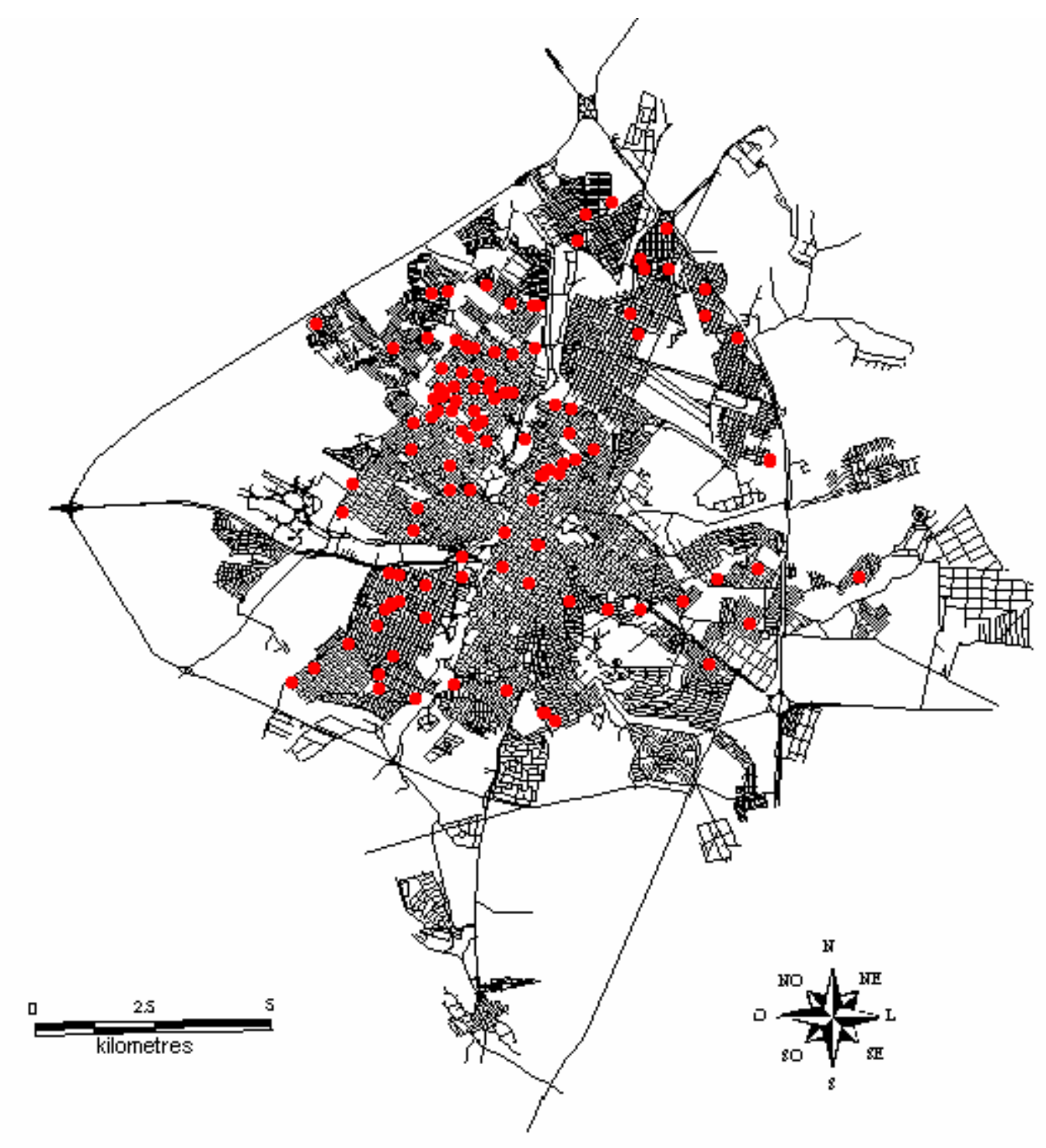

Figura 9: Distribuição dos casos de Tuberculose segundo endereço de residência. Ribeirão Preto - SP. 2002 